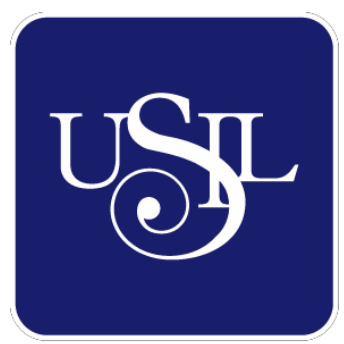

UNIVERSIDAD

SAN IGNACIO

DE LOYOLA

FACULTAD DE CIENCIAS EMPRESARIALES

Carrera de International Business

\title{
RELACIÓN ENTRE GESTIÓN DE LA CALIDAD TOTAL $Y$ DESEMPEÑO DE LAS EMPRESAS MYPES EXPORTADORAS DE QUINUA, PERÚ 2020
}

Tesis para optar el Título Profesional de Licenciado en International Business

KATTYA RAYMUNDO BAUTISTA (0000-0002-0534-9135) MELISSA LUCERO PAUCAR ESPIRITU (0000-0003-43272535)

Asesor:

MG. OSCAR FEDERICO MURO DOIG (0000-0002-51838327)

Lima - Perú

2020 


\section{Dedicatoria}

A cada uno de nuestros padres, que siempre nos apoyaron incondicionalmente. Motivándonos a nunca rendirnos y siempre seguir adelante a pesar de las adversidades.

Con toda nuestra gratitud y cariño les dedicamos la tesis.

Kattya Raymundo y Melissa Paucar 


\section{Resumen}

La presente investigación tuvo como objetivo analizar la relación entre la gestión de la calidad total y el desempeño de las empresas MYPES exportadoras de quinua del Perú 2020. Para lo cual se tomó como muestra a 106 administradores o gerentes de estas empresas. Se usó un enfoque cuantitativo con un tipo de investigación de alcance correlacional, el diseño fue no experimental, transversal y correlacional. Se usó como instrumento de medición un cuestionario de 30 afirmaciones para la variable gestión de la calidad total y de 9 afirmaciones para la variable desempeño exportador, con respuestas de escala likert del 1 al 5. Usándose el estadístico rho de spearman para contrastar las hipótesis planteadas. Finalmente se concluyó que la gestión de la calidad total si se relaciona positivamente con el desempeño exportador de las empresas MYPES exportadoras de quinua.

Palabras claves: Gestion de la calidad total, Desempeño exportador. 


\begin{abstract}
The objective of this research was to analyze the relationship between total quality management and the performance of MYPES companies exporting quinoa from Peru 2020. For which, 106 administrators or managers of these companies were taken as a sample. A quantitative approach was used with a type of research of correlational scope, the design was non-experimental, cross-sectional and correlational. A questionnaire of 30 statements for the total quality management variable and 9 statements for the exporter performance variable was used as a measurement instrument, with responses on a Likert scale from 1 to 5 . Using the spearman's rho statistic to contrast the hypotheses raised. Finally, it was concluded that total quality management is positively related to the export performance of MYPES companies that export quinoa.
\end{abstract}

Keywords: Total quality management, Export performance. 


\section{Índice}

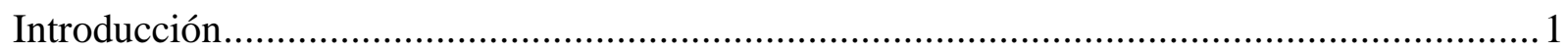

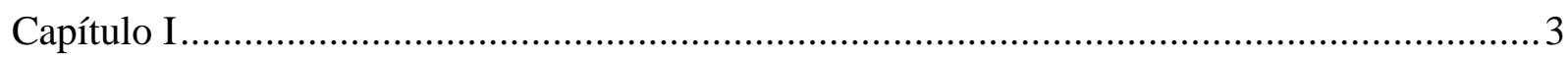

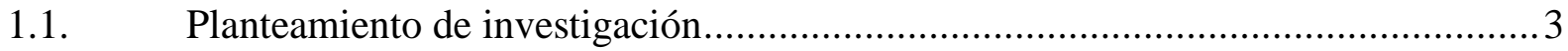

1.1.1. Planteamiento del problema............................................................... 3

1.1.2. Formulación del problema...................................................................... 4

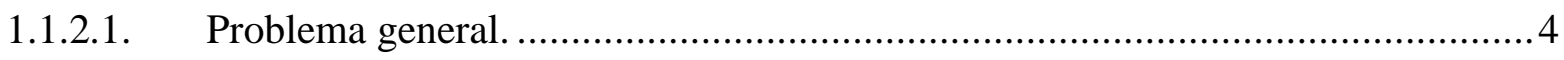

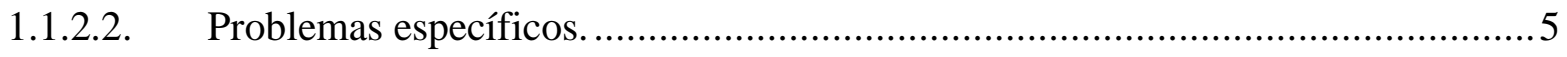

1.1.3. Justificación de la investigación..............................................................

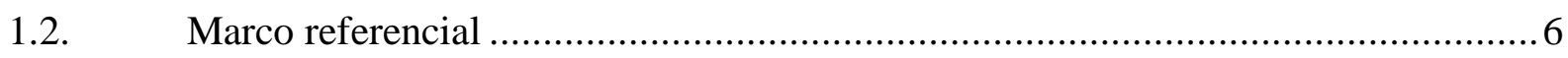

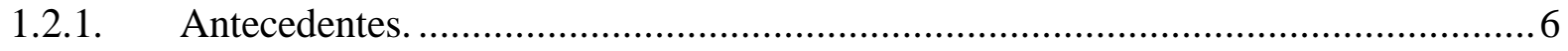

1.2.2. Marco teórico. ..................................................................................... 15

1.2.2.1. Gestión de la calidad total................................................................. 15

1.2.2.1.1. Definición............................................................................. 15

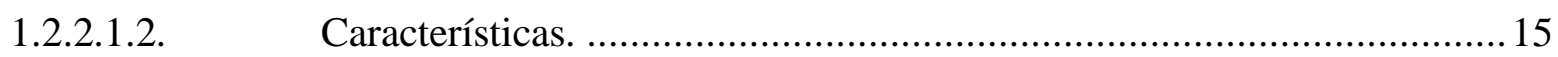

1.2.2.1.3. Teoría de gestión de la calidad total. ............................................ 16

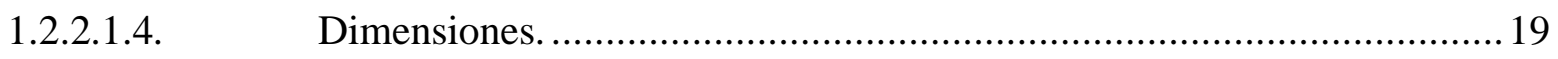

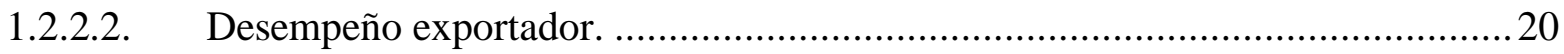

1.2.2.2.1. Definición........................................................................... 20

1.2.2.2.2. Teoría de desempeño exportador............................................. 21

1.2.2.2.3. Dimensiones. ................................................................ 23

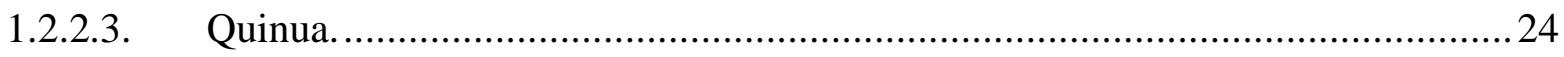

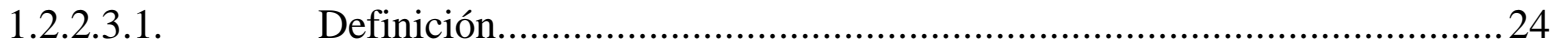


1.2.2.3.2. Precio internacional de la quinua peruana. .....................................25

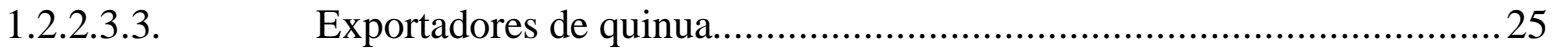

1.2.2.3.4. Principales destinos de la quinua peruana. .....................................26

1.2.2.3.5. Principales empresas exportadoras de quinua en el Perú......................26

1.2.2.3.6. $\quad$ Principales zonas productoras de quinua......................................2 27

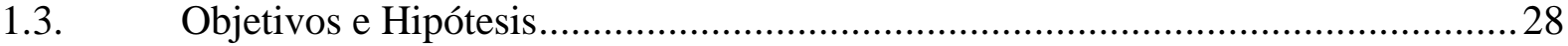

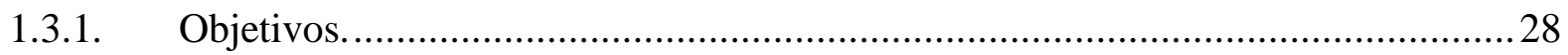

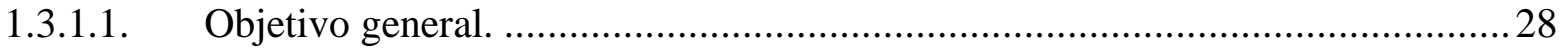

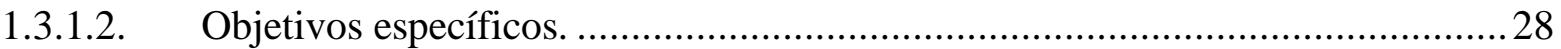

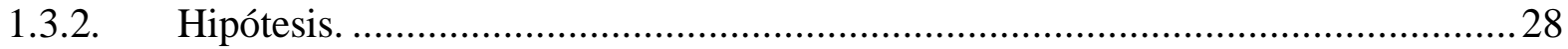

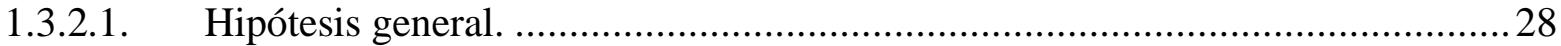

1.3.2.2. Hipótesis específicas...................................................................29

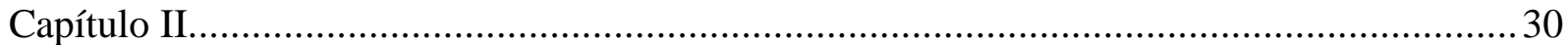

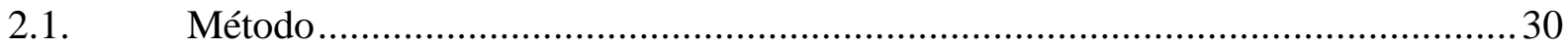

2.1.1. Tipo de investigación. ................................................................ 30

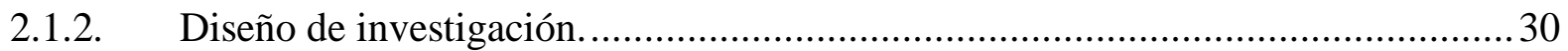

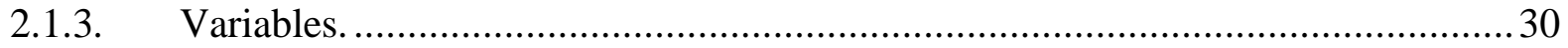

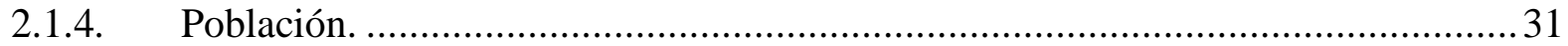

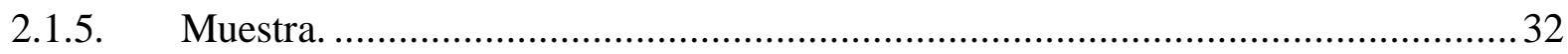

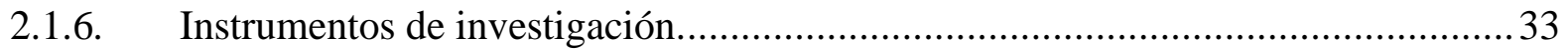

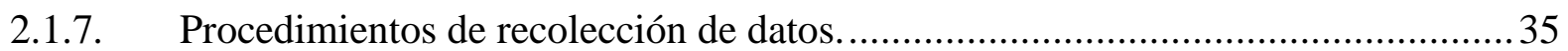

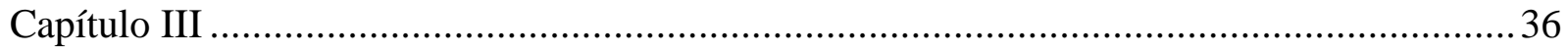

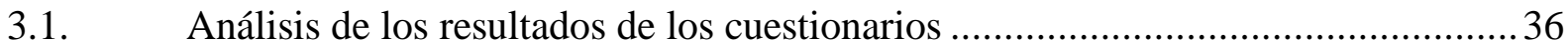


3.1.1. Análisis de los resultados de gestión de la calidad total...................................36

3.1.2. Análisis de los resultados de desempeño exportador ...................................52

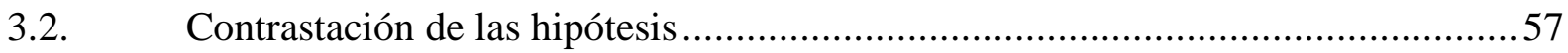

3.2.1. Prueba de Shapiro-Wilk.................................................................. 57

3.2.2. Validación de constructo: Análisis factorial exploratorio ..............................61

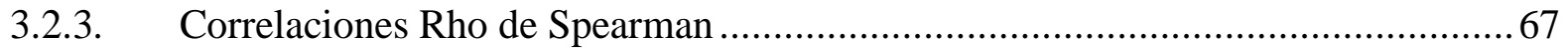

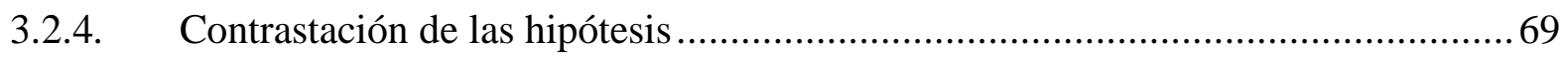

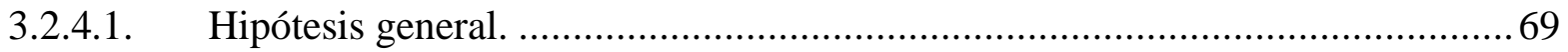

3.2.4.2. Primera hipótesis específica. ...................................................... 70

3.2.4.3. Segunda hipótesis específica....................................................... 71

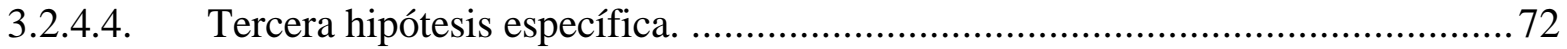

3.2.4.5. Cuarta hipótesis específica. ............................................................. 73

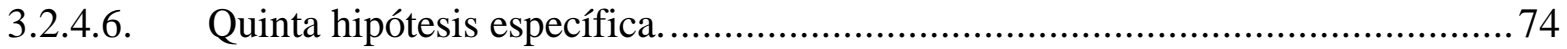

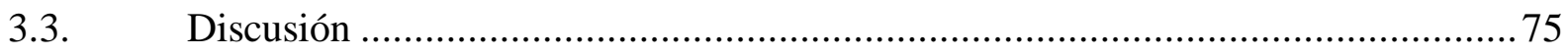

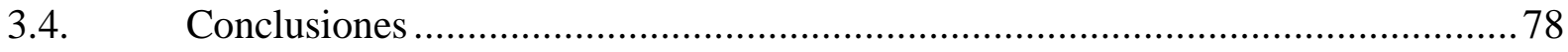

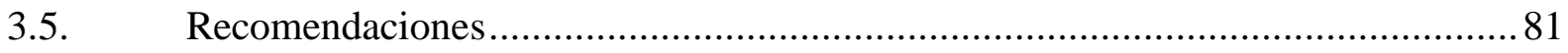

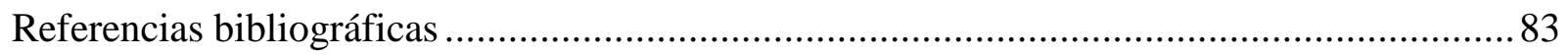

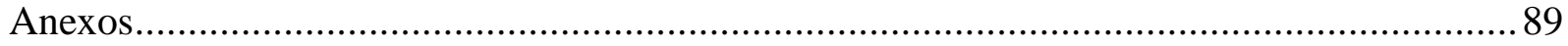

Anexo 1. Matriz de consistencia............................................................................... 89

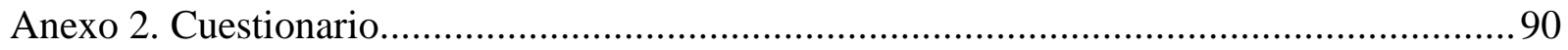

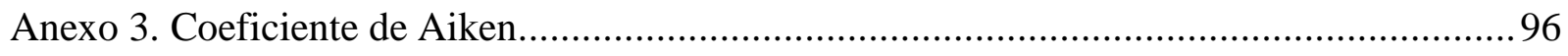

Anexo 4. Validación de jueces ....................................................................... 98

Anexo 5. Alfa de Cronbach Gestión de calidad total......................................................... 113 
Anexo 6. Alfa de Cronbach Desempeño exportador ........................................................... 118

Anexo 7. Análisis factorial Gestión de la calidad total....................................................... 121

Anexo 8. Análisis factorial Desempeño exportador .......................................................... 123

\section{Índice de tablas}

Tabla 1: Dimensiones de gestión de la calidad total............................................................. 19

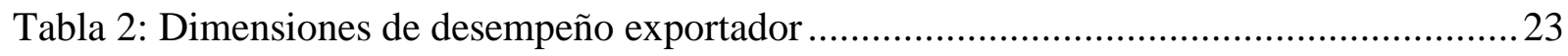

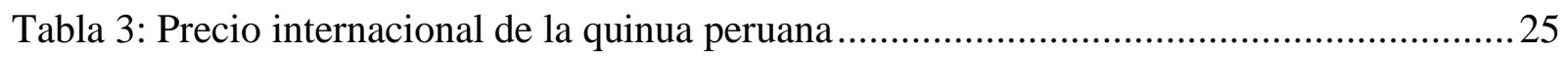

Tabla 4: Países exportadores de quinua (cantidad exportada en toneladas) ...........................25

Tabla 5: Países que importan la quinua peruana …………….............................................2. 26

Tabla 6: Población de empresas MYPES exportadoras de quinua ............................................ 31

Tabla 7: Muestra de empresas MYPES exportadoras de quinua...............................................33

Tabla 8: Cuestionario de gestión de la calidad total ................................................................ 34

Tabla 9: Cuestionario de desempeño exportador.................................................................... 34

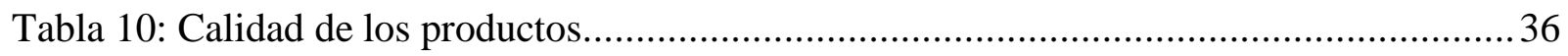

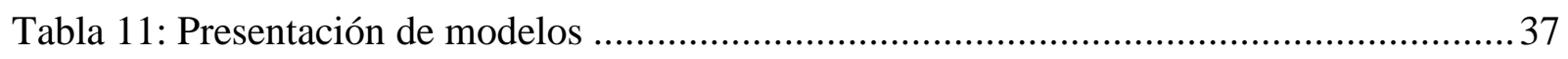

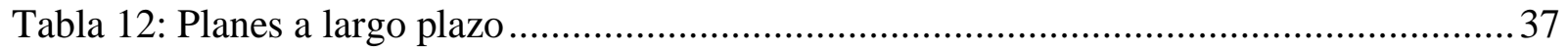

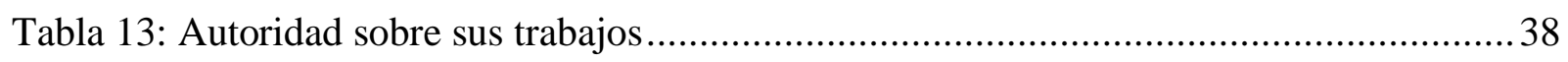

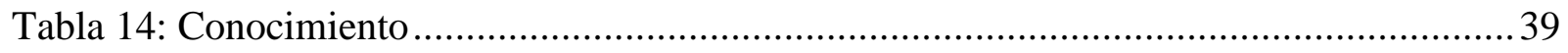

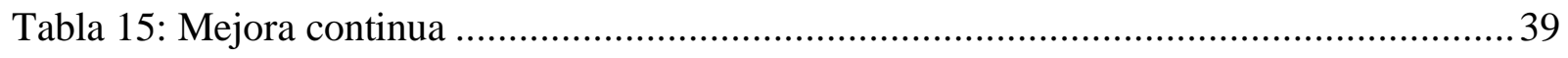

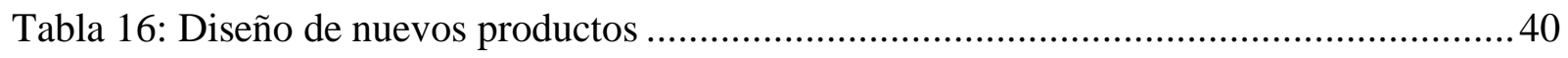

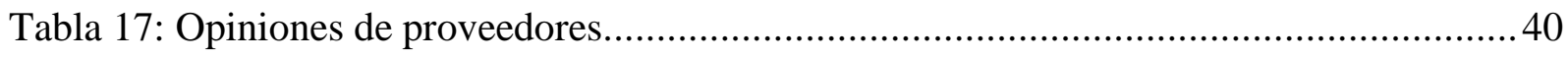




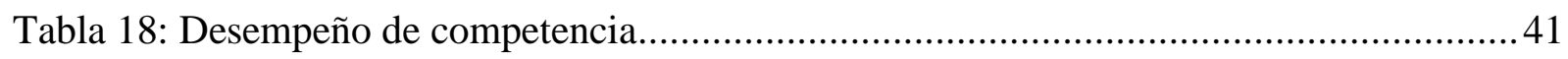

Tabla 19: Medición sistemática de perdidas ...................................................................... 41

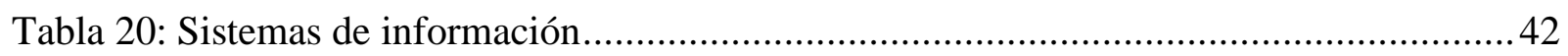

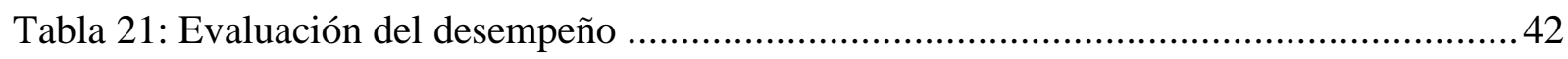

Tabla 22: Puntos de vista de empleados .............................................................................

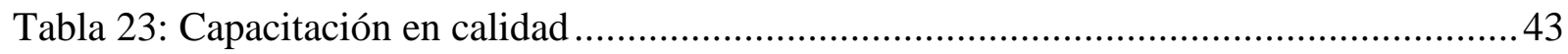

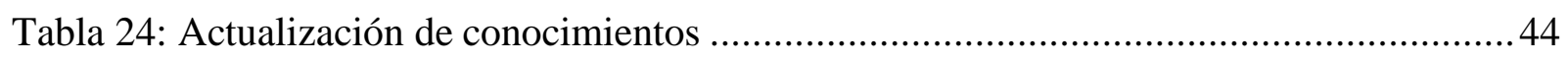

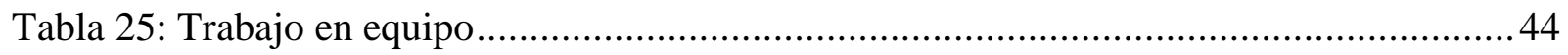

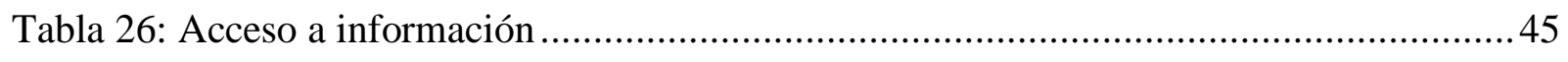

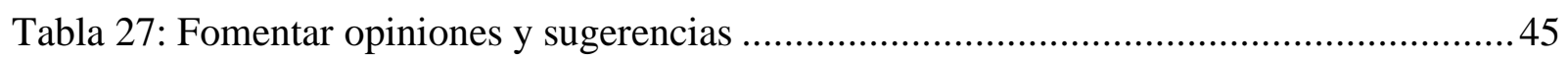

Tabla 28: Desarrollo de asociaciones con proveedores .........................................................46

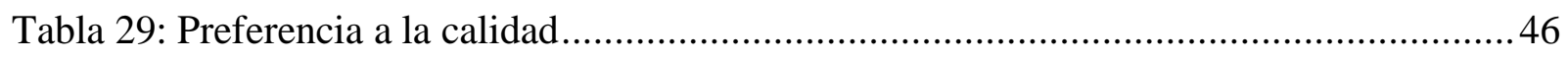

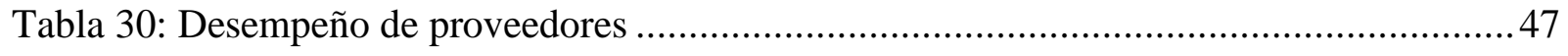

Tabla 31: Proporción de información y recursos.................................................................. 47

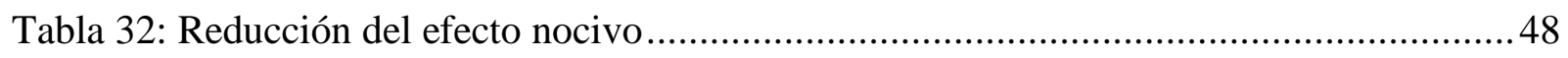

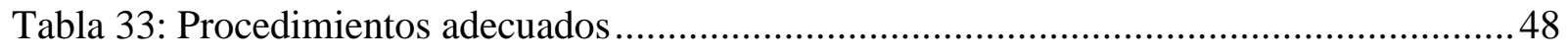

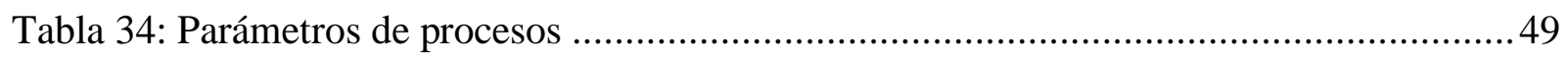

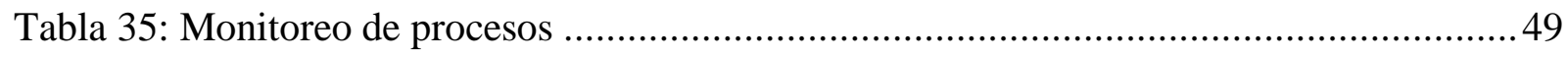

Tabla 36: Desarrollo e innovación de procesos ....................................................................50

Tabla 37: Departamento de investigación y desarrollo..........................................................50

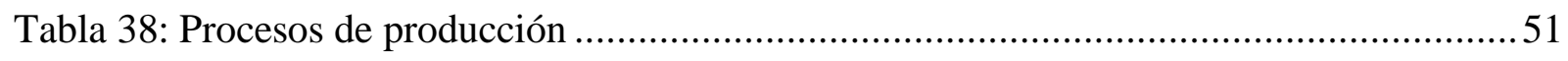

Tabla 39: Sistemas para quejas................................................................................... 51

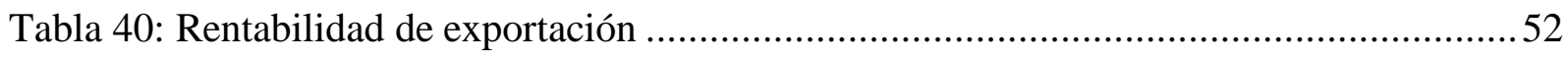




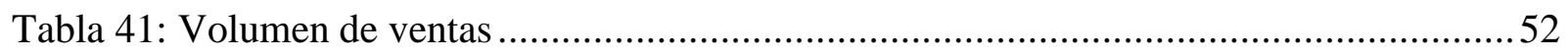

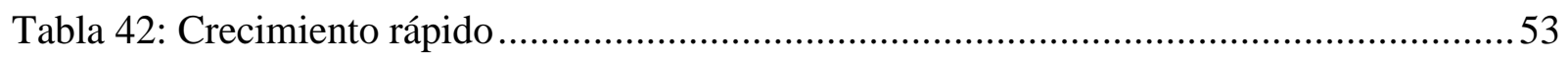

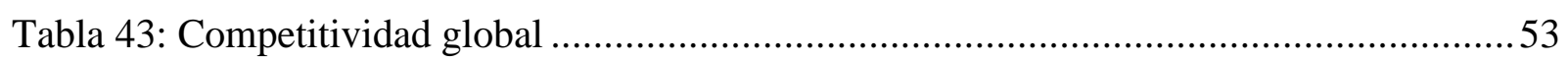

Tabla 44: Posición estratégica ....................................................................................... 54

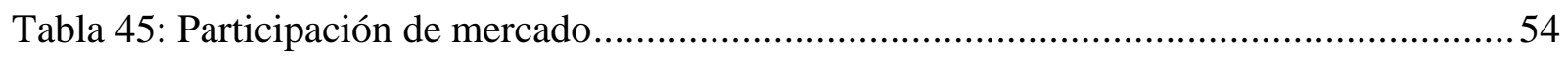

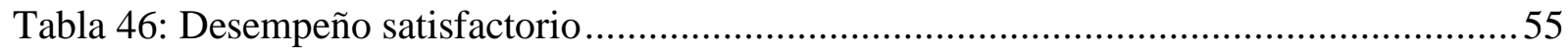

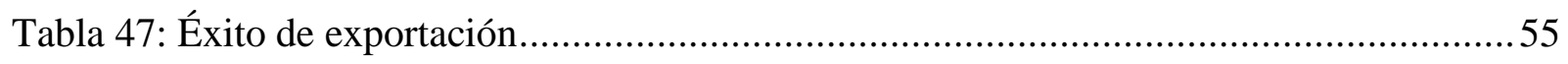

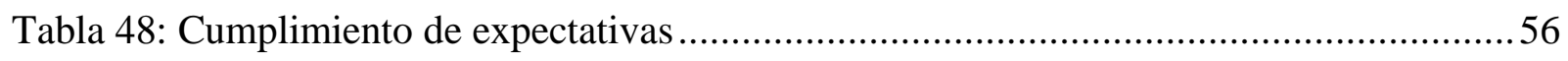

Tabla 49: Prueba de normalidad Shapiro-Wilk - gestión de la calidad total.............................57

Tabla 50: Prueba de normalidad Shapiro-Wilk - desempeño exportador ..................................60

Tabla 51: "Prueba de KMO, Bartlett y Método de extracción" - gestión de la calidad total....61

Tabla 52: "Varianza Total Explicada"- gestión de la calidad total............................................62

Tabla 53: "Método de rotación: Varimax con normalización Kaiser"- gestión de la calidad

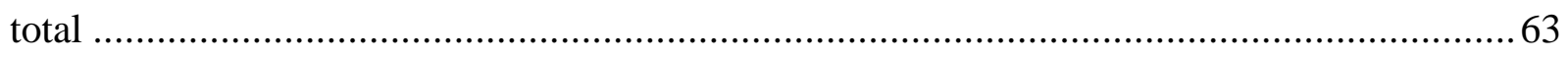

Tabla 54: "Prueba de KMO, Bartlett y Método de extracción"- desempeño exportador ..........66

Tabla 55: "Varianza Total Explicada"- desempeño exportador................................................66

Tabla 56: "Método de rotación: Varimax con normalización Kaiser"- desempeño exportador67

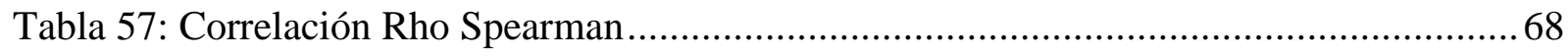

Tabla 58: Hipótesis general - Resultado de Rho de Spearman ..................................................69

Tabla 59: Primera hipótesis específica - Resultado de Rho de Spearman .................................70

Tabla 60: Segunda hipótesis específica - Resultado de Rho de Spearman ................................71

Tabla 61: Tercera hipótesis específica - Resultado de Rho de Spearman...................................72

Tabla 62: Cuarta hipótesis específica - Resultado de Rho de Spearman ................................... 73 
Tabla 63: Quinta hipótesis específica - Resultado de Rho de Spearman............................ 74

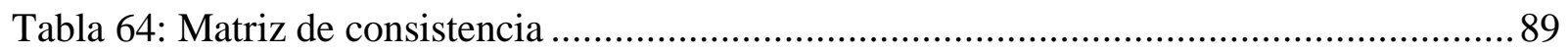

Tabla 65: Cuestionario de gestión de la calidad total ............................................... 90

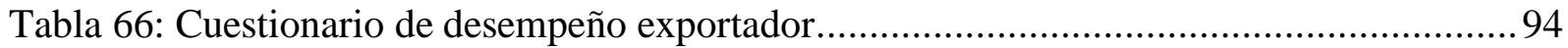

\section{Índice de figuras}

Figura 1. Principales empresas exportadoras de quinua

Figura 2. Principales zonas de producción de la quinua 


\section{Introducción}

La exportación en todos los países es una actividad importante para sus economías y la balanza comercial de cada país. Además, la actividad de exportación maximiza las reservas de divisas e ingresos del país. El término de desempeño de la empresa no es nuevo en el contexto de la gestión estratégica. El desempeño de las exportaciones es el método en que las empresas miden los éxitos tanto financiero como estratégico (Cavusgil \& Zou, 1994). En la literatura de micro y pequeñas empresas (MYPES), numerosos estudios han investigado el desempeño de las MYPES. Se investiga cómo las MYPES también proporcionan valores para los propietarios, los clientes y el país. El desempeño de exportación de las MYPES se puede medir para investigar la variable financiera o las variables no financieras (Zou \& Stan, 1998).

Sin embargo, existen estudios publicados que han demostrado que la gestión de calidad total posee una relación con el desempeño de las exportaciones de las MYPES (Abeykoon \& de Alwis, 2015; Imran, Aziz \& Hamid, 2017; Lages, Silva \& Styles, 2009). Además, Imran, Aziz y Abdul (2016) destacaron que el desempeño de las exportaciones de las MYPES también depende de recursos estratégicos firmes. La gestión de calidad total se considera dentro de una empresa como intangible y con un recurso natural de capacidad dinámica (El Shenawy, Baker \& Lemak, 2007) que podría ser beneficioso para el desempeño de las exportaciones de las MYPES.

La gestión de calidad total ahora es considerada por prácticamente todas las empresas líderes y profesionales de la calidad como el camino a seguir, para obtener una ventaja competitiva (Goh \& Ridgway, 1994). Además, Valos y Baker (1996) establecieron que los sistemas como la gestión de la calidad total son ingredientes vitales en la capacidad general de una empresa, lo que sugiere que un mero aumento en las competencias de producción es trascendental para el 
desempeño de las exportaciones. Además, una evaluación detallada de la literatura ha revelado que estudios muy limitados investigaron el efecto de la gestión de calidad total en el éxito de las exportaciones de MYPES.

Por lo tanto, en este trabajo de investigación, se trata de investigar la relación entre la gestión de calidad total y el desempeño de las empresas MYPES exportadoras de quinua en el Perú.

En el primer capítulo se presenta la problemática para la presente investigación, para que así se pueda conocer cuáles son los puntos más críticos con la finalidad de diseñar diferentes recomendaciones novedosas, de igual manera se muestran los antecedentes de diferentes investigadores que tomaron en cuenta el estudio de las mismas variables de este trabajo de investigación, así como el desarrollo del marco teórico y los objeticos e hipótesis, generales y específicos.

En el segundo capítulo se detalla cual es la metodología por usarse, enfatizando en el tipo y diseño de investigación, y se explica las variables consideradas, así la población y la muestra y se explica cuáles son los instrumentos de investigación, así como el procedimiento para la recolección de los datos necesarios para el desarrollo de este trabajo de investigación.

En el tercer capítulo se presentan los análisis de los resultados de los cuestionarios, la contrastación de las hipótesis, donde se desarrollaron la prueba de Shapiro-Wilk, el análisis factorial exploratorio, la correlación Rho de Spearman y las contrastaciones de las hipótesis, así mismo se presentan las discusiones, las conclusiones y las recomendaciones. Concluyendo con las referencias bibliográficas y los anexos, tanto la matriz de consistencia y los cuestionarios. 


\section{Capítulo I}

\subsection{Planteamiento de investigación}

\subsubsection{Planteamiento del problema.}

Perú ha sido reconocido como el mayor exportador mundial de quinua durante cinco años consecutivos. El volumen de exportación fue de 48.000 toneladas, representando el $44 \%$ de las exportaciones mundiales; Bolivia ocupó el segundo lugar con 33.000 toneladas, representando el 29,4\%; de acuerdo con las estadísticas anuales de 2019 reportadas por Trade Map, aplicativo del Centro de Comercio Internacional, Organización Mundial del Comercio y Solicitud de agencia conjunta de las Naciones Unidas.

El progreso en la demanda mundial de quinua se refleja en el precio y ha afectado el valor de exportación de US \$ 289 millones 700 mil, un aumento de 7,5\% desde el valor de US \$269 millones 600 mil obtenido en el 2018. Al mismo tiempo, Perú exportó USD 124 millones 133 mil lo que representa el $44 \%$ de la totalidad de los envíos mundiales. Los principales mercados de destino de la quinua peruana son Canadá, Estados Unidos, Reino Unido, Holanda (Países Bajos), Francia e Italia, se exporta a más de 71 países de América del Norte, Europa, Asia, África y Medio Oriente (MINAGRI, 2019).

Edgar Vásquez (2020), ministro de Comercio Exterior y Turismo, menciona que se han multiplicado por siete las exportaciones de la quinua con valor agregado respecto a hace algunos años diversificándonos por productos y destinos. Se refirió que los acuerdos de libre comercio han permitido reducir los impactos en escenarios globales difíciles y aprovechar al máximo las oportunidades en las épocas de bonanza. El ministro adelantó que uno de los objetivos del Perú es tener un acuerdo de libre comercio con el Reino Unido y continuar expandiéndonos en términos comerciales en el ámbito Transpacífico, la India y acentuar las relaciones con China. 
Las MYPES exportadoras de quinua muestran ciertos problemas con relación a como gestionan la calidad total en sus productos, como la no implementación de políticas, objetivos y procesos adecuados, a raíz de la pobre capacitación que se les da a los empleados, llevándolos a no desarrollar su verdadero potencial, ya sea grupal ni individual. Así mismo se encuentra que los líderes no desarrollan ni facilitan que se alcance la visión ni la misión de las empresas. Además de que las empresas MYPES exportadoras de quinua no poseen las habilidades de la gestión de la calidad total, lo que les daría la posibilidad de obtener una mejor reputación comercial, y que no tienen estrategias centradas en el sector agrícola o en el mercado de otros países para realizar las exportaciones, así como que no gestionan ni diseñan procesos que logren agregar un valor creciente para satisfacer a los clientes (Agrodata Perú, 2019).

Las empresas MYPES que exportan la quinua desde el Perú se encuentran en la necesidad de mejorar sus procesos internos, para poder ofrecer productos y servicios competitivos en los mercados internacionales, una manera básica de lograr esto son las certificaciones de calidad, lo cual la mayoría de las empresas MYPES que exportan la quinua no la tienen, a pesar que es de suma importancia para poder demostrarles a sus clientes extranjeros que pueden ofrecer un producto de muy buena calidad (Lizarzaburu, 2016).

\subsubsection{Formulación del problema.}

\subsubsection{Problema general.}

¿Cómo se relaciona la gestión de la calidad total con el desempeño de las empresas MYPES exportadoras de quinua del Perú 2020? 


\subsubsection{Problemas específicos.}

¿Cómo se relaciona el liderazgo con el desempeño de las empresas MYPES exportadoras de quinua del Perú 2020?

¿Cómo se relaciona la estrategia y el desempeño de las empresas MYPES exportadoras de quinua del Perú 2020?

¿Cómo se relacionan las personas con el desempeño de las empresas MYPES exportadoras de quinua del Perú 2020?

¿Cómo se relacionan los recursos con el desempeño de las empresas MYPES exportadoras de quinua del Perú 2020?

¿Cómo se relacionan los procesos con el desempeño de las empresas MYPES exportadoras de quinua del Perú 2020?

\subsubsection{Justificación de la investigación.}

El propósito de este estudio es determinar si existe alguna relación entre la gestión de la calidad total y el desempeño de las empresas MYPES exportadoras de quinua del Perú, así como la relación entre las diversas dimensiones de la gestión de la calidad total (personas, recursos, procesos, estrategia y liderazgo) y el desempeño exportador de las mismas empresas.

$\mathrm{Al}$ momento que se finalice este trabajo de investigación, se logrará reunir datos importantes para las empresas MYPES exportadoras de quinua del Perú, así como para otras empresas dedicadas a la exportación de diferentes productos peruanos pero que podrá usar dichos datos de manera referencial. Es de vital importancia que las empresas MYPES exportadoras de quinua sepan como la gestión de la calidad total les ayudara a que tengan el mejor desempeño en sus exportaciones. 
De acuerdo con las relaciones que se logren hallar entre la gestión de la calidad total y el desempeño exportador, se estará en la posición para poder elaborar estrategias que les den muchos beneficios a las empresas exportadoras de quinua, con la finalidad de que los gerentes, dueños o administradores puedan tomar las mejores decisiones para el bienestar de la empresa.

El mayor beneficiado apenas se termine con el desarrollo de la presente investigación serán las mismas empresas exportadoras de quinua, dado que los gerentes, dueños o administradores tomando como base los resultados alcanzados, sabrán cuales son los puntos clave de la gestión de la calidad total que les den el crecimiento necesario para proseguir exportando sus productos. Igualmente, los clientes de las empresas exportadoras de quinua se verán beneficiados con la buena aplicación de la gestión de la calidad total, puesto que el principal objetivo de las empresas es darles productos de calidad a sus clientes.

Los gerentes, dueños o administradores de las empresas exportadoras de quinua del Perú llegaran a estar en la mejor posición, basados en los resultados alcanzados, para utilizar las estrategias que se lleguen a recomendar en la presente investigación, en como la gestión de la calidad total ayudara a que sus ventas aumenten y por ende su desempeño exportador. Es de esperar igualmente que esta investigación sea de mucha utilidad para investigaciones futuras que tomen la decisión de estudiar la gestión de la calidad total y al desempeño exportador de las empresas. Así mismo esta investigación servirá para cubrir las brechas académicas existentes en la literatura nacional.

\subsection{Marco referencial}

\subsubsection{Antecedentes.}

De acuerdo con los investigadores Gharakhani, Rahmati, Farrokhi y Farahmandian (2013) en su artículo denominado "Total quality management and organizational performance." La 
gestión de calidad total (TQM) se considera un factor muy importante para el éxito a largo plazo de una organización. La implementación de TQM ha sido un aspecto importante para mejorar la eficiencia organizacional. Numerosos estudiosos han investigado los vínculos entre TQM y el rendimiento. Este artículo se basó en la revisión de la literatura en relación a la gestión de calidad total y el desempeño exportador, tomando como base a investigadores como Mahesh, C. (1993), Zollo, M. y Winter, S., (2002), Kaynak, H., (2003) entre otros. Al examinar la relación entre TQM y el rendimiento, los académicos han utilizado diferentes tipos de rendimiento, como el rendimiento financiero, innovador, operativo y de calidad. Investigaciones recientes sobre la gestión de la calidad total han examinado las relaciones entre la gestión de la calidad total y el desempeño organizacional. TQM se enfoca en la mejora continua de procesos dentro de las organizaciones para proporcionar un valor superior al cliente y satisfacer las necesidades del cliente. TQM se adopta una guía popular para la gestión organizacional para desarrollar infomaps estratégicos e infocharts para una organización de información.

De acuerdo con los investigadores Abeykoon y De Alwis (2015) titulado "The Impact of Total Quality Management Practices on Export Performance of Apparel Exporters in Sri Lanka." en la competencia global y la liberalización económica de hoy, la calidad se ha convertido en uno de los factores importantes para lograr ventajas competitivas. Por lo tanto, la calidad y su avance continuo ha desarrollado un significado significativo para el negocio de hoy. Los países desarrollados a menudo se resisten a las exportaciones de los países en desarrollo si las exportaciones no cumplen con los estándares de calidad de sus países. Sri Lanka, como otras economías en desarrollo, también está tratando de explotar las oportunidades comerciales en los mercados internacionales y ha tenido éxito en la industria textil y de la confección. La intención de este estudio fue reconocer el impacto de las prácticas de gestión de calidad total (TQMP) en 
el desempeño de exportación (EP) de los exportadores de indumentaria de Sri Lanka. La escala Likert de cinco puntos se utilizó como herramienta principal para la recopilación de datos y se recopilaron datos de 65 exportadores de prendas de vestir en Sri Lanka. Se utilizan ocho dimensiones para medir el TQMP, que incluyen capacitación, liderazgo, información y análisis, gestión de empleados, gestión de procesos, gestión de proveedores, mejora continua y enfoque en el cliente. Se utilizaron análisis de regresión y correlación para examinar el impacto de TQMP en EP y la relación entre TQMP y EP. En este estudio, se examinó el impacto de TQMP en EP de los exportadores de prendas de vestir de Sri Lanka. Sobre la base de todos los hallazgos del presente estudio se confirma que el TQMP genera un impacto significativo en EP de los exportadores de prendas de vestir de Sri Lanka. El estudio apoyó la hipótesis de que existe una relación entre TQMP y EP. Sin embargo, se encuentra que existe una relación positiva moderada significativa entre TQMP y EP y concluye que el aumento de TQMP resultará en un aumento de EP de los exportadores de ropa.

En el documento de Jonah, Ornguga \& Torsen (2016) denominado "The Effect of Total 4 Quality Management (TQM) on the Organizational Growth of Adama Beverages: A Marketing Mix Perspective." Se examinó el efecto de las prácticas de Gestión de Calidad Total en el crecimiento organizacional de las bebidas Adama. Específicamente, determinar el efecto de la gestión de calidad total en el crecimiento organizacional, el impacto de la mezcla de marketing produce un crecimiento organizacional y el efecto a largo plazo La gestión de calidad total en el crecimiento organizacional. El diseño de investigación explicativo fue adoptado. La población objetivo estaba compuesta por el jefe de departamentos y la unidad de distribución en Adama Beverages, cuya población total era de 120. El tamaño de la muestra de 90 encuestados se extrajo mediante muestreo aleatorio estratificado. Se utilizaron cuestionarios 
para recopilar datos primarios. Se utilizó el Paquete Estadístico para Ciencias Sociales (SPSS) para realizar los datos. Los hallazgos respaldan la hipótesis de que existe un efecto positivo y significativo de la gestión de la calidad total en el crecimiento de la organización, por lo que cualquier gerente de la organización que tenga como objetivo lograr un desempeño organizacional debe prestar mucha atención a todos los elementos de la gestión de la calidad total.

Para los investigadores Tahir, Batool y Takrim (2016) en su trabajo denominado "The Effects of Total Quality Management on Exports in Manufacturing Based Small and Medium Enterprise's: A Case Study of Organizations from Selected Regions of Pakistan." La importancia de las exportaciones y el desarrollo de las pequeñas y medianas empresas no puede socavarse para el desarrollo económico y social de ningún país. El estudio actual está motivado debido a la comprensión limitada de la Gestión de Calidad Total (TQM) entre las PYME basadas en la fabricación en el contexto de Pakistán. El objetivo del estudio se estableció para evaluar el nivel de implementación de TQM y su impacto en las exportaciones en el caso de las PYME basadas en la fabricación en Pakistán. El estudio utilizó la metodología de la encuesta y los datos se recopilan a través de un muestreo conveniente de 120 encuestados pertenecientes a PYMEs basadas en la fabricación ubicadas en Peshawar, Haripur y Rawalpindi. Se realizaron análisis de correlación y regresión sobre los datos. Los hallazgos clave indican que hay un bajo nivel de implementación de TQM a pesar de sus efectos positivos en la promoción de exportaciones en las empresas de muestra. La baja implementación puede estar asociada a recursos limitados, la baja educación del propietario y el interés en la calidad y el apoyo limitado del gobierno y sus agencias relacionadas. Se sugiere que el aumento de la implementación de TQM entre las pymes 
basadas en la fabricación en Pakistán puede producir algunos resultados deseables, como las exportaciones.

La investigación de Imran, Aziz y Hamid (2017) denominado "Total quality management, export market orientation and firm export performance: A conceptual framework.” planteó que la orientación al mercado de exportación puede facilitar un entendimiento claro de la gestión de calidad total y su relación con el desempeño de las exportaciones de la empresa. Específicamente, el marco propuesto vincula la gestión de la calidad total y la orientación del mercado de exportación con el desempeño de la empresa en el mercado internacional. Este artículo se basó los indicadores de desempeño de las exportaciones en medidas objetivas (cuantitativas) y subjetivas (actitudes, percepciones, cualitativas). La escala EXPERF para medir el desempeño de las exportaciones en una naturaleza multidimensional, es decir, cubrió la medida, tanto financiera como no financiera, del desempeño de las exportaciones en términos objetivos y subjetivos. Esta escala ha sido validada empíricamente en los exportadores de Estados Unidos y Japón, así como validada en el Reino Unido y Australia; y un estudio del exportador británico fortaleciendo su valor como una medida válida de desempeño de exportación generalizada. Esta relación ha producido algunas propuestas que explican cómo TQM tiene una relación recíproca con la orientación al mercado e influye en el desempeño de las empresas en diversos mercados internacionales.

Según los investigadores Iqbal, Huq y Bhutta (2018) en su trabajo titulado "Agile manufacturing relationship building with TQM, JIT, and firm performance: An exploratory study in apparel export industry of Pakistan.” Investigaciones recientes sobre fabricación ágil han examinado su relación con la gestión de calidad total (TQM), Just in Time (JIT) y los diferentes niveles de rendimiento de la empresa. Se han informado resultados mixtos, 
probablemente debido a la falta de disponibilidad de construcciones de AM bien validadas. Esta investigación (cuantitativo-correlacional) desarrolla un modelo de 3 etapas y examina la relación directa y / o indirecta de AM con las infraestructuras comunes, TQM y JIT y sus efectos en diferentes niveles de desempeño de la empresa en el contexto de los sectores industriales paquistaníes, específicamente la industria de exportación de prendas de vestir. Se recopilan datos de 248 empresas de exportación de indumentaria paquistaníes y el modelo se estima utilizando modelos de ecuaciones estructurales. El instrumento de encuesta fue probado y validado externamente a partir de datos de encuestas e internamente a partir de literatura y estudios existentes. El cuestionario de la encuesta está disponible a pedido. Se desarrolló un instrumento de encuesta para examinar nuestros objetivos de investigación. También se solicitaron comentarios de consultores de la industria sobre el cuestionario y se incorporaron sus comentarios. Se desarrolló un cuestionario por correo electrónico basado en Internet utilizando Qualtrics (www.qualtrics.com) para recopilar los datos. Los resultados indican que la infraestructura común (interna) y TQM tienen una relación positiva con AM específicamente en las empresas de exportación de prendas de vestir en una economía del tercer mundo donde el sector industrial se encuentra en un estado naciente. Mientras que la relación JIT está mediada positivamente a través de infraestructura externa, TQM y JIT no parecían contribuir directamente en el desempeño operativo. Sin embargo, esta relación es significativa cuando está mediada por la fabricación ágil. El desempeño del mercado media positivamente la relación entre el desempeño operativo y el desempeño financiero de la empresa. Se discuten las implicaciones de los hallazgos para los investigadores y los profesionales, que examinan los sectores industriales en el mundo en desarrollo, y se ofrecen instrucciones de investigación. 
El propósito del estudio de Imran, Aziz, Hamid, Shabbir, Salman y Jian (2018) titulado “The mediating role of total quality management between entrepreneurial orientation and SMEs export performance." es investigar el rol intermediario de la gestión de la calidad total (TQM) en la industria manufacturera de Pakistán entre la orientación empresarial (EO) y el desempeño de las PYME. Esta investigación surge del hecho de que existen muy pocos estudios que examinen cómo los recursos intangibles y las capacidades corporativas (como EO y TQM) impulsan el desempeño exportador de las PYME. Se usaron algunas escalas Likert para la recopilación de datos y se recibieron 364 respuestas útiles de propietarios/apoderados de PYMES exportadoras. Los datos se analizaron por medio del modelado de ecuaciones estructurales de mínimos cuadrados parciales (PLS-SEM). Se revelo como resultado una relación significativa entre EO y TQM con el rendimiento de exportación de las PYME. Además, este estudio encontró el papel mediador complementario de TQM entre EO y el desempeño exportador de las PYME del sector manufacturero de Pakistán. Este estudio tiene alcances para cada propietario/apoderado de PYME. Los resultados ofrecen una mejor comprensión de la implementación de EO y TQM para los propietarios / gerentes de PYMES. Por lo tanto, los propietarios/gerentes de las PYME pueden tomar mejores decisiones para la implementación de las prácticas de TQM. Además, según el mejor conocimiento del investigador, este estudio es el primer trabajo, que examina el desempeño de exportación de las PYME de Pakistán en asociación con el TQM como el factor mediador entre el desempeño de exportación de EO y SME.

El trabajo de Imran, Hamid y Aziz (2018) titulado "The influence of TQM on export performance of SMEs: Empirical evidence from manufacturing sector in Pakistan using PLSSEM" el impacto de la gestión de la calidad total (TQM) en el desempeño de las exportaciones 
de la industria manufacturera de las pequeñas y medianas empresas (PYME) de Pakistán. Obtener datos de pequeñas y medianas empresas manufactureras involucradas en la exportación, recibir 364 respuestas y utilizarlas para analizar estadísticamente. Este estudio fue cuantitativo, correlacional y no experimental. Las medidas de la variable se adaptaron de estudios anteriores. La TQM en este estudio contiene cinco dimensiones que incluyen liderazgo, estrategia, personas, recursos y procesos contenidos. Además, se adaptó la escala de desempeño de las exportaciones (EXPERF) con 9 ítems. Se utilizó una escala Likert de siete puntos para asegurar la alta variabilidad estadística entre las respuestas, que van desde 1 (Muy en desacuerdo), 2 (En desacuerdo), 3 (Algo en desacuerdo), 4 (Neutral), 5 (Algo de acuerdo), 6 (De acuerdo), 7 (Totalmente de acuerdo). El análisis estadístico SEM se evaluó a través de Smart PLS-3. Los resultados del estudio muestran que TQM tuvo un rol importante en el desempeño exportador de las PYME. La ejecución con niveles altos por parte de las empresas acerca de TQM les da la posibilidad de obtener éxitos en los diversos mercados internacionales y conseguirán mejorar su desempeño de exportación. Por lo tanto, el estudio revela que TQM es un recurso intangible valioso y dinámico que puede aumentar el rendimiento de exportación de las PYME. El estudio presentó la relación entre TQM y el rendimiento de exportación de las PYME y proporcionó algunas ideas para los profesionales y los investigadores. Es decir, los investigadores y los profesionales tomaran mejores decisiones a raíz de que puedan implementar el TQM. Además, este estudio ayudó a la literatura del desempeño de las exportaciones de TQM y SME, empíricamente. La ausencia de TQM puede influir el desempeño de la empresa en los mercados internacionales.

El estudio de Imran y Khaliq (2019) titulado “The Influence of Total Quality Management and Export Market Orientation on company export performance of Furniture Industry in 
Pakistan: A moderating role of Business Network." analizó el papel moderador de la red comercial (BN) en la relación entre la orientación al mercado de exportación (EMO), la gestión de calidad total (TQM) y el desempeño de exportación de la empresa (CEP). Este estudio fue cuantitativo-correlacional. La gestión de la calidad total en este estudio contiene cuatro dimensiones, donde el liderazgo, la estrategia, las personas y el proceso, la segunda variable independiente EMO contenía tres dimensiones, a saber, generación de información, difusión de información, capacidad de respuesta a la información. La escala BN se adaptó con cuatro dimensiones: adquisición de información, habilitación de oportunidades, movilización de recursos de vínculos fuertes, movilización de recursos de vínculos débiles. El presente estudio utilizó la técnica de modelado de ecuaciones estructurales de mínimos cuadrados parciales (PLS-SEM) en empresas exportadoras de muebles de tamaño de muestra 119. Los resultados de este estudio mostraron la relación de significación positiva entre EMO, TQM y CEP. Además, el estudio encontró el papel moderador de BN entre la relación de EMO, TQM y CEP. Por lo tanto, esto reveló que BN se considera la variable influyente para mejorar la efectividad de EMO y TQM, lo que conduce a un mayor CEP. Este estudio contribuye a la literatura y a la práctica de las empresas al ayudarlas a comprender cómo el proceso de EMO, TQM y BN produce un mejor rendimiento de exportación a través de la orientación al mercado de exportación. 


\subsubsection{Marco teórico.}

\subsubsection{Gestión de la calidad total.}

\subsection{Definición.}

Sadikoglu y Zehir (2010) afirman que la gestión de calidad total es un enfoque sistemático de mejora de la calidad para la gestión de toda la empresa con el fin de mejorar el rendimiento en términos de calidad, productividad, satisfacción del cliente y rentabilidad.

De acuerdo con Abeykoon y De Alwis (2015) la gestión de calidad total es principalmente una mejora de la calidad del producto final y reduce las deficiencias en la producción, lo que conduce a la reducción de costos.

Imran, Hamid y Aziz (2018) expresaron que la gestión de la calidad total es el proceso de mejorar de los procesos, productos y servicios que posee la empresa para conseguir que sus clientes se sientan satisfechos a un costo bajo.

Imran y Khaliq (2019) definieron la gestión de calidad total como una filosofía de gestión que tenía como objetivo conocer y cumplir con las expectativas del cliente y considerar reducir los costos.

Para Shafiq, Lasrado y Hafeez (2019) la gestión de calidad total es la integración de todas las funciones y procesos dentro de una organización para lograr la mejora continua de la calidad de los bienes y servicios

\subsection{Características.}

Según Mahmud y Hilmi (2014) las características de la gestión de la calidad total son:

- Proceso consistente.

- Planificación estratégica. 
- Dirigido hacia el cliente.

- Trabajo en equipo.

- Relación con la mejora continua de la calidad.

- Involucra al empleado en la mejora de la calidad.

\subsection{Teoría de gestión de la calidad total.}

\section{La teoría de Deming}

La teoría de Deming de la gestión de la calidad total se basa en catorce puntos de gestión que identificó, el sistema de conocimiento profundo y el ciclo de Shewart (Plan-Do-Check-Act). Es conocido por su relación: la calidad es igual al resultado de los esfuerzos de trabajo sobre los costos totales. Si una empresa se enfoca en los costos, el problema es que los costos aumentan mientras que la calidad se deteriora. El sistema de conocimiento profundo de Deming consta de los siguientes cuatro puntos:

- Apreciación del sistema: una comprensión de la forma en que funcionan los procesos y sistemas de la empresa

- Conocimiento de variación: una comprensión de la variación que ocurre y las causas de la variación

- Teoría del conocimiento: la comprensión de lo que se puede saber

- Conocimiento de psicología: la comprensión de la naturaleza humana.

Al conocer los diferentes tipos de conocimiento asociados con una organización, la calidad puede abordarse como tema. La calidad implica ajustar los procesos utilizando el conocimiento. Los catorce puntos de la teoría de gestión de la calidad total de Deming son los siguientes:

1) Crear constancia de propósito. 
2) Adopta la nueva filosofía.

3) Detener las dependencias de las inspecciones masivas.

4) No premie negocios basados en el precio.

5) Objetivo para la producción continua y la mejora del servicio.

6) Trae entrenamiento de vanguardia en el trabajo.

7) Implemente métodos de vanguardia para el liderazgo.

8) Abolir el miedo de la empresa.

9) Reconstruir barreras departamentales.

10) Deshágase de los objetivos de trabajo basados en la cantidad.

11) Deshágase de las cuotas y los estándares.

12) Apoye el orgullo de la artesanía.

13) Asegúrese de que todos estén capacitados y educados.

14) Asegúrese de que la estructura de la alta dirección sea compatible con los trece puntos anteriores.

Plan-Do-Check-Act (PDCA) es un ciclo creado para la mejora continua. En la fase de planificación, se describen los objetivos y las acciones. luego, realiza sus acciones e implementa las mejoras del proceso. A continuación, verifica para garantizar la calidad frente al original. finalmente actuar requiere que usted determine dónde deben ocurrir los cambios para una mejora continua antes de regresar a la fase del plan.

\section{La teoría de Crosby}

Philip Crosby es otra persona acreditada con el inicio del movimiento de la gestión de la calidad total. Él señaló, al igual que Deming que, si gastas dinero en calidad, es dinero que está 
bien gastado. Crosby se basa en cuatro absolutos de gestión de calidad y su propia lista de catorce pasos para mejorar la calidad.

Los cuatro absolutos de Crosby son:

- Definimos la calidad como el cumplimiento de los requisitos.

- La prevención es la mejor manera de garantizar la calidad.

- Cero defectos (errores) es el estándar de rendimiento para la calidad

- La calidad se mide por el precio de la no conformidad

Los catorce pasos para la mejora continua de la calidad, para Crosby, son:

1. Alcanzar el compromiso total de la gerencia.

2. Forme un equipo de mejora de calidad.

3. Cree métricas para cada actividad de mejora de calidad.

4. Determine el costo de la calidad y muestre cómo la mejora contribuirá a las ganancias.

5. Capacitar a los supervisores adecuadamente.

6. Anime a los empleados a corregir defectos y mantener registros de problemas.

7. Crear un comité de cero defectos.

8. Asegúrese de que los empleados y los supervisores entiendan los pasos hacia la calidad.

9. Demuestre el compromiso de su empresa celebrando un día de cero defectos.

10. Las metas se establecen en un horario de 30, 60 o 90 días.

11. Determine las causas raíz de los errores, elimínelos de los procesos.

12. Crear programas de incentivos para empleados.

13. Crea un consejo de calidad y celebra reuniones periódicas.

14. Repita desde el paso uno. 


\subsection{Dimensiones.}

Tabla 1:

Dimensiones de gestión de la calidad total

\begin{tabular}{cl}
\hline \multicolumn{1}{c}{ Autores } & \multicolumn{1}{c}{ Dimensiones } \\
\hline Bon y Mustafa & Liderazgo \\
& Cliente y enfoque de mercado \\
& Enfoque laboral \\
& Planificación estratégica \\
& Gestión de proceso \\
& Información y análisis \\
& Desempeño del negocio \\
& Liderazgo, \\
Imran, Hamid y Aziz & Estrategia, \\
& Personas, \\
& Recursos, y \\
& Procesos. \\
\hline
\end{tabular}

Fuente: Bon, A. T., \& Mustafa, E. M. (2013); Imran, M., Hamid, S., \& Aziz, A. (2018)

Elaboración: Raymundo y Paúcar (2020)

Las dimensiones de la gestión de la calidad total se explicaron basados en la adaptación de los investigadores Imran, Hamid y Aziz (2018), porque son las personas que mejor pueden explicar las dimensiones.

\section{Liderazgo}

Los líderes excelentes desarrollan y facilitan el logro de la misión y la visión. Desarrollan valores y sistemas organizacionales necesarios para el éxito sostenible y los implementan a través de sus acciones y comportamientos.

\section{Estrategia}

Las organizaciones excelentes implementan su misión y visión mediante el desarrollo de una estrategia centrada en las partes interesadas que tenga en cuenta el mercado y el sector en el que opera. Las políticas, los planes, los objetivos y los procesos se desarrollan e implementan para ofrecer una estrategia.

\section{Personas}


Las organizaciones excelentes administran, desarrollan y liberan todo el potencial de sus empleados a nivel individual, de equipo y organizacional. Promueven la equidad y la igualdad e involucran y capacitan a su gente.

\section{Recursos}

Las organizaciones excelentes planean administrar asociaciones externas, proveedores y recursos internos para apoyar políticas y estrategias y la operación efectiva de los procesos.

\section{Procesos}

Las excelentes organizaciones diseñan, gestionan y mejoran procesos para satisfacer plenamente y generar un valor creciente para los clientes y otras partes interesadas.

\subsubsection{Desempeño exportador.}

\subsection{Definición.}

Para el investigador Sorokina (2012) el desempeño de las exportaciones se ha definido conceptualmente como el resultado de las actividades de la empresa en los mercados extranjeros.

Según Abeykoon y De Alwis (2015) el desempeño de las exportaciones se define conceptualmente como el resultado integral de las ventas en el extranjero de una empresa.

Imran, Aziz y Hamid (2017) definieron el desempeño exportador como manera en que una empresa puede medir sus logros basados en sus objetivos financieros y estratégicos cuando la empresa exporta el producto en el mercado internacional.

Para los investigadores Imran, Hamid y Aziz (2018) el desempeño de las exportaciones es la manera en que una empresa mide el logro de sus objetivos financieros y estratégicos. 
Imran y Khaliq (2019) definen el desempeño de exportación como la capacidad para mejorar las ventas, la participación en el mercado, asegurar la competencia de la compañía en el mercado internacional, presentar y ofrecer productos / servicios innovadores y de calidad a los clientes.

\subsection{Teoría de desempeño exportador.}

\section{La visión basada en recursos}

La visión basada en recursos proporciona una base teórica para las actividades de exportación basadas en diversos aspectos de los recursos y capacidades de la empresa (Morgan, Kaleka \& Katsikeas, 2004). La visión basada en recursos trata a la empresa como un paquete único de recursos intangibles e tangibles (capacidades, activos, atributos gerenciales, procesos, conocimiento e información) que permite a la empresa crear y establecer estrategias dirigidas a mejorar su eficacia y eficiencia (Barney, 1991; Wernerfelt, 1984). La visión basada en recursos sustenta que los determinantes principales del desempeño de exportación de una empresa son sus recursos organizacionales internos, los cuales tienen ventajas en el uso y son difíciles de imitar o sustituir (Barney, 2001; Collis, 1991). Porter (1985) cree que la estrategia competitiva involucra desarrollar una fórmula amplia de cómo compiten las empresas, cuáles deberían ser sus objetivos y qué políticas se necesitan para lograr estos objetivos. El objetivo de la estrategia competitiva de la empresa es alcanzar un desempeño excelente y sostenible, creando así una ventaja competitiva en las operaciones (Hofer \& Schendel, 1978). Por otro lado, Wernerfelt (1984) cree que los recursos son cualquier cosa que pueda considerarse una fortaleza, incluidos los activos tangibles e intangibles relacionados con las operaciones de la empresa. Ejemplos de estos recursos incluyen branding, conocimiento técnico interno, contratación de personal calificado, contratos comerciales, maquinaria y capital. En cuanto a la ubicación de los recursos, Wernerfelt (1984) cree que mientras estos recursos sean realistas, el propietario de los recursos 
en la empresa puede mantener la ubicación a través de otros propietarios y terceros. Además, los propietarios de recursos pueden disfrutar de la protección a largo plazo de las ubicaciones de los recursos.

\section{Teoría de la capacidad dinámica}

Siguiendo la visión basada en los recursos (Barney, 1991), Dutta, Zbaracki y Bergen (2003) sugieren que las empresas pueden generar renta mediante el uso de recursos y capacidades superiores. En general, el enfoque basado en recursos afirma que los paquetes de recursos y las capacidades pueden variar de una empresa a otra. Si una empresa desea establecer una ventaja competitiva, debe acumular recursos y capacidades que la diferencien de otras empresas. La implementación de una estrategia de creación de valor puede conducir a una ventaja competitiva sostenida (Barney, 1991). Además, para generar renta económica, una empresa también debe establecer precios apropiados. El proceso de fijación y cambio de precios puede observarse como una capacidad que le permite a una empresa lograr una ventaja competitiva. Por lo tanto, una empresa debe basar sus capacidades en una combinación de rutinas, mecanismos de coordinación, sistemas, habilidades y otros recursos complementarios que son difíciles de imitar (Dutta, Zbaracki \& Bergen, 2003). Como ya se mencionó, las empresas que operan internacionalmente se encuentran en un entorno complejo y dinámico (Phatak, 1998).

Por lo tanto, las ventajas de los recursos pueden no ser suficientes, y la empresa necesita desarrollar capacidades distintivas para hacer un mejor uso de sus recursos (Prange \& Verdier, 2011). Es posible que las empresas compitan en función de su capacidad para aprender y aplicar el conocimiento a los mercados extranjeros, es decir, en función de sus capacidades dinámicas (Chang \& Rosenzweig, 2001). Dichas capacidades desempeñan un papel importante porque permiten a las empresas hacer frente a entornos de rápido movimiento, competencia mundial 
feroz o cambio tecnológico rápido (Teece, 2007). La perspectiva de capacidades dinámicas se basa en la visión basada en recursos y se enfoca en la creación de recursos que son valiosos, raros, difíciles de imitar e imperfectamente sustituibles. Además, los recursos pueden actualizarse en entornos cambiantes (Teece, 2014). Ambrosini y Bowman (2009) sostienen que esta perspectiva es una extensión de la visión basada en recursos.

\subsection{Dimensiones.}

Tabla 2:

Dimensiones de desempeño exportador

\begin{tabular}{cl}
\hline Autores & \multicolumn{1}{c}{ Dimensiones } \\
\hline Voerman & Efectividad, \\
& Eficiencia, y \\
& Adaptabilidad. \\
Imran. Hamid y Azizz & Financial, \\
& Estratégico, y \\
& Satisfacción. \\
\hline
\end{tabular}

Fuente: Yoerman, J. A. (2003); Imran, M., Hamid, S., \& Aziz, A. (2018)

Elaboración: Raymundo y Paúcar (2020)

Las dimensiones de desempeño exportador se explicaron basados en la adaptación de los investigadores Imran, Hamid y Aziz (2018), porque son las personas que mejor pueden explicar las dimensiones.

\section{Financial}

Los medios más comunes para conceptualizar y medir el desempeño de las exportaciones se centran en los resultados financieros de las exportaciones. La creencia subyacente aquí es que exportar es parte del programa de marketing de una empresa. Por lo tanto, se deduce que el desempeño de una empresa de exportación debe medirse de la misma manera que las operaciones de comercialización se calculan, es decir, en términos financieros.

\section{Estratégico}


Otro medio importante para conceptualizar el desempeño de la exportación se basa en capturar el resultado estratégico de la exportación. El objetivo principal aquí es que las empresas a menudo tienen un conjunto de objetivos estratégicos, así como objetivos financieros, en la exportación. Este punto de vista sostiene que el logro de objetivos estratégicos como la mejora de la competitividad, el aumento de la cuota de mercado o el fortalecimiento de la posición estratégica deberían considerarse una parte integral del desempeño de las exportaciones.

\section{Satisfacción}

Otra conceptualización más del desempeño de las exportaciones aboga por el uso de medidas de desempeño perceptivas o de actitud. La lógica detrás de esta conceptualización es que estar dispuesto positivamente a exportar y / o estar satisfecho con las operaciones de exportación es una fuerte indicación de éxito en la exportación. Los estudios con esta perspectiva tienden a medir el desempeño de exportación de una empresa, ya sea directamente, como el éxito y la satisfacción de la exportación percibida con las empresas de exportación o indirectamente a medida que los cambios de actitud de la empresa hacia la exportación.

\subsubsection{Quinua.}

\subsection{Definición.}

Es una planta herbácea anual, que normalmente alcanza una altura de 1 a $3 \mathrm{~m}$. Las hojas, alternas, son anchas y polimorfas; el tallo central puede estar más o menos ramificado, dependiendo de la variedad o densidad del sembrado. Las flores, organizadas en panículas, son pequeñas y carecen de pétalos. Las terminales son hermafroditas o masculinas y las laterales generalmente femeninas. El fruto es un utrículo (aquenio de pericarpo membranoso) de unos 2 mm de diámetro; tiene semillas lenticulares con abundante perisperma harinoso (MINAGRI, 2020). 


\subsection{Precio internacional de la quinua peruana.}

Según con Trade Map (2020) el precio de la quinua expresado en dólares por tonelada de los últimos cinco años.

Tabla 3:

Precio internacional de la quinua peruana

\begin{tabular}{cc}
\hline Año & Precio \\
\hline 2015 & 3.461 \\
2016 & 2.323 \\
2017 & 2.347 \\
2018 & 2.432 \\
2019 & 2.756 \\
\hline
\end{tabular}

Fuente: Trade Map (2020)

Elaboración: Raymundo y Paúcar (2020)

\subsection{Exportadores de quinua.}

En seguida se presentan los principales que exportan la quinua en el mundo (Trade Map, 2020).

Tabla 4:

Países exportadores de quinua (cantidad exportada en toneladas)

\begin{tabular}{lccccc}
\hline \multirow{2}{*}{ Exportadores } & 2015 & 2016 & 2017 & 2018 & 2019 \\
\cline { 2 - 6 } & $\begin{array}{l}\text { Cant expor, } \\
\text { Ton. }\end{array}$ & $\begin{array}{c}\text { Cant expor, } \\
\text { Ton }\end{array}$ & $\begin{array}{c}\text { Cant expor, } \\
\text { Ton }\end{array}$ & $\begin{array}{c}\text { Cant expor, } \\
\text { Ton }\end{array}$ & $\begin{array}{c}\text { Cant exporo } \\
\text { Ton }\end{array}$ \\
\hline Mundo & 86596 & 94485 & 109462 & 112769 & 114279 \\
Perú & 41458 & 44363 & 52043 & 50084 & 48781 \\
Bolivia & 25102 & 29416 & 32347 & 33106 & 33602 \\
España & 229 & 449 & 1166 & 3104 & 5085 \\
Paises Bajos & 2049 & 3952 & 4821 & 7461 & 4880 \\
Canadá & 3176 & 2212 & 3718 & 3344 & 4001 \\
Estados Unidos de América & 8357 & 5252 & 4417 & 4434 & 3830 \\
Ecuador & 1438 & 1771 & 1938 & 1719 & 2389 \\
Francia & 1074 & 1497 & 1455 & 1642 & 2043 \\
Alemania & 1327 & 1316 & 1767 & 1723 & 2009 \\
Bélgica & 276 & 725 & 966 & 1473 & 1787 \\
\hline
\end{tabular}

Fuente: Trade Map (2020)

Elaboración: Raymundo y Paúcar (2020) 


\subsection{Principales destinos de la quinua peruana.}

Según con Trade Map (2020) los principales países que importan la quinua desde el Perú son:

Tabla 5:

Países que importan la quinua peruana

\begin{tabular}{lccccc}
\hline \multirow{2}{*}{\multicolumn{1}{c}{ Importadores }} & 2015 & 2016 & 2017 & 2018 & 2019 \\
\cline { 2 - 6 } & $\begin{array}{c}\text { Cantidad } \\
\text { exportada, } \\
\text { Toneladas }\end{array}$ & $\begin{array}{c}\text { Cantidad } \\
\text { exportada, } \\
\text { Toneladas }\end{array}$ & $\begin{array}{c}\text { Cantidad } \\
\text { exportada, } \\
\text { Toneladas }\end{array}$ & $\begin{array}{c}\text { Cantidad } \\
\text { exportada, } \\
\text { Toneladas }\end{array}$ & $\begin{array}{c}\text { Cantidad } \\
\text { exportada, } \\
\text { Toneladas }\end{array}$ \\
\hline Estados Unidos de América & 18091 & 13889 & 18939 & 17017 & 16108 \\
Canadá & 3305 & 3148 & 4291 & 4073 & 3484 \\
Francia & 1629 & 2333 & 2115 & 2732 & 2729 \\
Paises Bajos & 3104 & 4575 & 3432 & 2792 & 2543 \\
Reino Unido & 2811 & 3511 & 2827 & 2880 & 2448 \\
Italia & 2147 & 3299 & 3546 & 2491 & 2194 \\
España & 464 & 2616 & 2449 & 2052 & 2120 \\
Brasil & 846 & 1045 & 1329 & 1940 & 1594 \\
Chile & 433 & 645 & 1112 & 1541 & 1528 \\
Bélgica & 355 & 255 & 787 & 720 & 1499 \\
\hline
\end{tabular}

Fuente: Trade Map (2020)

Elaboración: Raymundo y Paúcar (2020)

\subsection{Principales empresas exportadoras de quinua en el Perú.}

Según Agro data (2020) actualmente las principales empresas peruanas que exportan la quinua son. 


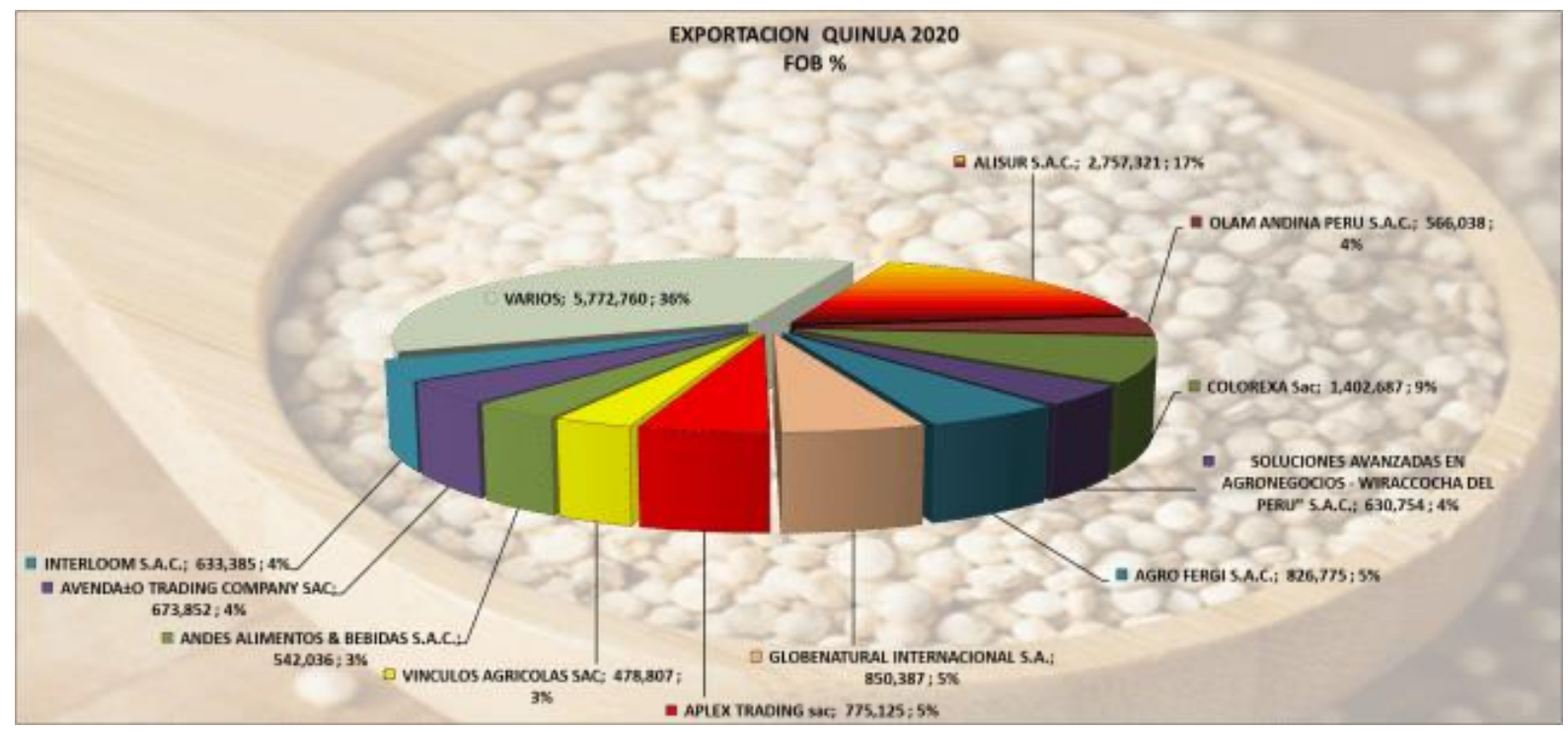

Figura 1. Principales empresas exportadoras de quinua Fuente: Agro data (2020)

\subsection{Principales zonas productoras de quinua.}

De acuerdo con el ministerio de agricultura y riego (MINAGRI, 2020) las principales zonas en donde se produce la quinua en el Perú son:

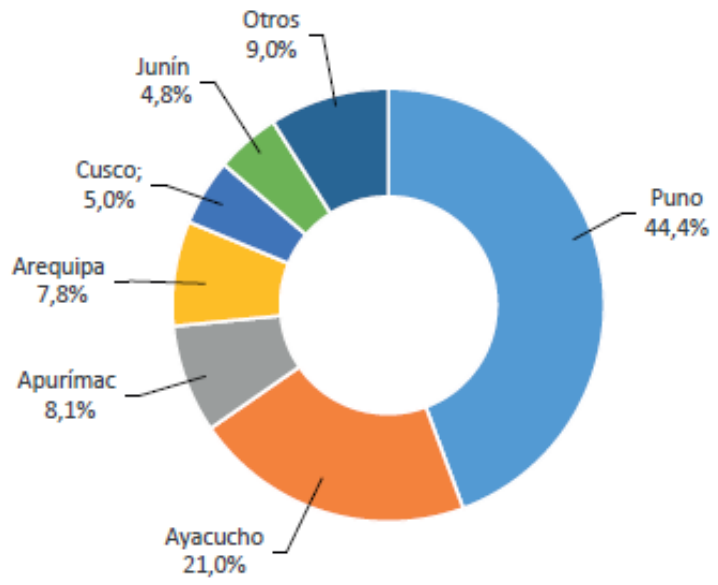

Figura 2. Principales zonas de producción de la quinua Fuente: MINAGRI (2020) 


\subsection{Objetivos e Hipótesis}

\subsubsection{Objetivos.}

\subsubsection{Objetivo general.}

Analizar la relación entre la gestión de la calidad total y el desempeño de las empresas MYPES exportadoras de quinua del Perú 2020.

\subsubsection{Objetivos específicos.}

Analizar la relación entre el liderazgo y el desempeño de las empresas MYPES exportadoras de quinua del Perú 2020.

Analizar la relación entre la estrategia y el desempeño de las empresas MYPES exportadoras de quinua del Perú 2020.

Analizar la relación entre las personas y el desempeño de las empresas MYPES exportadoras de quinua del Perú 2020.

Analizar la relación entre los recursos y el desempeño de las empresas MYPES exportadoras de quinua del Perú 2020.

Analizar la relación entre los procesos y el desempeño de las empresas MYPES exportadoras de quinua del Perú 2020.

\subsubsection{Hipótesis.}

\subsubsection{Hipótesis general.}

La gestión de la calidad total se relaciona con el desempeño de las empresas MYPES exportadoras de quinua del Perú 2020. 


\subsubsection{Hipótesis específicas.}

El liderazgo se relaciona con el desempeño de las empresas MYPES exportadoras de quinua del Perú 2020.

La estrategia se relaciona con el desempeño de las empresas MYPES exportadoras de quinua del Perú 2020.

Las personas se relacionan con el desempeño de las empresas MYPES exportadoras de quinua del Perú 2020.

Los recursos se relacionan con el desempeño de las empresas MYPES exportadoras de quinua del Perú 2020.

Los procesos se relacionan con el desempeño de las empresas MYPES exportadoras de quinua del Perú 2020. 


\section{Capítulo II}

\subsection{Método}

La metodología utilizada en este trabajo de investigación fue el enfoque cuantitativo, ya que las hipótesis se basaron en el planteamiento del problema, en el marco teórico y en los antecedentes que han sido revisados, y porque se llegó a reunir datos importantes para poder comprobar las hipótesis planteadas, basado en las mediciones numéricas y en el análisis estadístico con la finalidad de corroborar las hipótesis de acuerdo con Hernández, Fernández y Baptista (2014).

\subsubsection{Tipo de investigación.}

Se usó el tipo correlacional enfatizando en el tipo de análisis cuantitativo, que según con los investigadores Hernández et al. (2014) es el estudio en donde las variables se asociaran por medio de una pauta para poder predecir una población o grupo.

\subsubsection{Diseño de investigación.}

El diseño que se usó es no experimental transversal correlacional, puesto que las variables en estudio no fueron modificadas, según con Hernández et al. (2014) es un diseño en el que las variables no son manejadas de manera deliberada y observadas en su contexto originario para poder analizarlas; y transversal dado la recolección de datos en un momento único.

\subsubsection{Variables.}

Variable X1: gestión de la calidad total

Imran, Hamid y Aziz (2018) expresaron que la gestión de la calidad total es el proceso de mejorar de los procesos, productos y servicios que posee la empresa para conseguir que sus 
clientes se sientan satisfechos a un costo bajo. Y citaron que las dimensiones de la gestión de la calidad total son las siguientes:

- X1A: liderazgo.

- X1B: estrategia.

- X1C: personas.

- X1D: recursos.

- X1E: procesos.

Variable X2: desempeño exportador

Para los investigadores Imran, Hamid y Aziz (2018) el desempeño de las exportaciones es la manera en que una empresa mide el logro de sus objetivos financieros y estratégicos. Y citaron que las dimensiones del desempeño exportador son las siguientes:

- $\mathrm{X} 2 \mathrm{~A}$ : financiero.

- X2B: estratégico.

- X2C: satisfacción.

\subsubsection{Población.}

La población se encontró constituida por 145 empresas MYPES exportadoras de quinua del Perú (SIICEX, 2020), las mismas que se encuentran segmentadas como se presenta a continuación:

Tabla 6:

Población de empresas MYPES exportadoras de quinua

\begin{tabular}{lc}
\hline \multicolumn{1}{c}{ Tamaño de empresa } & Número de empresas \\
\hline Pequeñas & 19 \\
Micro & 126 \\
\hline Total & 145 \\
\hline Fuente: SIICEX (2020) & \\
Elaboración: Raymundo y Paúcar (2020)
\end{tabular}




\subsubsection{Muestra.}

La fórmula para muestras aleatorias estratificados para poblaciones finitas es la forma en que se calculó la muestra, con el fin de encontrar el subgrupo que represente a la población, como se muestra en seguida (Scheaffer, Mendenhall \& Ott, 2006):

$$
n=\frac{\left(\sum_{h=1}^{H} N_{h} \sqrt{p_{h}\left(1-p_{h}\right)}\right)^{2}}{\left(N^{2}\left(\varepsilon^{2} / Z^{2}{ }_{1-\frac{\alpha}{2}}\right)+\sum_{h=1}^{H} N_{h} P_{h}\left(1-p_{h}\right)\right.}
$$

Donde:

- $\mathrm{N}=$ Tamaño de población: 145 empresas MYPES exportadoras de quinua.

- $\mathrm{n}=$ Tamaño de muestra de las empresas MYPES exportadoras de quinua.

- $\boldsymbol{N}_{h}$ : Cantidad de empresas en el estrato $\mathrm{h}$.

- $Z_{1-\frac{a}{2}}^{2}=1.96$, para un nivel de confianza del $95 \%$

- $p_{h}=0.5$ : proporción de empresas MYPES exportadoras con buen desempeño en el estrato $\mathrm{h}$, se ha considerado un valor de 0.5 .

- $\varepsilon=0.05$ : error de estimación máximo.

Después de realizar el cálculo oportuno con la formula que se presentó anteriormente se tiene:

$$
\begin{gathered}
n=\frac{(19 \sqrt{0.5 \times 0.5}+126 \sqrt{0.5 \times 05})^{2}}{145^{2}\left(\frac{0.05^{2}}{1.96^{2}}\right)+(19 \times 0.5 \times 0.5+126 \times 0.5 \times 0.5)} \\
n=106 \text { empresas MYPES exportadoras de quinua }
\end{gathered}
$$


Se llegan a considerar 106 empresas MYPES exportadoras de quinua del Perú, de acuerdo con los cálculos realizados, por ende, por medio del muestreo probabilístico estratificado se determina que el número de empresas MYPES exportadoras de quinua de acuerdo a el tipo de empresa, es el siguiente:

$$
\begin{aligned}
& n_{1}=\frac{N_{1}}{N} \times n=\frac{19}{145} \times 106=13.88 \cong 14 \\
& n_{2}=\frac{N_{2}}{N} \times n=\frac{126}{145} \times 106=92.11 \cong 92
\end{aligned}
$$

Tabla 7:

Muestra de empresas MYPES exportadoras de quinua

\begin{tabular}{lc}
\hline \multicolumn{1}{c}{ Tamaño de empresa } & Número de empresas \\
\hline Pequeñas & 14 \\
Micro & 92 \\
\hline Total & 106 \\
\hline Elaboración: Raymundo y Paúcar (2020)
\end{tabular}

\subsubsection{Instrumentos de investigación.}

Para medir las variables tomadas en cuenta se tomaron en cuenta dos cuestionarios. Para la primera variable "gestión de la calidad total" se usó un cuestionario constituido por 30 ítems divididos entre sus cinco dimensiones: liderazgo (6 ítems), estrategia (6 ítems), personas (6 ítems), recursos (5 ítems) y procesos ( 7 ítems), con una escala de Likert del 1 al 5 en donde 1 es totalmente en desacuerdo, 2 es en desacuerdo, 3 es neutral, 4 es de acuerdo y 5 es totalmente de acuerdo. 
Tabla 8:

Cuestionario de gestión de la calidad total

\begin{tabular}{ll}
\hline Nombre: & Cuestionario de gestión de la calidad total \\
Procedencia: & Pakistán \\
Idioma original & Inglés \\
Autores: & Imran, Hamid y Aziz \\
Año: & 2018 \\
Número de İtems: & 30 items \\
Duración: & 10 a 15 minutos \\
Forma de Aplicación: & Individual - Colectivo \\
Ámbito de Aplicación: & Adultos \\
Edades de Aplicación: & Mayores de 18 años \\
Confiabilidad & Alfa de Cronbach: 0.812 \\
Validez: & Coeficiente de Aiken: 0.85 \\
\hline Elaboración: Bautista y Paúcar (2020)
\end{tabular}

Y en la variable "desempeño exportador" se utilizó un cuestionario constituido por 9 ítems dividido entre sus tres dimensiones: financiero ( 3 ítems), estratégico ( 3 ítems) y satisfacción (3 ítems) con una escala de Likert del 1 al 5 donde 1 es totalmente en desacuerdo, 2 es en desacuerdo, 3 es neutral, 4 es de acuerdo y 5 es totalmente de acuerdo, ambos cuestionarios les pertenecen a los investigadores Imran, Hamid y Aziz (2018).

Tabla 9:

Cuestionario de desempeño exportador

\begin{tabular}{ll}
\hline Nombre: & Cuestionario de desempeño exportador \\
Procedencia: & Pakistán \\
Idioma original & Inglés \\
Autores: & Imran. Hamid y Aziz \\
Año: & 2018 \\
Número de Ítems: & 9 items \\
Duración: & 10 a 15 minutos \\
Forma de Aplicación: & Individual - Colectivo \\
Ámbito de Aplicación: & Adultos \\
Edades de Aplicación: & Mayores de 18 años \\
Confiabilidad & Alfa de Cronbach: 0.92 \\
Validez: & Coeficiente de Aiken: 0.87 \\
\hline Elaboración: Bautista y Paúcar (2020)
\end{tabular}


Los instrumentos de investigación se aprobaron por el juicio de expertos (anexo 3) y se promediaron sus evaluaciones por medio del coeficiente de Aiken (gestión de la calidad total: 0.85 y desempeño exportador: 0.87), y su fiabilidad se verificó por medio del alfa de Cronbach (liderazgo: 0.908, estrategia: 0.883, personas: 0.885, recursos: 0.899, procesos: 0.938, financiero: 0.883, estratégico: 0.764 y satisfacción: 0.902). De igual manera las hipótesis fueron contrastadas por medio de la prueba de Spearman, que según con Hernández et al. (2014) se usa para confirmar la correlación de dos variables o más.

\subsubsection{Procedimientos de recolección de datos.}

Para el procedimiento de recolección de datos se usaron los dos cuestionarios que ayudaron para la recolección de los datos precisos y confiables, estos cuestionarios fueron aplicados a los administradores y/o gerentes de las empresas MYPES exportadoras de quinua del Perú mediante correos electrónicos entre el 14 de septiembre del 2020 al 3 de octubre del 2020, previa coordinación con los mismos administradores y/o gerentes de las mismas empresas exportadoras de quinua, donde se les pidió como parte de las instrucciones que sus respuesta sean sinceras y como representantes de sus respectivas empresas, para poder tabularlos mediante el software SPSS 22, con la finalidad de encontrar relaciones entre ambas variables de acuerdo con las hipótesis planteadas, para después comprobarlas mediante la prueba de Spearman, el cual es recomendado para las variables ordinales. El Excel (exposición de tablas) y el SPSS 22 (tabula cuestionarios) son los dos programas básicos que sirvieron de ayuda para poder desarrollar este trabajo de investigación. 


\section{Capítulo III}

En la presente investigación se usó el tipo de error del 5\%, dado que dentro de una investigación en las ciencias sociales se encuentran dos tipos de errores, el 1\% y el 5\%, donde este último es el más usado. Por lo tanto, las personas encargadas de desarrollar esta investigación tienen $95 \%$ de confiabilidad para que los resultados puedan ser generalizados sin errar. Asimismo, este capítulo introduce el análisis de resultados de los cuestionarios, la contrastación de las hipótesis, donde se desarrolló la prueba de normalidad Shapiro-Wilk, el análisis factorial exploratorio, la correlación de Rho de Spearman y la correlación de las hipótesis, así mismo se presentan las discusiones, las conclusiones y las recomendaciones.

\subsection{Análisis de los resultados de los cuestionarios}

En seguida, se exponen los resultados que se han obtenido de los 106 cuestionarios, los cuales fueron aplicados a cada administrador y/o gerente de las empresas MYPES exportadoras de quinua del Perú, en cuanto a la relación de la gestión de la calidad total y el desempeño exportador de las mismas empresas MYPES exportadoras de quinua.

\subsubsection{Análisis de los resultados de gestión de la calidad total}

Tabla 10:

Calidad de los productos

\begin{tabular}{|c|c|c|c|c|c|}
\hline \multicolumn{6}{|c|}{$\begin{array}{l}\text { GCT1. Los gerentes de nuestra empresa consideran que el costo es más importante en } \\
\text { comparación con la calidad de los productos. }\end{array}$} \\
\hline & & Frecuencia & Porcentaje & $\begin{array}{l}\text { Porcentaje } \\
\text { válido }\end{array}$ & $\begin{array}{l}\text { Porcentaje } \\
\text { acumulado }\end{array}$ \\
\hline \multirow{4}{*}{ Valido } & En desacuerdo & 12 & 11.3 & 11.3 & 11.3 \\
\hline & $\begin{array}{l}\text { Ni de acuerdo ni en } \\
\text { desacuerdo }\end{array}$ & 32 & 30.2 & 30.2 & 41.5 \\
\hline & De acuerdo & 41 & 38.7 & 38.7 & 80.2 \\
\hline & Totalmente de acuerdo & 21 & 19.8 & 19.8 & 100.0 \\
\hline
\end{tabular}


Interpretación: en la tabla 10 se observa que del $100 \%$ de encargados, el $58.5 \%$ se halla totalmente de acuerdo y de acuerdo con la afirmación "Los gerentes de nuestra empresa consideran que el costo es más importante en comparación con la calidad de los productos”, el $30.2 \%$ se halla ni de acuerdo ni en desacuerdo y el $11.3 \%$ se halla en desacuerdo. Por ende, se interpreta que la gran mayoría de encargados aseguran que los gerentes de la empresa consideran que el costo es más importante en comparación con la calidad de los productos.

Tabla 11:

Presentación de modelos

\begin{tabular}{|c|c|c|c|c|c|}
\hline \multicolumn{6}{|c|}{$\begin{array}{c}\text { GCT2. Los gerentes de nuestra empresa se presentan como modelos a seguir para los } \\
\text { empleados. }\end{array}$} \\
\hline & & Frecuencia & Porcentaje & $\begin{array}{l}\text { Porcentaje } \\
\text { válido }\end{array}$ & $\begin{array}{l}\text { Porcentaje } \\
\text { acumulado }\end{array}$ \\
\hline \multirow{4}{*}{ Valido } & $\begin{array}{l}\text { Ni de acuerdo ni en } \\
\text { desacuerdo }\end{array}$ & 6 & 5.7 & 5.7 & 5.7 \\
\hline & De acuerdo & 40 & 37.7 & 37.7 & 43.4 \\
\hline & Totalmente de acuerdo & 60 & 56.6 & 56.6 & 100.0 \\
\hline & Total & 106 & 100.0 & 100.0 & \\
\hline
\end{tabular}

Interpretación: en la Tabla 11 se observa que del 100\% de encargados, el $94.3 \%$ se halla totalmente de acuerdo y de acuerdo con la afirmación "Los gerentes de nuestra empresa se presentan como modelos a seguir para los empleados" y el 30.2\% se halla ni de acuerdo ni en desacuerdo. Por ende, se interpreta que la gran mayoría de encargados aseguran que los gerentes de la empresa se presentan como modelos a seguir para los empleados.

Tabla 12:

Planes a largo plazo

\begin{tabular}{|c|c|c|c|c|c|}
\hline & & Frecuencia & Porcentaje & $\begin{array}{l}\text { Porcentaje } \\
\text { válido }\end{array}$ & $\begin{array}{l}\text { Porcentaje } \\
\text { acumulado }\end{array}$ \\
\hline \multirow{5}{*}{ Valido } & \multirow{4}{*}{$\begin{array}{l}\text { En desacuerdo } \\
\text { Ni de acuerdo ni en } \\
\text { desacuerdo } \\
\text { De acuerdo } \\
\text { Totalmente de acuerdo }\end{array}$} & 17 & 16.0 & 16.0 & 16.0 \\
\hline & & 22 & 20.8 & 20.8 & 36.8 \\
\hline & & 33 & 31.1 & 31.1 & 67.9 \\
\hline & & 34 & 32.1 & 32.1 & 100.0 \\
\hline & Total & 106 & 100.0 & 100.0 & \\
\hline
\end{tabular}


Interpretación: en la Tabla 12 se observa que del $100 \%$ de encargados, el $63.2 \%$ se halla totalmente de acuerdo y de acuerdo con la afirmación "Los gerentes de nuestra empresa se aseguran de que los empleados conozcan los planes a largo plazo de la empresa", el 20.8\% se halla ni de acuerdo ni en desacuerdo y el $16 \%$ se halla en desacuerdo. Por ende, se interpreta que la gran mayoría de encargados aseguran que los gerentes de la empresa se aseguran de que los empleados conozcan los planes a largo plazo de la empresa.

Tabla 13:

Autoridad sobre sus trabajos

\begin{tabular}{|c|c|c|c|c|c|}
\hline & & Frecuencia & Porcentaje & $\begin{array}{l}\text { Porcentaje } \\
\text { válido }\end{array}$ & $\begin{array}{l}\text { Porcentaje } \\
\text { acumulado }\end{array}$ \\
\hline \multirow{5}{*}{ Valido } & En desacuerdo & 12 & 11.3 & 11.3 & 11.3 \\
\hline & $\begin{array}{l}\text { Ni de acuerdo ni en } \\
\text { desacuerdo }\end{array}$ & 8 & 7.5 & 7.5 & 18.9 \\
\hline & De acuerdo & 52 & 49.1 & 49.1 & 67.9 \\
\hline & Totalmente de acuerdo & 34 & 32.1 & 32.1 & 100.0 \\
\hline & Total & 106 & 100.0 & 100.0 & \\
\hline
\end{tabular}

Interpretación: en la Tabla 13 se observa que del 100\% de encargados, el $81.2 \%$ se halla totalmente de acuerdo y de acuerdo con la afirmación "Los gerentes de nuestra empresa no desean otorgar autoridad a los empleados para que tomen decisiones sobre sus trabajos", el 7.5\% se halla ni de acuerdo ni en desacuerdo y el $11.3 \%$ se halla en desacuerdo. Por ende, se interpreta que la gran mayoría de encargados aseguran que los gerentes de la empresa no desean otorgar autoridad a los empleados para que tomen decisiones sobre sus trabajos. 
Tabla 14:

Conocimiento

\begin{tabular}{llrrrr}
\hline \multicolumn{6}{c}{$\begin{array}{l}\text { GCT5. Los gerentes de nuestra empresa adquieren y actualizan continuamente su } \\
\text { conocimiento, que es valioso para la organización. }\end{array}$} \\
\hline & Frecuencia & Porcentaje & $\begin{array}{c}\text { Porcentaje } \\
\text { válido }\end{array}$ & $\begin{array}{c}\text { Porcentaje } \\
\text { acumulado }\end{array}$ \\
\hline \multirow{5}{*}{ Valido } & & 12 & 11.3 & 11.3 & 11.3 \\
& $\begin{array}{l}\text { Ni de acuerdo ni en } \\
\text { desacuerdo }\end{array}$ & 34 & 32.1 & 32.1 & 43.4 \\
& $\begin{array}{l}\text { De acuerdo } \\
\text { Totalmente de acuerdo }\end{array}$ & 60 & 56.6 & 56.6 & 100.0 \\
\cline { 2 - 6 } & Total & 106 & 100.0 & 100.0 & \\
\hline
\end{tabular}

Interpretación: en la Tabla 14 se observa que del 100\% de encargados, el $88.7 \%$ se halla totalmente de acuerdo y de acuerdo con la afirmación "Los gerentes de nuestra empresa adquieren y actualizan continuamente su conocimiento, que es valioso para la organización” y el $11.3 \%$ se halla ni de acuerdo ni en desacuerdo. Por ende, se interpreta que la gran mayoría de encargados aseguran que los gerentes de la empresa adquieren y actualizan continuamente su conocimiento, que es valioso para la organización.

Tabla 15:

Mejora continua

\begin{tabular}{llrrrr}
\hline \multicolumn{3}{c}{ GCT6. Los gerentes de nuestra empresa fomentan y participan en iniciativas de mejora } \\
continua.
\end{tabular}

Interpretación: en la Tabla 15 se observa que del $100 \%$ de encargados, el $85.8 \%$ se halla totalmente de acuerdo y de acuerdo con la afirmación "Los gerentes de nuestra empresa fomentan y participan en iniciativas de mejora continua”, el 9.4\% se halla ni de acuerdo ni en desacuerdo y el $4.7 \%$ se halla en desacuerdo. Por ende, se interpreta que la gran mayoría de encargados aseguran que los gerentes de la empresa fomentan y participan en iniciativas de mejora continua. 
Tabla 16:

Diseño de nuevos productos

GCT7. En nuestra empresa, las opiniones de los clientes (las personas / empresas que compran o desean comprar los productos de su empresa) se consideran importantes al diseñar nuevos productos.

\begin{tabular}{llrrrr}
\hline & Frecuencia & Porcentaje & $\begin{array}{c}\text { Porcentaje } \\
\text { válido }\end{array}$ & $\begin{array}{c}\text { Porcentaje } \\
\text { acumulado }\end{array}$ \\
\hline \multirow{5}{*}{ Valido } & & & 1.9 & 1.9 \\
& $\begin{array}{l}\text { En desacuerdo } \\
\text { Ni de acuerdo ni en }\end{array}$ & 11 & 10.4 & 10.4 & 12.3 \\
desacuerdo & 55 & 51.9 & 51.9 & 64.2 \\
& $\begin{array}{l}\text { De acuerdo } \\
\text { Totalmente de acuerdo }\end{array}$ & 38 & 35.8 & 35.8 & 100.0 \\
\cline { 2 - 6 } & Total & 106 & 100.0 & 100.0 & \\
\hline
\end{tabular}

Interpretación: en la Tabla 16 se observa que del 100\% de encargados, el $87.7 \%$ se halla totalmente de acuerdo y de acuerdo con la afirmación "En nuestra empresa, las opiniones de los clientes (las personas / empresas que compran o desean comprar los productos de su empresa) se consideran importantes al diseñar nuevos productos", el $10.4 \%$ se halla ni de acuerdo ni en desacuerdo y el $1.9 \%$ se halla en desacuerdo. Por ende, se interpreta que la gran mayoría de encargados aseguran que en la empresa, las opiniones de los clientes (las personas/empresas que compran o desean comprar los productos de su empresa) se consideran importantes al diseñar nuevos productos.

Tabla 17:

Opiniones de proveedores

\begin{tabular}{|c|c|c|c|c|c|}
\hline \multicolumn{6}{|c|}{$\begin{array}{l}\text { GCTS. En nuestra empresa, se consideran las opiniones de los proveedores al configurar los } \\
\text { objetivos de la empresa. }\end{array}$} \\
\hline & & Frecuencia & Porcentaje & $\begin{array}{l}\text { Porcentaje } \\
\text { válido }\end{array}$ & $\begin{array}{l}\text { Porcentaje } \\
\text { acumulado }\end{array}$ \\
\hline \multirow{4}{*}{ Valido } & $\begin{array}{l}\text { Ni de acuerdo ni en } \\
\text { desacuerdo }\end{array}$ & 5 & 4.7 & 4.7 & 4.7 \\
\hline & De acuerdo & 23 & 21.7 & 21.7 & 26.4 \\
\hline & Totalmente de acuerdo & 78 & 73.6 & 73.6 & 100.0 \\
\hline & Total & 106 & 100.0 & 100.0 & \\
\hline
\end{tabular}

Interpretación: en la Tabla 17 se observa que del 100\% de encargados, el $95.3 \%$ se halla totalmente de acuerdo y de acuerdo con la afirmación "En nuestra empresa, se consideran las opiniones de los proveedores al configurar los objetivos de la empresa" y el $4.7 \%$ se halla ni de 
acuerdo ni en desacuerdo. Por ende, se interpreta que la gran mayoría de encargados aseguran que en la empresa, se consideran las opiniones de los proveedores al configurar los objetivos de la empresa.

Tabla 18:

Desempeño de competencia

\begin{tabular}{llrrrr}
\hline GCT9. En nuestra empresa, se evalúa y analiza el desempeño de los competidores y las mejores \\
compañias de su clase.
\end{tabular}

Interpretación: en la Tabla 18 se observa que del $100 \%$ de encargados, el $94.4 \%$ se halla totalmente de acuerdo y de acuerdo con la afirmación "En nuestra empresa, se evalúa y analiza el desempeño de los competidores y las mejores compañías de su clase" y el 5.7\% se halla ni de acuerdo ni en desacuerdo. Por ende, se interpreta que la gran mayoría de encargados aseguran que en la empresa, se evalúa y analiza el desempeño de los competidores y las mejores compañías de su clase.

Tabla 19:

Medición sistemática de perdidas

\begin{tabular}{|c|c|c|c|c|c|}
\hline \multicolumn{6}{|c|}{$\begin{array}{l}\text { GCT10. En nuestra empresa, se realiza una medición sistemática de pérdidas (como pérdidas } \\
\text { de producción, pérdidas por rechazo de productos terminados, etc.). }\end{array}$} \\
\hline & & Frecuencia & Porcentaje & $\begin{array}{l}\text { Porcentaje } \\
\text { válido }\end{array}$ & $\begin{array}{l}\text { Porcentaje } \\
\text { acumulado }\end{array}$ \\
\hline \multirow{4}{*}{ Valido } & $\begin{array}{l}\text { Ni de acuerdo ni en } \\
\text { desacuerdo }\end{array}$ & 6 & 5.7 & 5.7 & 5.7 \\
\hline & De acuerdo & 22 & 20.8 & 20.8 & 26.4 \\
\hline & Totalmente de acuerdo & 78 & 73.6 & 73.6 & 100.0 \\
\hline & Total & 106 & 100.0 & 100.0 & \\
\hline
\end{tabular}

Interpretación: en la Tabla 19 se observa que del 100\% de encargados, el $94.4 \%$ se halla totalmente de acuerdo y de acuerdo con la afirmación "En nuestra empresa, se realiza una medición sistemática de pérdidas (como pérdidas de producción, pérdidas por rechazo de productos terminados, etc.)" y el $5.7 \%$ se halla ni de acuerdo ni en desacuerdo. Por ende, se 
interpreta que la gran mayoría de encargados aseguran que en la empresa, se realiza una medición sistemática de pérdidas (como pérdidas de producción, pérdidas por rechazo de productos terminados, etc.).

Tabla 20:

Sistemas de información

\begin{tabular}{llrrrr}
\hline GCT11. En nuestra empresa, existen sistemas de información para capturar información sobre \\
clientes y mercados.
\end{tabular}

Interpretación: en la Tabla 20 se observa que del 100\% de encargados, el $83 \%$ se halla totalmente de acuerdo y de acuerdo con la afirmación "En nuestra empresa, existen sistemas de información para capturar información sobre clientes y mercados", el 15.1\% se halla ni de acuerdo ni en desacuerdo y el $1.9 \%$ se halla en desacuerdo. Por ende, se interpreta que la gran mayoría de encargados aseguran que en la empresa, existen sistemas de información para capturar información sobre clientes y mercados.

Tabla 21:

Evaluación del desempeño

GCT12. En nuestra empresa, periódicamente (por ejemplo, cada tres meses, seis meses o un año), el desempeño organizacional se evalúa en función de los objetivos y metas establecídos.

\begin{tabular}{|c|c|c|c|c|c|}
\hline & & Frecuencia & Porcentaje & $\begin{array}{l}\text { Porcentaje } \\
\text { válido }\end{array}$ & $\begin{array}{l}\text { Porcentaje } \\
\text { acumulado }\end{array}$ \\
\hline \multirow{4}{*}{ Valido } & $\begin{array}{l}\text { Ni de acuerdo ni en } \\
\text { desacuerdo }\end{array}$ & 2 & 1.9 & 1.9 & 1.9 \\
\hline & De acuerdo & 12 & 11.3 & 11.3 & 13.2 \\
\hline & Totalmente de acuerdo & 92 & 86.8 & 86.8 & 100.0 \\
\hline & Total & 106 & 100.0 & 100.0 & \\
\hline
\end{tabular}

Interpretación: en la Tabla 21 se observa que del 100\% de encargados, el $98.1 \%$ se halla totalmente de acuerdo y de acuerdo con la afirmación "En nuestra empresa, periódicamente (por ejemplo, cada tres meses, seis meses o un año), el desempeño organizacional se evalúa en 
función de los objetivos y metas establecidos” y el 1.9\% se halla ni de acuerdo ni en desacuerdo. Por ende, se interpreta que la gran mayoría de encargados aseguran que en la empresa, periódicamente (por ejemplo, cada tres meses, seis meses o un año), el desempeño organizacional se evalúa en función de los objetivos y metas establecidos.

Tabla 22:

Puntos de vista de empleados

GCT13. En nuestra empresa, los procesos formales se utilizan regularmente (encuestas de actitud, información de los empleados, etc.) para conocer las opiniones y puntos de vista de los empleados.

\begin{tabular}{llrrrr}
\hline & Frecuencia & Porcentaje & $\begin{array}{c}\text { Porcentaje } \\
\text { válido }\end{array}$ & $\begin{array}{c}\text { Porcentaje } \\
\text { acumulado }\end{array}$ \\
\hline \multirow{5}{*}{ Valido } & Nide acuerdo ni en & 10 & 9.4 & 9.4 & 9.4 \\
& desacuerdo & 60 & 56.6 & 56.6 & 66.0 \\
& De acuerdo & 36 & 34.0 & 34.0 & 100.0 \\
\cline { 2 - 6 } & Totalmente de acuerdo & 106 & 100.0 & 100.0 & \\
\hline
\end{tabular}

Interpretación: en la Tabla 22 se observa que del 100\% de encargados, el $90.6 \%$ se halla totalmente de acuerdo y de acuerdo con la afirmación "En nuestra empresa, los procesos formales se utilizan regularmente (encuestas de actitud, información de los empleados, etc.) para conocer las opiniones y puntos de vista de los empleados" y el 9.4\% se halla ni de acuerdo ni en desacuerdo. Por ende, se interpreta que la gran mayoría de encargados aseguran que en la empresa, los procesos formales se utilizan regularmente (encuestas de actitud, información de los empleados, etc.) para conocer las opiniones y puntos de vista de los empleados.

Tabla 23:

Capacitación en calidad

\begin{tabular}{|c|c|c|c|c|c|}
\hline \multicolumn{6}{|c|}{ GCT14. En nuestra empresa, se da capacitación especifica de calidad a los empleados. } \\
\hline & & Frecuencia & Porcentaje & $\begin{array}{l}\text { Porcentaje } \\
\text { válido }\end{array}$ & $\begin{array}{l}\text { Porcentaje } \\
\text { acumulado }\end{array}$ \\
\hline \multirow{4}{*}{ Valido } & $\begin{array}{l}\text { Ni de acuerdo ni en } \\
\text { desacuerdo }\end{array}$ & 17 & 16.0 & 16.0 & 16.0 \\
\hline & De acuerdo & 53 & 50.0 & 50.0 & 66.0 \\
\hline & Totalmente de acuerdo & 36 & 34.0 & 34.0 & 100.0 \\
\hline & Total & 106 & 100.0 & 100.0 & \\
\hline
\end{tabular}


Interpretación: en la Tabla 23 se observa que del 100\% de encargados, el $84 \%$ se halla totalmente de acuerdo y de acuerdo con la afirmación "En nuestra empresa, se da capacitación específica de calidad a los empleados" y el $16 \%$ se halla ni de acuerdo ni en desacuerdo. Por ende, se interpreta que la gran mayoría de encargados aseguran que en la empresa, se da capacitación específica de calidad a los empleados.

Tabla 24:

Actualización de conocimientos

GCT15. En nuestra empresa, se alienta a los empleados a actualizar sus conocimientos y habilidades.

\begin{tabular}{llrrrr}
\hline & Frecuencia & Porcentaje & $\begin{array}{c}\text { Porcentaje } \\
\text { válido }\end{array}$ & $\begin{array}{r}\text { Porcentaje } \\
\text { acumulado }\end{array}$ \\
\hline \multirow{5}{*}{ Valido } & & & 8.5 & 8.5 \\
Ni de acuerdo ni en & 9 & 8.5 & 55.7 & 64.2 \\
desacuerdo & 59 & 55.7 & 35.8 & 100.0 \\
\hline
\end{tabular}

Interpretación: en la Tabla 24 se observa que del 100\% de encargados, el $91.5 \%$ se halla totalmente de acuerdo y de acuerdo con la afirmación "En nuestra empresa, se alienta a los empleados a actualizar sus conocimientos y habilidades" y el $8.5 \%$ se halla ni de acuerdo ni en desacuerdo. Por ende, se interpreta que la gran mayoría de encargados aseguran que en la empresa, se alienta a los empleados a actualizar sus conocimientos y habilidades.

Tabla 25:

Trabajo en equipo

GCT16. En nuestra empresa, el trabajo en equipo es una práctica común dentro de la organización.

\begin{tabular}{llrrrr}
\hline & Frecuencia & Porcentaje & $\begin{array}{c}\text { Porcentaje } \\
\text { válido }\end{array}$ & $\begin{array}{c}\text { Porcentaje } \\
\text { acumulado }\end{array}$ \\
\hline \multirow{5}{*}{ Valido } & Ni de acuerdo ni en & 17 & 16.0 & 16.0 & 16.0 \\
& desacuerdo & 56 & 52.8 & 52.8 & 68.9 \\
& De acuerdo & 33 & 31.1 & 31.1 & 100.0 \\
\cline { 2 - 6 } & Totalmente de acuerdo & 106 & 100.0 & 100.0 & \\
\hline
\end{tabular}

Interpretación: en la Tabla 25 se observa que del 100\% de encargados, el $83.9 \%$ se halla totalmente de acuerdo y de acuerdo con la afirmación "En nuestra empresa, el trabajo en equipo 
es una práctica común dentro de la organización" y el $16 \%$ se halla ni de acuerdo ni en desacuerdo. Por ende, se interpreta que la gran mayoría de encargados aseguran que en la empresa, el trabajo en equipo es una práctica común dentro de la organización.

Tabla 26:

Acceso a información

GCT17. En nuestra empresa, los empleados tienen fácil acceso a la información relevante.

\begin{tabular}{llrrrr}
\hline & Frecuencia & Porcentaje & $\begin{array}{c}\text { Porcentaje } \\
\text { válido }\end{array}$ & $\begin{array}{r}\text { Porcentaje } \\
\text { acumulado }\end{array}$ \\
\hline \multirow{5}{*}{ Valido } & & & 11.3 & 11.3 & 11.3 \\
& En desacuerdo & 12 & 11.3 & 37.7 & 49.1 \\
Ni de acuerdo ni en & 40 & 37.7 & 40.6 & 89.6 \\
desacuerdo & 43 & 40.6 & 10.4 & 100.0 \\
\hline & 11 & 10.4 & 100.0 & \\
\hline
\end{tabular}

Interpretación: en la Tabla 26 se observa que del 100\% de encargados, el $51 \%$ se halla totalmente de acuerdo y de acuerdo con la afirmación "En nuestra empresa, los empleados tienen fácil acceso a la información relevante", el 37.7\% se halla ni de acuerdo ni en desacuerdo y el $11.3 \%$ se halla en desacuerdo. Por ende, se interpreta que la gran mayoría de encargados aseguran que en la empresa, los empleados tienen fácil acceso a la información relevante.

Tabla 27:

Fomentar opiniones y sugerencias

GCT18. En nuestra empresa, fomente las opiniones y sugerencias de los empleados sobre cualquiera de las actividades de la organización.

\begin{tabular}{llrrrr}
\hline & Frecuencia & Porcentaje & $\begin{array}{c}\text { Porcentaje } \\
\text { válido }\end{array}$ & $\begin{array}{r}\text { Porcentaje } \\
\text { acumulado }\end{array}$ \\
\hline \multirow{5}{*}{ Valido } & & & 5.7 & 5.7 \\
& En desacuerdo & 6 & 5.7 & 11.3 & 17.0 \\
Ni de acuerdo ni en & 12 & 11.3 & 67.9 & 84.9 \\
desacuerdo & 72 & 67.9 & 15.1 & 100.0 \\
\hline & 16 & 15.1 & 100.0 & \\
\hline
\end{tabular}

Interpretación: en la Tabla 27 se observa que del 100\% de encargados, el $83 \%$ se halla totalmente de acuerdo y de acuerdo con la afirmación "En nuestra empresa, fomente las opiniones y sugerencias de los empleados sobre cualquiera de las actividades de la organización", el $11.3 \%$ se halla ni de acuerdo ni en desacuerdo y el $5.7 \%$ se halla en 
desacuerdo. Por ende, se interpreta que la gran mayoría de encargados aseguran que la empresa, fomente las opiniones y sugerencias de los empleados sobre cualquiera de las actividades de la organización.

Tabla 28:

Desarrollo de asociaciones con proveedores

\begin{tabular}{llrrr}
\hline \multicolumn{6}{c}{ GCT19. En nuestra empresa, se alienta a los proveedores a desarrollar asociaciones con la } \\
organización.
\end{tabular}

Interpretación: en la Tabla 28 se observa que del $100 \%$ de encargados, el $88.7 \%$ se halla totalmente de acuerdo y de acuerdo con la afirmación "En nuestra empresa, se alienta a los proveedores a desarrollar asociaciones con la organización” y el 11.3\% se halla ni de acuerdo ni en desacuerdo. Por ende, se interpreta que la gran mayoría de encargados aseguran que en la empresa, se alienta a los proveedores a desarrollar asociaciones con la organización.

Tabla 29:

Preferencia a la calidad

\begin{tabular}{|c|c|c|c|c|c|}
\hline \multicolumn{6}{|c|}{$\begin{array}{l}\text { GCT20. En nuestra empresa no da preferencia a la calidad sobre el costo al hacer acuerdos de } \\
\text { compra con proveedores. }\end{array}$} \\
\hline & & Frecuencia & Porcentaje & $\begin{array}{l}\text { Porcentaje } \\
\text { válido }\end{array}$ & $\begin{array}{l}\text { Porcentaje } \\
\text { acumulado }\end{array}$ \\
\hline \multirow{5}{*}{ Valido } & En desacuerdo & 4 & 3.8 & 3.8 & 3.8 \\
\hline & $\begin{array}{l}\text { Ni de acuerdo ni en } \\
\text { desacuerdo }\end{array}$ & 21 & 19.8 & 19.8 & 23.6 \\
\hline & De acuerdo & 51 & 48.1 & 48.1 & 71.7 \\
\hline & Totalmente de acuerdo & 30 & 28.3 & 28.3 & 100.0 \\
\hline & Total & 106 & 100.0 & 100.0 & \\
\hline
\end{tabular}

Interpretación: en la Tabla 29 se observa que del 100\% de encargados, el $76.4 \%$ se halla totalmente de acuerdo y de acuerdo con la afirmación "En nuestra empresa no da preferencia a la calidad sobre el costo al hacer acuerdos de compra con proveedores", el $19.8 \%$ se halla ni de acuerdo ni en desacuerdo y el 3.8\% se halla en desacuerdo. Por ende, se interpreta que la gran 
mayoría de encargados aseguran que en la empresa no da preferencia a la calidad sobre el costo al hacer acuerdos de compra con proveedores.

Tabla 30:

Desempeño de proveedores

\begin{tabular}{llrrrr}
\hline \multicolumn{5}{c}{ GCT21. En nuestra empresa, el desempeño de los proveedores se evalúa periódicamente. } \\
\hline & Frecuencia & Porcentaje & $\begin{array}{c}\text { Porcentaje } \\
\text { válido }\end{array}$ & $\begin{array}{c}\text { Porcentaje } \\
\text { acumulado }\end{array}$ \\
\hline \multirow{4}{*}{ Valido } & & & 6.6 & 6.6 & 6.6 \\
& Ni de acuerdo ni en & 7 & 39.6 & 39.6 & 46.2 \\
& desacuerdo & 42 & 53.8 & 100.0 \\
\cline { 2 - 7 } & De acuerdo & 57 & 53.8 & 100.0 & \\
\cline { 2 - 3 } & 106 & 100.0 & & 10.0 \\
\hline
\end{tabular}

Interpretación: en la Tabla 30 se observa que del 100\% de encargados, el $93.4 \%$ se halla totalmente de acuerdo y de acuerdo con la afirmación "En nuestra empresa, el desempeño de los proveedores se evalúa periódicamente" y el 6.6\% se halla ni de acuerdo ni en desacuerdo. Por ende, se interpreta que la gran mayoría de encargados aseguran que en la empresa, el desempeño de los proveedores se evalúa periódicamente.

Tabla 31:

Proporción de información y recursos

\begin{tabular}{|c|c|c|c|c|c|}
\hline \multicolumn{6}{|c|}{$\begin{array}{c}\text { GCT22. En nuestra empresa, se proporciona información y recursos actualizados a todos los } \\
\text { empleados para realizar sus trabajos. }\end{array}$} \\
\hline & & Frecuencia & Porcentaje & $\begin{array}{l}\text { Porcentaje } \\
\text { válido }\end{array}$ & $\begin{array}{l}\text { Porcentaje } \\
\text { acumulado }\end{array}$ \\
\hline \multirow{4}{*}{ Valido } & $\begin{array}{l}\text { Ni de acuerdo ni en } \\
\text { desacuerdo }\end{array}$ & 7 & 6.6 & 6.6 & 6.6 \\
\hline & De acuerdo & 48 & 45.3 & 45.3 & 51.9 \\
\hline & Totalmente de acuerdo & 51 & 48.1 & 48.1 & 100.0 \\
\hline & Total & 106 & 100.0 & 100.0 & \\
\hline
\end{tabular}

Interpretación: en la Tabla 31 se observa que del 100\% de encargados, el $93.4 \%$ se halla totalmente de acuerdo y de acuerdo con la afirmación "En nuestra empresa, se proporciona información y recursos actualizados a todos los empleados para realizar sus trabajos” y el 6.6\% se halla ni de acuerdo ni en desacuerdo. Por ende, se interpreta que la gran mayoría de encargados aseguran que en la empresa, se proporciona información y recursos actualizados a todos los empleados para realizar sus trabajos. 
Tabla 32:

Reducción del efecto nocivo

GCT23. En nuestra empresa trata de reducir el efecto nocivo de sus actividades en el medio ambiente. (Asociación y recursos)

\begin{tabular}{|c|c|c|c|c|c|}
\hline & & Frecuencia & Porcentaje & $\begin{array}{l}\text { Porcentaje } \\
\text { válido }\end{array}$ & $\begin{array}{l}\text { Porcentaje } \\
\text { acumulado }\end{array}$ \\
\hline \multirow{4}{*}{ Valido } & $\begin{array}{l}\text { Ni de acuerdo ni en } \\
\text { desacuerdo }\end{array}$ & 7 & 6.6 & 6.6 & 6.6 \\
\hline & De acuerdo & 45 & 42.5 & 42.5 & 49.1 \\
\hline & Totalmente de acuerdo & 54 & 50.9 & 50.9 & 100.0 \\
\hline & Total & 106 & 100.0 & 100.0 & \\
\hline
\end{tabular}

Interpretación: en la Tabla 32 se observa que del 100\% de encargados, el $93.4 \%$ se halla totalmente de acuerdo y de acuerdo con la afirmación "En nuestra empresa trata de reducir el efecto nocivo de sus actividades en el medio ambiente. (Asociación y recursos)" y el 6.6\% se halla ni de acuerdo ni en desacuerdo. Por ende, se interpreta que la gran mayoría de encargados aseguran que la empresa trata de reducir el efecto nocivo de sus actividades en el medio ambiente. (Asociación y recursos).

Tabla 33:

Procedimientos adecuados

\begin{tabular}{llrrrr}
\hline GCT24. En nuestra empresa, se establecen procedimientos adecuados para realizar diferentes \\
trabajos.
\end{tabular}

Interpretación: en la Tabla 33 se observa que del 100\% de encargados, el $89.7 \%$ se halla totalmente de acuerdo y de acuerdo con la afirmación "En nuestra empresa, se establecen procedimientos adecuados para realizar diferentes trabajos", el 6.6\% se halla ni de acuerdo ni en desacuerdo y el $3.8 \%$ se halla en desacuerdo. Por ende, se interpreta que la gran mayoría de encargados aseguran que en la empresa, se establecen procedimientos adecuados para realizar diferentes trabajos. 
Tabla 34:

Parámetros de procesos

\begin{tabular}{|c|c|c|c|c|c|}
\hline \multicolumn{6}{|c|}{$\begin{array}{l}\text { GCT25. En nuestra empresa, los empleados conocen los parámetros (temperatura, presión, etc.) } \\
\text { de los diferentes procesos, que deben controlarse para una operación eficiente. }\end{array}$} \\
\hline & & Frecuencia & Porcentaje & $\begin{array}{l}\text { Porcentaje } \\
\text { válido }\end{array}$ & $\begin{array}{l}\text { Porcentaje } \\
\text { acumulado }\end{array}$ \\
\hline \multirow{6}{*}{ Valido } & Totalmente en desacuerdo & 4 & 3.8 & 3.8 & 3.8 \\
\hline & En desacuerdo & 2 & 1.9 & 1.9 & 5.7 \\
\hline & $\begin{array}{l}\text { Ni de acuerdo ni en } \\
\text { desacuerdo }\end{array}$ & 6 & 5.7 & 5.7 & 11.3 \\
\hline & De acuerdo & 44 & 41.5 & 41.5 & 52.8 \\
\hline & Totalmente de acuerdo & 50 & 47.2 & 47.2 & 100.0 \\
\hline & Total & 106 & 100.0 & 100.0 & \\
\hline
\end{tabular}

Interpretación: en la Tabla 34 se observa que del 100\% de encargados, el $88.7 \%$ se halla totalmente de acuerdo y de acuerdo con la afirmación "En nuestra empresa, los empleados conocen los parámetros (temperatura, presión, etc.) de los diferentes procesos, que deben controlarse para una operación eficiente", el 5.7\% se halla ni de acuerdo ni en desacuerdo y el $5.7 \%$ se halla en total desacuerdo y en desacuerdo. Por ende, se interpreta que la gran mayoría de encargados aseguran que en la empresa, los empleados conocen los parámetros (temperatura, presión, etc.) de los diferentes procesos, que deben controlarse para una operación eficiente.

Tabla 35:

Monitoreo de procesos

\begin{tabular}{llrrrr}
\hline \multicolumn{6}{c}{ GCT26. En nuestra empresa, se monitorea el desempeño de los procesos de producción. } \\
\hline & Frecuencia & Porcentaje & $\begin{array}{c}\text { Porcentaje } \\
\text { vảlido }\end{array}$ & $\begin{array}{c}\text { Porcentaje } \\
\text { acumulado }\end{array}$ \\
\hline \multirow{5}{*}{ Valido } & & & 7.5 & 7.5 & 7.5 \\
& $\begin{array}{l}\text { En desacuerdo } \\
\text { Ni de acuerdo ni en }\end{array}$ & 4 & 3.8 & 3.8 & 11.3 \\
& desacuerdo & 43 & 40.6 & 40.6 & 51.9 \\
& De acuerdo & 51 & 48.1 & 48.1 & 100.0 \\
\cline { 2 - 6 } & Totalmente de acuerdo & 106 & 100.0 & 100.0 & \\
\cline { 2 - 6 } & Total & & & &
\end{tabular}

Interpretación: en la Tabla 35 se observa que del 100\% de encargados, el $88.7 \%$ se halla totalmente de acuerdo y de acuerdo con la afirmación "En nuestra empresa, se monitorea el desempeño de los procesos de producción”, el 3.8\% se halla ni de acuerdo ni en desacuerdo y el $7.5 \%$ se halla en desacuerdo. Por ende, se interpreta que la gran mayoría de encargados aseguran que en la empresa, se monitorea el desempeño de los procesos de producción. 
Tabla 36:

Desarrollo e innovación de procesos

\begin{tabular}{llrrrr}
\hline \multicolumn{2}{c}{ GCT27. En nuestra empresa, se enfatiza el desarrollo y la innovación de los procesos de } \\
producción.
\end{tabular}

Interpretación: en la Tabla 36 se observa que del 100\% de encargados, el $79.2 \%$ se halla totalmente de acuerdo y de acuerdo con la afirmación "En nuestra empresa, se enfatiza el desarrollo y la innovación de los procesos de producción”, el 15.1\% se halla ni de acuerdo ni en desacuerdo y el $5.7 \%$ se halla en desacuerdo. Por ende, se interpreta que la gran mayoría de encargados aseguran que en la empresa, se enfatiza el desarrollo y la innovación de los procesos de producción.

Tabla 37:

Departamento de investigación y desarrollo

\begin{tabular}{|c|c|c|c|c|c|}
\hline \multicolumn{6}{|c|}{$\begin{array}{l}\text { GCT2S. En nuestra empresa, el departamento de investigación y desarrollo (I + D) trabaja } \\
\text { continuamente en el desarrollo y la meiora de los productos. }\end{array}$} \\
\hline & & Frecuencia & Porcentaje & $\begin{array}{l}\text { Porcentaje } \\
\text { válido }\end{array}$ & $\begin{array}{l}\text { Porcentaje } \\
\text { acumulado }\end{array}$ \\
\hline \multirow{5}{*}{ Valido } & En desacuerdo & 8 & 7.5 & 7.5 & 7.5 \\
\hline & $\begin{array}{l}\text { Ni de acuerdo ni en } \\
\text { desacuerdo }\end{array}$ & 10 & 9.4 & 9.4 & 17.0 \\
\hline & De acuerdo & 45 & 42.5 & 42.5 & 59.4 \\
\hline & Totalmente de acuerdo & 43 & 40.6 & 40.6 & 100.0 \\
\hline & Total & 106 & 100.0 & 100.0 & \\
\hline
\end{tabular}

Interpretación: en la Tabla 37 se observa que del 100\% de encargados, el $83.1 \%$ se halla totalmente de acuerdo y de acuerdo con la afirmación "En nuestra empresa, el departamento de investigación y desarrollo (I + D) trabaja continuamente en el desarrollo y la mejora de los productos”, el 9.4\% se halla ni de acuerdo ni en desacuerdo y el 7.5\% se halla en desacuerdo. Por ende, se interpreta que la gran mayoría de encargados aseguran que la empresa, el 
departamento de investigación y desarrollo (I + D) trabaja continuamente en el desarrollo y la mejora de los productos.

Tabla 38:

Procesos de producción

\begin{tabular}{llrrrr}
\hline GCT29. En nuestra empresa, los procesos de producción son capaces de producir productos de \\
acuerdo con las especificaciones de diseño.
\end{tabular}

Interpretación: en la Tabla 38 se observa que del 100\% de encargados, el $85.8 \%$ se halla totalmente de acuerdo y de acuerdo con la afirmación "En nuestra empresa, los procesos de producción son capaces de producir productos de acuerdo con las especificaciones de diseño", el $10.4 \%$ se halla ni de acuerdo ni en desacuerdo y el $3.8 \%$ se halla en desacuerdo. Por ende, se interpreta que la gran mayoría de encargados aseguran que en la empresa, los procesos de producción son capaces de producir productos de acuerdo con las especificaciones de diseño.

Tabla 39:

Sistemas para quejas

GCT30. En nuestra empresa, existen sistemas adecuados para atender las quejas de los clientes.

\begin{tabular}{llrrrr}
\hline & Frecuencia & Porcentaje & $\begin{array}{c}\text { Porcentaje } \\
\text { válido }\end{array}$ & $\begin{array}{c}\text { Porcentaje } \\
\text { acumulado }\end{array}$ \\
\hline \multirow{5}{*}{ Valido } & & & 5.7 & 5.7 & 5.7 \\
& En desacuerdo & 6 & 5.7 & 8.5 & 14.2 \\
Ni de acuerdo ni en & 9 & 8.5 & 36.8 & 50.9 \\
& desacuerdo & 39 & 36.8 & 49.1 & 100.0 \\
\hline & De acuerdo & 52 & 49.1 & 100.0 & \\
\cline { 2 - 6 } & Totalmente de acuerdo & 106 & 100.0 & & \\
\hline
\end{tabular}

Interpretación: en la Tabla 39 se observa que del 100\% de encargados, el $85.9 \%$ se halla totalmente de acuerdo y de acuerdo con la afirmación "En nuestra empresa, existen sistemas adecuados para atender las quejas de los clientes", el $8.5 \%$ se halla ni de acuerdo ni en desacuerdo y el 5.7\% se halla en desacuerdo. P Por ende, se interpreta que la gran mayoría de 
encargados aseguran en la empresa, existen sistemas adecuados para atender las quejas de los clientes.

\subsubsection{Análisis de los resultados de desempeño exportador}

Tabla 40:

Rentabilidad de exportación

\begin{tabular}{llrrrr}
\hline \multicolumn{6}{c}{ DEl. La exportación de la empresa ha sido muy rentable. } \\
\hline & Frecuencia & Porcentaje & $\begin{array}{c}\text { Porcentaje } \\
\text { válido }\end{array}$ & $\begin{array}{c}\text { Porcentaje } \\
\text { acumulado }\end{array}$ \\
\hline \multirow{5}{*}{ Valido } & & 8 & 7.5 & 7.5 & 7.5 \\
& En desacuerdo & 18 & 17.0 & 17.0 & 24.5 \\
Ni de acuerdo ni en & 59 & 55.7 & 55.7 & 80.2 \\
& desacuerdo & 51 & 19.8 & 19.8 & 100.0 \\
\cline { 2 - 6 } & De acuerdo & 106 & 100.0 & 100.0 & \\
\cline { 2 - 7 } & Totalmente de acuerdo & 106 & &
\end{tabular}

Interpretación: en la Tabla 40 se observa que del 100\% de encargados, el $75.5 \%$ se halla totalmente de acuerdo y de acuerdo con la afirmación "La exportación de la empresa ha sido muy rentable", el 17\% se halla ni de acuerdo ni en desacuerdo y el 7.5\% se halla en desacuerdo. Por ende, se interpreta que la gran mayoría de encargados aseguran que la exportación de la empresa ha sido muy rentable.

Tabla 41:

Volumen de ventas

\begin{tabular}{|c|c|c|c|c|c|}
\hline \multicolumn{6}{|c|}{ DE2. La exportación de la empresa ha generado un alto volumen de ventas. } \\
\hline & & Frecuencia & Porcentaje & $\begin{array}{l}\text { Porcentaje } \\
\text { válido }\end{array}$ & $\begin{array}{l}\text { Porcentaje } \\
\text { acumulado }\end{array}$ \\
\hline \multirow{5}{*}{ Valido } & En desacuerdo & 8 & 7.5 & 7.5 & 7.5 \\
\hline & $\begin{array}{l}\text { Ni de acuerdo ni en } \\
\text { desacuerdo }\end{array}$ & 21 & 19.8 & 19.8 & 27.4 \\
\hline & De acuerdo & 52 & 49.1 & 49.1 & 76.4 \\
\hline & Totalmente de acuerdo & 25 & 23.6 & 23.6 & 100.0 \\
\hline & Total & 106 & 100.0 & 100.0 & \\
\hline
\end{tabular}

Interpretación: en la Tabla 41 se observa que del 100\% de encargados, el $72.7 \%$ se halla totalmente de acuerdo y de acuerdo con la afirmación "La exportación de la empresa ha generado un alto volumen de ventas", el $19.8 \%$ se halla ni de acuerdo ni en desacuerdo y el 
7.5\% se halla en desacuerdo. Por ende, se interpreta que la gran mayoría de encargados aseguran que la exportación de la empresa ha generado un alto volumen de ventas.

Tabla 42:

Crecimiento rápido

\begin{tabular}{llrrrr}
\hline \multicolumn{5}{c}{ DE3. La exportación de la empresa ha logrado un rápido crecimiento. } \\
\hline & Frecuencia & Porcentaje & $\begin{array}{c}\text { Porcentaje } \\
\text { válido }\end{array}$ & $\begin{array}{l}\text { Porcentaje } \\
\text { acumulado }\end{array}$ \\
\hline En desacuerdo & & & 1.9 & 1.9 & 1.9 \\
Ni de acuerdo ni en & 2 & 7.5 & 7.5 & 9.4 \\
Valido & 8 & 32.1 & 32.1 & 41.5 \\
desacuerdo & 34 & 32.1 & 58.5 & 100.0 \\
De acuerdo & 62 & 58.5 & 100.0 & \\
\cline { 2 - 6 } & Totalmente de acuerdo & 106 & 100.0 & 100 &
\end{tabular}

Interpretación: en la Tabla 42 se observa que del 100\% de encargados, el $90.6 \%$ se halla totalmente de acuerdo y de acuerdo con la afirmación "La exportación de la empresa ha logrado un rápido crecimiento", el 7.5\% se halla ni de acuerdo ni en desacuerdo y el 1.9\% se halla en desacuerdo. Por ende, se interpreta que la gran mayoría de encargados aseguran que la exportación de la empresa ha logrado un rápido crecimiento.

Tabla 43:

Competitividad global

\begin{tabular}{|c|c|c|c|c|c|}
\hline \multicolumn{6}{|c|}{ DE4. La exportación de la empresa ha mejorado nuestra competitividad global. } \\
\hline & & Frecuencia & Porcentaje & $\begin{array}{l}\text { Porcentaje } \\
\text { válido }\end{array}$ & $\begin{array}{l}\text { Porcentaje } \\
\text { acumulado }\end{array}$ \\
\hline \multirow{5}{*}{ Valido } & \multirow{5}{*}{$\begin{array}{l}\text { En desacuerdo } \\
\text { Ni de acuerdo ni en } \\
\text { desacuerdo } \\
\text { De acuerdo } \\
\text { Totalmente de acuerdo }\end{array}$} & 2 & 1.9 & 1.9 & 1.5 \\
\hline & & 23 & 21.7 & 21.7 & 23. \\
\hline & & 62 & 58.5 & 58.5 & 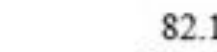 \\
\hline & & 19 & 17.9 & 17.9 & 100.0 \\
\hline & & 106 & 100.0 & 100.0 & \\
\hline
\end{tabular}

Interpretación: en la Tabla 43 se observa que del 100\% de encargados, el $76.4 \%$ se halla totalmente de acuerdo y de acuerdo con la afirmación "La exportación de la empresa ha mejorado nuestra competitividad global", el 21.7\% se halla ni de acuerdo ni en desacuerdo y el $1.9 \%$ se halla en desacuerdo. Por ende, se interpreta que la gran mayoría de encargados aseguran que la exportación de la empresa ha mejorado la competitividad global. 
Tabla 44:

Posición estratégica

\begin{tabular}{|c|c|c|c|c|c|}
\hline \multicolumn{6}{|c|}{ DE5. La exportación de la empresa ha fortalecido nuestra posición estratégica. } \\
\hline & & Frecuencia & Porcentaje & $\begin{array}{l}\text { Porcentaje } \\
\text { válido }\end{array}$ & $\begin{array}{l}\text { Porcentaje } \\
\text { acumulado }\end{array}$ \\
\hline \multirow{5}{*}{ Valido } & En desacuerdo & 4 & 3.8 & 3.8 & 3.8 \\
\hline & $\begin{array}{l}\text { Ni de acuerdo ni en } \\
\text { desacuerdo }\end{array}$ & 21 & 19.8 & 19.8 & 23.6 \\
\hline & De acuerdo & 58 & 54.7 & 54.7 & 78.3 \\
\hline & Totalmente de acuerdo & 23 & 21.7 & 21.7 & 100.0 \\
\hline & Total & 106 & 100.0 & 100.0 & \\
\hline
\end{tabular}

Interpretación: en la Tabla 44 se observa que del 100\% de encargados, el $76.4 \%$ se halla totalmente de acuerdo y de acuerdo con la afirmación "La exportación de la empresa ha fortalecido nuestra posición estratégica”, el 19.8\% se halla ni de acuerdo ni en desacuerdo y el $3.8 \%$ se halla en desacuerdo. Por ende, se interpreta que la gran mayoría de encargados aseguran que la exportación de la empresa ha fortalecido la posición estratégica.

Tabla 45:

Participación de mercado

\begin{tabular}{llrrrr}
\hline DE6. La exportación de la empresa ha aumentado significativamente nuestra participación en \\
el mercado global.
\end{tabular}

Interpretación: en la Tabla 45 se observa que del 100\% de encargados, el $92.5 \%$ se halla totalmente de acuerdo y de acuerdo con la afirmación "La exportación de la empresa ha aumentado significativamente nuestra participación en el mercado global” y el $7.5 \%$ se halla ni de acuerdo ni en desacuerdo. Por ende, se interpreta que la gran mayoría de encargados aseguran que la exportación de la empresa ha aumentado significativamente la participación en el mercado global. 
Tabla 46:

Desempeño satisfactorio

\begin{tabular}{|c|c|c|c|c|c|}
\hline \multicolumn{6}{|c|}{ DE7. El desempeño de exportación de nuestra firma ha sido satisfactorio. } \\
\hline & & Frecuencia & Porcentaje & $\begin{array}{c}\text { Porcentaje } \\
\text { válido }\end{array}$ & $\begin{array}{l}\text { Porcentaje } \\
\text { acumulado }\end{array}$ \\
\hline \multirow{5}{*}{ Valido } & En desacuerdo & 2 & 1.9 & 1.9 & 1.9 \\
\hline & $\begin{array}{l}\text { Ni de acuerdo ni en } \\
\text { desacuerdo }\end{array}$ & 15 & 14.2 & 14.2 & 16.0 \\
\hline & De acuerdo & 40 & 37.7 & 37.7 & 53.8 \\
\hline & Totalmente de acuerdo & 49 & 46.2 & 46.2 & 100.0 \\
\hline & Total & 106 & 100.0 & 100.0 & \\
\hline
\end{tabular}

Interpretación: en la Tabla 46 se observa que del 100\% de encargados, el $83.9 \%$ se halla totalmente de acuerdo y de acuerdo con la afirmación "El desempeño de exportación de nuestra firma ha sido satisfactorio", el 14.2\% se halla ni de acuerdo ni en desacuerdo y el $1.9 \%$ se halla en desacuerdo. Por ende, se interpreta que la gran mayoría de encargados aseguran que el desempeño de exportación de la firma ha sido satisfactorio.

Tabla 47:

Éxito de exportación

\begin{tabular}{llrrrr}
\hline \multicolumn{5}{c}{ DES. La exportación de la empresa ha sido exitosa. } \\
\hline & Frecuencia & Porcentaje & $\begin{array}{c}\text { Porcentaje } \\
\text { válido }\end{array}$ & $\begin{array}{c}\text { Porcentaje } \\
\text { acumulado }\end{array}$ \\
\hline Totalmente en desacuerdo & 2 & 1.9 & 1.9 & 1.9 \\
En desacuerdo & 8 & 7.5 & 7.5 & 9.4 \\
Nide acuerdo ni en & 11 & 10.4 & 10.4 & 19.8 \\
Valido & 50 & 47.2 & 47.2 & 67.0 \\
& desacuerdo & 35 & 33.0 & 33.0 & 100.0 \\
De acuerdo & 106 & 100.0 & 100.0 & \\
Totalmente de acuerdo & Total & & &
\end{tabular}

Interpretación: en la Tabla 47 se observa que del 100\% de encargados, el $80.2 \%$ se halla totalmente de acuerdo y de acuerdo con la afirmación "La exportación de la empresa ha sido exitosa", el 10.4\% se halla ni de acuerdo ni en desacuerdo y el 9.4\% se halla en desacuerdo. Por ende, se interpreta que la gran mayoría de encargados aseguran que la exportación de la empresa ha sido exitosa. 
Tabla 48:

Cumplimiento de expectativas

\begin{tabular}{|c|c|c|c|c|c|}
\hline \multicolumn{6}{|c|}{ DE9. La exportación de la empresa ha cumplido plenamente nuestras expectativas. } \\
\hline & & Frecuencia & Porcentaje & $\begin{array}{c}\text { Porcentaje } \\
\text { válido }\end{array}$ & $\begin{array}{l}\text { Porcentaje } \\
\text { acumulado }\end{array}$ \\
\hline \multirow{5}{*}{ Valido } & En desacuerdo & 2 & 1.9 & 1.9 & 1.9 \\
\hline & $\begin{array}{l}\text { Ni de acuerdo ni en } \\
\text { desacuerdo }\end{array}$ & 18 & 17.0 & 17.0 & 18.9 \\
\hline & De acuerdo & 54 & 50.9 & 50.9 & 69.8 \\
\hline & Totalmente de acuerdo & 32 & 30.2 & 30.2 & 100.0 \\
\hline & Total & 106 & 100.0 & 100.0 & \\
\hline
\end{tabular}

Interpretación: en la Tabla 48 se observa que del 100\% de encargados, el $58.5 \%$ se halla totalmente de acuerdo y de acuerdo con la afirmación "La exportación de la empresa ha cumplido plenamente nuestras expectativas", el $30.2 \%$ se halla ni de acuerdo ni en desacuerdo y el $11.3 \%$ se halla en desacuerdo. Por ende, se interpreta que la gran mayoría de encargados aseguran que la exportación de la empresa ha cumplido plenamente las expectativas. 


\subsection{Contrastación de las hipótesis}

\subsubsection{Prueba de Shapiro-Wilk}

La prueba de Shapiro-Wilk se llevó a cabo para conocer si los datos recopilados tienen una distribución normal o no, se desarrolló la prueba de Shapiro-Wilk. Como se presenta en la Tabla 49 y en la Tabla 50, los resultados de los dos cuestionarios presentan distribución no normal, por lo tanto, se efectuó una prueba no paramétrica. Por tanto, se usa el coeficiente de correlación Rho de Spearman para probar la hipótesis formuladas.

De acuerdo con lo citado por Hernández et al. (2014), se usa el coeficiente de correlación Rho de Spearman para calcular la correlación de variables a nivel de medida ordenada, con el propósito de clasificar los elementos que han sido examinados en diferentes niveles. De similar forma, el coeficiente se usa en la relación de niveles de niveles tipo Likert.

Tabla 49:

Prueba de normalidad Shapiro-Wilk - gestión de la calidad total

\begin{tabular}{|c|c|c|c|c|c|c|}
\hline \multicolumn{7}{|c|}{ Pruebas de normalidad } \\
\hline & \multicolumn{3}{|c|}{ Kolmogorox-Smimox" } & \multicolumn{3}{|c|}{ Shapiro-Wilk } \\
\hline & Estadistica & df & Sig. & Estadistica & df & Sig. \\
\hline $\begin{array}{l}\text { GCT1. Los gerentes de nuestra empresa } \\
\text { consideran que el costo es más importante en } \\
\text { comparación con la calidad de los productos. }\end{array}$ & .225 & 106 & .000 & .877 & 106 & .000 \\
\hline $\begin{array}{l}\text { GCT2. Los gerentes de nuestra empresa se } \\
\text { presentan como modelos a seguir para los } \\
\text { empleados. }\end{array}$ & 357 & 106 & .000 & .709 & 106 & .000 \\
\hline $\begin{array}{l}\text { GCT3. Los gerentes de nuestra empresa se } \\
\text { aseguran de que los empleados conozcan los } \\
\text { planes a largo plazo de la empresa. }\end{array}$ & .209 & 106 & .000 & .849 & 106 & .000 \\
\hline GCT4. Los gerentes de nuestra empresa no & & & & & & \\
\hline $\begin{array}{l}\text { desean otorgar autoridad a los empleados para } \\
\text { que tomen decisiones sobre sus trabajos. }\end{array}$ & .303 & 106 & .000 & .792 & 100 & .000 \\
\hline
\end{tabular}


GCT5. Los gerentes de nuestra empresa

adquieren y actualizan continuamente su

conocimiento, que es valioso para la

$\begin{array}{llllll}.352 & 106 & .000 & .723 & 106 & .000\end{array}$

organización.

GCT6. Los gerentes de nuestra empresa fomentan

y participan en iniciativas de mejora continua.

$\begin{array}{llllll}.328 & 106 & .000 & .774 & 106 & .000\end{array}$

GCT7. En nuestra empresa, las opiniones de los

clientes (las personas / empresas que compran o

desean comprar los productos de su empresa) se

$\begin{array}{llllll}.263 & 106 & .000 & .792 & 106 & .000\end{array}$

consideran importantes al diseñar nuevos

productos.

GCTS. En nuestra empresa, se consideran las

opiniones de los proveedores al configurar los

objetivos de la empresa.

GCT9. En nuestra empresa, se evalia y analiza el desempeño de los competidores y las mejores companilas de su clase.

GCT10. En nuestra empresa, se realiza una medición sistemática de pérdidas (como pérdidas de producción, pérdidas por rechazo de productos $\begin{array}{llllll}.446 & 106 & .000 & .587 & 106 & .000\end{array}$ terminados, etc.).

GCT11. En nuestra empresa, existen sistemas de información para capturar información sobre $\begin{array}{llllll}.254 & 106 & .000 & .816 & 106 & .000\end{array}$ clientes y mercados.

GCT12. En nuestra empresa, periódicamente (por ejemplo, cada tres meses, seis meses o un año), el desempeño organizacional se evalúa en función $\begin{array}{llllll}.447 & 106 & .000 & .587 & 106 & .000\end{array}$ $\begin{array}{llllll}.446 & 106 & .000 & .587 & 106 & .000\end{array}$ de los objetivos y metas establecidos.

GCT13. En nuestra empresa, los procesos formales se utilizan regularmente (encuestas de actitud, información de los empleados, etc.) para $\begin{array}{llllll}.316 & 106 & .000 & .764 & 106 & .000\end{array}$ conocer las opiniones y puntos de vista de los empleados.

GCT14. En nuestra empresa, se da capacitación especifica de calidad a los empleados.

$\begin{array}{llllll}.263 & 106 & .000 & .795 & 106 & .000\end{array}$

GCT15. En nuestra empresa, re alienta a los empleados a actualizar sus conocimientos y habilidades.

$\begin{array}{llllll}.512 & 106 & .000 & .409 & 106 & .000\end{array}$

$\begin{array}{llllll}.315 & 106 & .000 & .759 & 106 & .000\end{array}$


GCT16. En nuestra empresa, el trabajo en equipo

es una práctica comin dentro de la organización.

GCT17. En nuestra empresa, los empleados

tienen facil acceso a la información relevante.

GCT18. En nuestra empresa, fomente las

opiniones y sugerencias de los empleados sobre

cualquiera de las actividades de la organización.

GCT19. En nuestra empresa, se alienta a los

proveedores a desarrollar asociaciones con la

organización.

GCT20. En nuestra empresa no da preferencia a

la calidad sobre el costo al hacer acuerdos de

compra con proveedores.

GCT21. En nuestra empresa, el desempeño de los

proveedores se evalua periódicamente.

GCT22. En nuestra empresa, se proporciona

información y recursos actualizados a todos los

empleados para realizar sus trabajos.

GCT23. En nuestra empresa trata de reducir el efecto nocivo de sus actividades en el medio

ambiente. (Asociación y recursos)

GCT24. En nuestra empresa, se establecen

procedimientos adecuados para realizar diferentes

trabajos.

GCT25. En nuestra empresa, los empleados

conocen los parámetros (temperatura, presión,

etc.) de los diferentes procesos, que deben

controlarse para una operación eficiente.

GCT26. En nuestra empresa, se monitorea el

desempeño de los procesos de producción.

GCT27. En nuestra empresa, se enfatiza el desarrollo y la innovación de los procesos de producción.

GCT28. En nuestra empresa, el departamento de investigación y desarrollo $(I+D)$ trabaja continuamente en el desarrollo y la mejora de los productos.

\begin{tabular}{|c|c|c|c|c|c|}
\hline .277 & 106 & .000 & .794 & 106 & .000 \\
\hline .236 & 106 & .000 & .869 & 106 & .000 \\
\hline .373 & 106 & .000 & .745 & 106 & .000 \\
\hline .294 & 106 & .000 & .765 & 106 & .000 \\
\hline .259 & 106 & .000 & .840 & 106 & .000 \\
\hline .341 & 106 & .000 & .725 & 106 & .000 \\
\hline .310 & 106 & .000 & .741 & 106 & .000 \\
\hline .325 & 106 & .000 & .734 & 106 & .000 \\
\hline .281 & 106 & .000 & .753 & 106 & .000 \\
\hline .276 & 106 & .000 & .708 & 106 & .000 \\
\hline .275 & 106 & .000 & .730 & 106 & .000 \\
\hline & 106 & .000 & .772 & 106 & \\
\hline
\end{tabular}

$\begin{array}{llllll}.258 & 106 & .000 & .790 & 106 & .000\end{array}$


GCT29. En nuestra empresa, los procesos de $\begin{array}{lllllll}\text { producción son capaces de producir productos de } & .288 & 106 & .000 & .771 & 106 & .000\end{array}$ acuerdo con las especificaciones de diseño.

GCT30. En nuestra empresa, existen sistemas adecuados para atender las quejas de los clientes.

$\begin{array}{llllll}.288 & 106 & .000 & .758 & 106 & .000\end{array}$

Elaboración: Raymundo y Paúcar (2020) - Extraido de SPSS 22

Tabla 50:

Prueba de normalidad Shapiro-Wilk - desempeño exportador

\begin{tabular}{|c|c|c|c|c|c|c|}
\hline \multicolumn{7}{|c|}{ Pruebas de normalidad } \\
\hline & \multicolumn{3}{|c|}{ Kolmogorox-Smirnove } & \multicolumn{3}{|c|}{ Shapiro-Wilk } \\
\hline & Estadistica & $\mathrm{df}$ & Sig. & Estadistica & df & Sig. \\
\hline $\begin{array}{l}\text { DE1. La exportación de la empresa ha sido muy } \\
\text { rentable. }\end{array}$ & .315 & 106 & .000 & .825 & 106 & .000 \\
\hline $\begin{array}{l}\text { DE2. La exportación de la empresa ha generado } \\
\text { un alto volumen de ventas. }\end{array}$ & .279 & 106 & .000 & .848 & 106 & .000 \\
\hline $\begin{array}{l}\text { DE3. La exportación de la empresa ha logrado } \\
\text { un rápido crecimiento. }\end{array}$ & .353 & 106 & .000 & .712 & 106 & .000 \\
\hline $\begin{array}{l}\text { DE4. La exportación de la empresa ha mejorado } \\
\text { nuestra competitividad global. }\end{array}$ & .308 & 106 & .000 & .815 & 106 & .000 \\
\hline $\begin{array}{l}\text { DE5. La exportación de la empresa ha } \\
\text { fortalecido nuestra posición estratégica. }\end{array}$ & .294 & 106 & .000 & .831 & 106 & .000 \\
\hline $\begin{array}{l}\text { DE6. La exportación de la empresa ha } \\
\text { aumentado significativamente nuestra } \\
\text { participación en el mercado global. }\end{array}$ & .365 & 106 & .000 & .706 & 106 & .000 \\
\hline $\begin{array}{l}\text { DE7. El desempeño de exportación de nuestra } \\
\text { firma ha sido satisfactorio. }\end{array}$ & .284 & 106 & .000 & .789 & 106 & .000 \\
\hline $\begin{array}{l}\text { DE\&. La exportación de la empresa ha sido } \\
\text { exitosa. }\end{array}$ & .294 & 106 & .000 & .808 & 106 & .000 \\
\hline $\begin{array}{l}\text { DE9. La exportación de la empresa ha cumplido } \\
\text { plenamente nuestras expectativas. }\end{array}$ & .260 & 106 & .000 & .823 & 106 & .000 \\
\hline
\end{tabular}

Elaboración: Raymundo y Paúcar (2020) - Extraido de SPSS 22 


\subsubsection{Validación de constructo: Análisis factorial exploratorio}

El análisis factorial exploratorio tiene como objetivo confirmar las dimensiones de las dos variables en estudio y confirmar cómo se agrupan. Los métodos utilizados son los siguientes: método de componente principal (usado para extraer las afirmaciones) y método Varimax (usado para rotar las afirmaciones). En seguida, se exponen los resultados obtenidos para la variable gestión de la calidad total: un 0.000 en la significancia, un 2962.828 en el aproximado del Chi-cuadrado y un 0.757 en el estadístico Kaiser-Meyer-Olkin (KMO). Según estos resultados se observa que existe un buen ajuste factorial a raíz de la capacidad de la aplicación del estadístico KMO (0.757). Tomando como base el análisis adecuado desarrollado, se observa que la variable gestión de la calidad total posee cinco dimensiones o factores, los cuales explican el $72.613 \%$ en la varianza total.

Tabla 51:

"Prueba de KMO, Bartlett y Método de extracción" - gestión de la calidad total

\begin{tabular}{lcc}
\hline \multicolumn{3}{c}{ Prueba de KMO y Bartlett } \\
\hline Medida Kaiser-Meyer-Olkin de adecuación de muestreo. & .757 \\
Prueba de esfericidad de Bartlett & Aprox. Chi-cuadrado & 2962.828 \\
& Df & 435 \\
& Sig. & .000 \\
\hline
\end{tabular}

Elaboración: Raymundo y Paúcar (2020) - Extraido de SPSS 22

La dimensión "procesos" es el primer factor con una varianza de $24.956 \%$, la dimensión "liderazgo" es el segundo factor con una varianza de 15.726\%, la dimensión "estrategias” es el tercer factor con una varianza de $13.239 \%$, la dimensión "personas" es el cuarto factor con una varianza de $10.403 \%$ y la dimensión "recursos" es el quinto factor con una varianza de 8.289\%. 
Tabla 52:

"Varianza Total Explicada"- gestión de la calidad total

\begin{tabular}{|c|c|c|c|c|c|c|c|c|c|}
\hline \multicolumn{10}{|c|}{ Varianza Total Explicada } \\
\hline \multirow[t]{2}{*}{ Componente } & \multicolumn{3}{|c|}{ Valores propios Iniciales } & \multicolumn{3}{|c|}{$\begin{array}{c}\text { Suma de rotación de cargas } \\
\text { al cuadrado }\end{array}$} & \multicolumn{3}{|c|}{$\begin{array}{c}\text { Sumas de rotación de cargas } \\
\text { al cuadrado }\end{array}$} \\
\hline & Total & $\begin{array}{c}\% \text { de } \\
\text { varianza }\end{array}$ & $\begin{array}{c}\text { acumulado } \\
\%\end{array}$ & Total & $\begin{array}{l}\% \text { de } \\
\text { varianza }\end{array}$ & $\begin{array}{c}\text { acumulado } \\
\% \\
\end{array}$ & Total & $\begin{array}{l}\% \text { de } \\
\text { varianza }\end{array}$ & $\begin{array}{c}\text { acumulado } \\
\%\end{array}$ \\
\hline 1 & 7.487 & 24.956 & 24.956 & 7.487 & 24.956 & 24.956 & 5.269 & 17.565 & 17.565 \\
\hline 2 & 4.718 & 15.726 & 40.682 & 4.718 & 15.726 & 40.682 & 4.467 & 14.891 & 32.456 \\
\hline 3 & 3.972 & 13.239 & 53.921 & 3.972 & 13.239 & 53.921 & 4.277 & 14.255 & 46.711 \\
\hline 4 & 3.121 & 10.403 & 64.324 & 3.121 & 10.403 & 64.324 & 4.075 & 13.583 & 60.295 \\
\hline 5 & 2.487 & 8.289 & 72.613 & 2.487 & 8.289 & 72.613 & 3.695 & 12.318 & 72.613 \\
\hline 6 & .987 & 3.291 & 75.903 & & & & & & \\
\hline 7 & .915 & 3.051 & 78.954 & & & & & & \\
\hline 8 & .821 & 2.737 & 81.692 & & & & & & \\
\hline 9 & .691 & 2.303 & 83.995 & & & & & & \\
\hline 10 & .635 & 2.117 & 86.112 & & & & & & \\
\hline 11 & .609 & 2.029 & 88.140 & & & & & & \\
\hline 12 & .500 & 1.667 & 89.807 & & & & & & \\
\hline 13 & .388 & 1.294 & 91.101 & & & & & & \\
\hline 14 & .348 & 1.159 & 92.260 & & & & & & \\
\hline 15 & .318 & 1.059 & 93.319 & & & & & & \\
\hline 16 & .279 & .928 & 94.248 & & & & & & \\
\hline 17 & .256 & .853 & 95.101 & & & & & & \\
\hline 18 & .241 & .804 & 95.904 & & & & & & \\
\hline 19 & .213 & .709 & 96.613 & & & & & & \\
\hline 20 & .172 & .572 & 97.186 & & & & & & \\
\hline 21 & .155 & .517 & 97.703 & & & & & & \\
\hline 22 & .121 & .404 & 98.107 & & & & & & \\
\hline 23 & .109 & .363 & 93.470 & & & & & & \\
\hline 24 & .099 & .331 & 98.801 & & & & & & \\
\hline 25 & .085 & .284 & 99.084 & & & & & & \\
\hline 26 & .073 & .242 & 99.327 & & & & & & \\
\hline 27 & .064 & .212 & 99.538 & & & & & & \\
\hline 28 & .055 & .183 & 99.722 & & & & & & \\
\hline 29 & .048 & .162 & 99.883 & & & & & & \\
\hline 30 & .035 & .117 & 100.000 & & & & & & \\
\hline
\end{tabular}

Elaboracion: Raymundo y Paucar (2020) - Extraido de SPSS 22 
De acuerdo con el método Varimax, este método se utiliza para simplificar la expresión de subgrupos específicos con algunos componentes principales, con normalización Kaiser. En la matriz de componente rotado de la variable gestión de la calidad total, la dimensión "procesos" es el primer factor y se halla agrupado entre las afirmaciones 24 y 30, la dimensión "liderazgo" es el segundo factor y se halla agrupado entre las afirmaciones 1 y 6, la dimensión "estrategias" es el tercer factor y se halla agrupado entre las afirmaciones 7 y 12, la dimensión "personas" es el cuarto factor y se halla agrupado entre las afirmaciones 13 y 18 y la dimensión "recursos" es el quinto factor y se halla agrupado entre las afirmaciones 19 y 23 .

Tabla 53:

"Método de rotación: Varimax con normalización Kaiser"- gestión de la calidad total

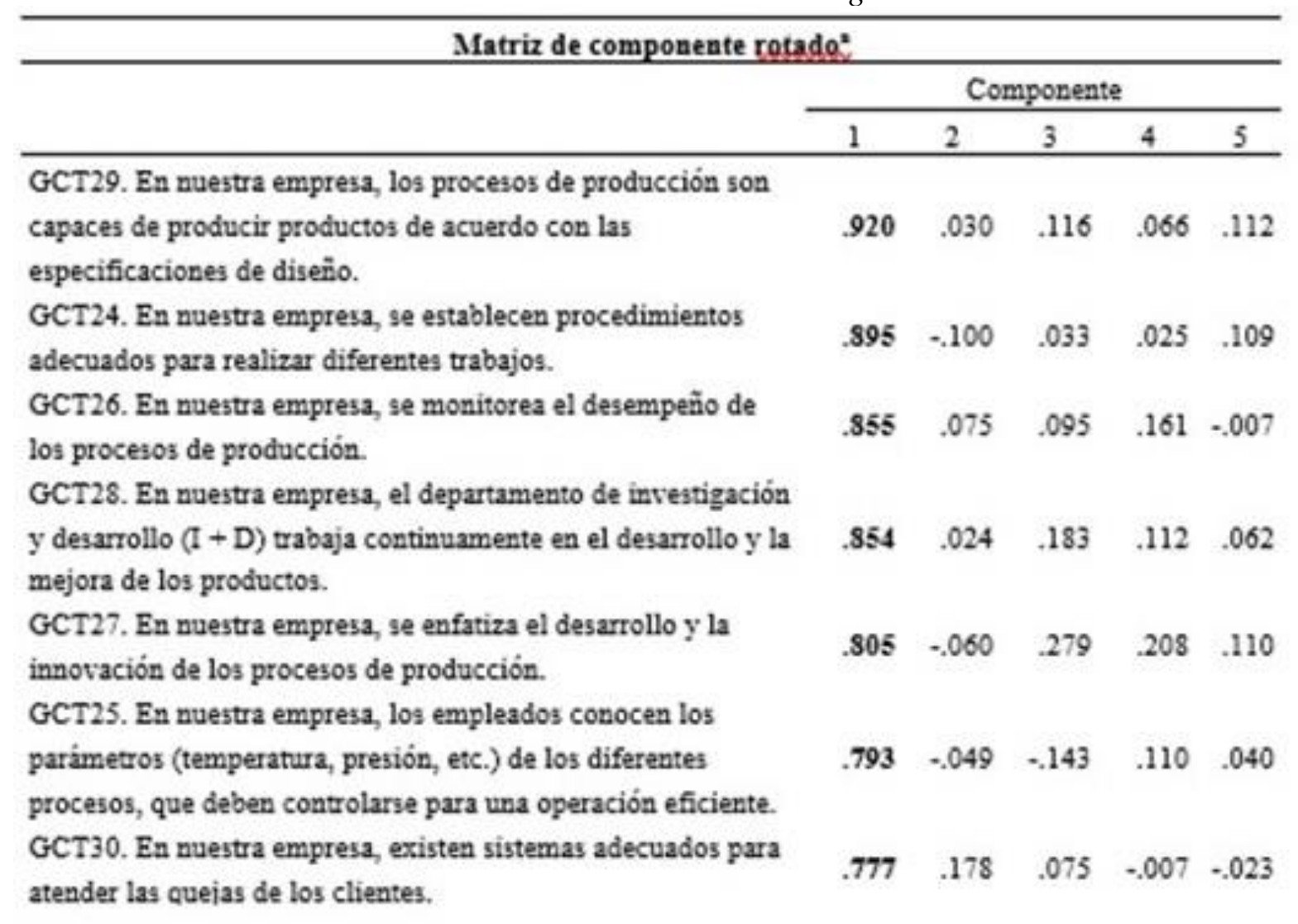


GCT1. Los gerentes de muestra empresa conaideran que el costo es mas importante en comperacion con la $\begin{array}{lllll}-028 & 937 & .025 & .138 & .058\end{array}$ calidad de los productos.

GCT5. Los gerentes de nuestra empresa adquieren y actualion continuamente su conocimiento, que es valioso para la organización.

GCT2. Los gerentes de nuestra empresa se presentan como modelos a seguir para los empleados.

GCT3. Los gerentes de muestra empresa se aseguran de que los empleados conozcan los planes a largo plazo de la empreas.

GCT4. Los gerentes de nuestra empresa no desem otorgar autoridad a los empleados para que tomen deciaiones sobre sus trabajos.

GCT6. Los gerentes de muestra empresa fomentan y participan en iniciativas de mejora continus.

$\begin{array}{lllll}-.019 & 917 & .123 & .084 & .090\end{array}$

$\begin{array}{lllll}012 & .875 & .144 & .092 & .035\end{array}$

$\begin{array}{lllll}-.027 & .767 & .295 & .090 & .039\end{array}$

GCT12. En ruestra empresa, periódicanente (por ejemplo, cada tres meses, seis meses o un nono), el desemper̃o organizscional se evalua en función de los objetivos y metas establecidos.

GCT7. En nuestra empresa, las opiniones de los cliertes (las persocas / empresas que compran o desean comprar los procuctos de su empresa) se corsideran importantes al diseñar muevos productos.

GCT8. En nuestra empresa, se consideran las opiniones de los proveedores al configurar los objetivos de la empresa

GCT11. En nuestra empresa, existen sistemas de $\begin{array}{llllll}\text { informacion para capturar información sobre clientes y } & -027 & .021 & .770 & .093 & -.058\end{array}$ mercados.

GCT10. En muestra enpresa, se revliza una mecición sistematica de pérdidas (como pérdidas de producción. pérdidas por rechazo de productos teminados, exc). GCT9. En nuestra empresa, se evalia y analiza el desemperio de los competidores y las mejores companiza: de su clase.

GCT14. En ruestra empresa, se da capacitación especifica de calidad a los empleados.

$\begin{array}{lllll}.155 & .077 & .821 & .104 & -.086\end{array}$

$\begin{array}{lllll}.056 & .760 & .000 & .032 & .098\end{array}$

$\begin{array}{lllll}.102 & .658 & .011 & .353 & -.052\end{array}$

$\begin{array}{lllll}.117 & -.011 & .875 & .041 & .018\end{array}$ GCT13. En ruestra enpresa, los procesos formales se utilizan regularmente (encuestas de actirud, información de los empleados, etc.) para conocer las opiniones y $\begin{array}{lllll}.139 & .001 & .783 & .060 & .093\end{array}$ puntos de vista de los empleados.

$\begin{array}{llllll}.047 & .256 & .750 & .165 & -.062 \\ .082 & .200 & .705 & .084 & .075 \\ .045 & .069 & .160 & .940 & -.049 \\ .054 & -.004 & .197 & .876 & -.018\end{array}$


GCT15. En nuestra empresa, se alienta a los empleados a actualizar sus conocimientos $y$ habilidades.

GCT16. En nuestra empress, el trabajo en equipo es una práctica común dentro de la organización.

GCT17. En nuestra empresa, los empleados tienen fácil acceso a la información relevante.

GCT18. En nuestra empresa, fomente las opiniones y

sugerencias de los empleados sobre cualquiera de las

actividades de la organización.

GCT21. En nuestra empresa, el desempeño de los proveedores se evalua periódicamente.

GCT19. En nuestra empresa, se alienta a los proveedores a

desarrollar asociaciones con la organización.

GCT23. En nuestra empresa trata de reducir el efecto nocivo de sus actividades en el medio ambiente. (Asociacion y recursos)

GCT22. En nuestra empresa, se proporciona información y recursos actualizados a todos los empleados para realizar sus trabajos.

GCT20. En nuestra empresa no da preferencia a la calidad sobre el costo al hacer acuerdos de compra con proveedores. $\begin{array}{lllll}.021 & .122 & .128 & .852 & .056\end{array}$

$\begin{array}{lllll}.134 & .123 & .056 & .733 & -.077\end{array}$

$\begin{array}{lllll}.305 & .125 & .133 & .709 & -.055\end{array}$

$\begin{array}{llllll}.082 & .282 & -.108 & .559 & -.105\end{array}$

$\begin{array}{lllll}-.003 & .116 & .034 & .007 & 918\end{array}$

$\begin{array}{lllll}.121 & .169 & -.037 & -.064 & .894\end{array}$

$\begin{array}{lllll}-.062 & -.082 & .014 & -.036 & .880\end{array}$

$\begin{array}{lllll}.198 & .132 & .289 & -.111 & .774\end{array}$

$\begin{array}{lllll}.135 & -.037 & -.257 & -.046 & .746\end{array}$

Elaboración: Raymundo y Paicar (2020) - Extraido de SPSS 22

Así mismo se muestran los resultados obtenidos de la variable desempeño exportador: un 0.000 en la significancia, un 539.666 en el aproximado del Chi-cuadrado y un 0.731 en el estadístico Kaiser-Meyer-Olkin (KMO). Según estos resultados se observa que existe un buen ajuste factorial a raíz de la capacidad de la aplicación del estadístico KMO (0.731). tomando como base el análisis adecuado desarrollado, se observa que la variable desempeño exportador posee tres dimensiones o factores, los cuales explican el $79.668 \%$ en la varianza total. 
Tabla 54:

"Prueba de KMO, Bartlett y Método de extracción"- desempeño exportador

\begin{tabular}{|c|c|c|}
\hline \multicolumn{3}{|c|}{ Prueba de KMO y Bartlett } \\
\hline \multicolumn{2}{|c|}{ Medida Kaiser-Meyer-Olkin de adecuación de muestreo. } & .731 \\
\hline \multirow[t]{3}{*}{ Prueba de esfericidad de Bartlett } & Aprox. Chi-cuadrado & 539.666 \\
\hline & Df & 36 \\
\hline & Sig. & .000 \\
\hline
\end{tabular}

Elaboración: Raymundo y Paúcar (2020) - Extraido de SPSS 22

La dimensión “financiero" es el primer factor con una varianza de 37.419\%, la dimensión "satisfacción" es el segundo factor con una varianza de 27.733\% y la dimensión "estrategias" es el tercer factor con una varianza de $14.517 \%$.

Tabla 55:

“Varianza Total Explicada”- desempeño exportador

\begin{tabular}{|c|c|c|c|c|c|c|c|c|c|}
\hline \multicolumn{10}{|c|}{ Varianza Total Explicada } \\
\hline \multirow[t]{2}{*}{ Componente } & \multicolumn{3}{|c|}{ Valores propios Iniciales } & \multicolumn{3}{|c|}{$\begin{array}{c}\text { Suma de rotación de cargas } \\
\text { al cuadrado }\end{array}$} & \multicolumn{3}{|c|}{$\begin{array}{c}\text { Sumas de rotación de cargas } \\
\text { al cuadrado }\end{array}$} \\
\hline & Total & $\begin{array}{c}\% \text { de } \\
\text { varianza }\end{array}$ & $\begin{array}{c}\text { acumulado } \\
\% \\
\end{array}$ & Total & $\begin{array}{c}\% \text { de } \\
\text { varianza }\end{array}$ & $\begin{array}{c}\text { acumulado } \\
\% \\
\end{array}$ & Total & $\begin{array}{c}\% \text { de } \\
\text { varianza }\end{array}$ & $\begin{array}{c}\text { acumulado } \\
\% \\
\end{array}$ \\
\hline 1 & 3.368 & 37.419 & 37.419 & 3.368 & 37.419 & 37.419 & 2.544 & 28.264 & 28.264 \\
\hline 2 & 2.496 & 27.733 & 65.152 & 2.496 & 27.733 & 65.152 & 2.521 & 28.014 & 56.278 \\
\hline 3 & 1.306 & 14.517 & 79.668 & 1.306 & 14.517 & 79.668 & 2.105 & 23.391 & 79.668 \\
\hline 4 & .513 & 5.703 & 85.371 & & & & & & \\
\hline 5 & .418 & 4.640 & 90.011 & & & & & & \\
\hline 6 & .332 & 3.694 & 93.705 & & & & & & \\
\hline 7 & .252 & 2.805 & 96.509 & & & & & & \\
\hline 8 & .173 & 1.923 & 98.433 & & & & & & \\
\hline 9 & .141 & 1.567 & 100.000 & & & & & & \\
\hline
\end{tabular}

Elaboración: Raymundo y Paúcar (2020) - Extraido de SPSS 22

De acuerdo con el método Varimax, este método se utiliza para simplificar la expresión de subgrupos específicos con algunos componentes principales, con normalización Kaiser. En la matriz de componente rotado de la variable desempeño exportador la dimensión "financiero" es el primer factor y se halla agrupado entre las afirmaciones 1 y 3, la dimensión "satisfacción" es el segundo factor y se halla agrupado entre las afirmaciones 7 y 9, la dimensión “estrategias" es el tercer factor y se halla agrupado entre las afirmaciones 4 y 6. 
Tabla 56:

“Método de rotación: Varimax con normalización Kaiser”- desempeño exportador

\begin{tabular}{|c|c|c|c|}
\hline \multicolumn{4}{|l|}{ Matriz de componente rotado: } \\
\hline & \multicolumn{3}{|c|}{ Componente } \\
\hline & 1 & 2 & 3 \\
\hline DE2. La exportación de la empresa ha generado un alto volumen de ventas. & .919 & .033 & -.002 \\
\hline DE1. La exportación de la empresa ha sido muy rentable. & .890 & -.017 & .121 \\
\hline DE3. La exportación de la empresa ha logrado un rápido crecimiento. & .879 & .002 & .013 \\
\hline DE7. El desempeño de exportación de nuestra firma ha sido satisfactorio. & .033 & 910 & .248 \\
\hline $\begin{array}{l}\text { DE9. La exportación de la empresa ha cumplido plenamente nuestras } \\
\text { expectativas. }\end{array}$ & -.016 & .905 & .047 \\
\hline DE8. La exportación de la empresa ha sido exitosa. & .003 & .877 & .298 \\
\hline $\begin{array}{l}\text { DE6. La exportación de la empresa ha aumentado significativamente nuestra } \\
\text { participación en el mercado global. }\end{array}$ & .122 & .150 & .826 \\
\hline $\begin{array}{l}\text { DE4. La exportación de la empresa ha mejorado nuestra competitividad } \\
\text { global. }\end{array}$ & .266 & .242 & .797 \\
\hline DE5. La exportación de la empresa ha fortalecido nuestra posición estratégica. & -.217 & .153 & .788 \\
\hline
\end{tabular}

Elaboración: Raymundo y Paúcar (2020) - Extraido de SPSS 22

\subsubsection{Correlaciones Rho de Spearman}

El programa estadístico SPSS 22 se usa para tabular los datos conseguidos tomando como base los resultados obtenidos de los dos cuestionarios, y se agruparon ambas variables y sus respectivas dimensiones mediante la suma de puntajes, liderazgo de la GCT1 a la GCT6, estrategias de la GCT7 a la GCT12, personas de la GCT13 a la GCT18, recursos de la GCT19 a la GCT23, procesos de la GCT24 a la GCT30, financiero de la DE1 a la DE3, estrategias de la DE4 a la DE6 y satisfacción de la DE7 a la DE9. Terminando se llegaron a obtener resultados del coeficiente de correlación Rho de Spearman. En seguida, se muestran las relaciones encontradas entre la gestión de la calidad total y el desempeño exportador basados en los cuestionarios que se aplicaron a cada administrador y/o gerent de las empresas MYPES exportadoras de quinua del Perú (Tabla 57). 
Tabla 57:

Correlación Rho Spearman

\begin{tabular}{|c|c|c|c|c|c|c|c|c|}
\hline \multicolumn{9}{|c|}{ Correlaciones } \\
\hline & & & Liderazgo & Estrategia & Personas & Recursos & Procesos & Desemp Exp \\
\hline \multirow{13}{*}{ Spearman's rho } & \multirow{2}{*}{ Liderazgo } & $\begin{array}{l}\text { Coeficiente de } \\
\text { correlación }\end{array}$ & 1.000 & $.356^{\circ *}$ & $.263^{* *}$ & .153 & .125 & $.506^{* *}$ \\
\hline & & $\begin{array}{l}\text { Sig. (bilateral) } \\
\mathrm{N}\end{array}$ & 106 & $\begin{array}{l}.000 \\
106\end{array}$ & $\begin{array}{l}.006 \\
106\end{array}$ & $\begin{array}{l}.117 \\
106\end{array}$ & $\begin{array}{l}.201 \\
106\end{array}$ & $\begin{array}{l}.000 \\
106\end{array}$ \\
\hline & \multirow{2}{*}{ Estrategia } & $\begin{array}{l}\text { Coeficiente de } \\
\text { correlación }\end{array}$ & $.356^{* *}$ & 1.000 & $.254^{* *}$ & -.082 & $.194^{\circ}$ & $.354^{* *}$ \\
\hline & & $\begin{array}{l}\text { Sig. (bilateral) } \\
\mathrm{N}\end{array}$ & $\begin{array}{l}.000 \\
106\end{array}$ & 106 & $\begin{array}{l}.009 \\
106\end{array}$ & $\begin{array}{l}405 \\
106\end{array}$ & $\begin{array}{l}.046 \\
106\end{array}$ & $\begin{array}{l}.000 \\
106\end{array}$ \\
\hline & \multirow{2}{*}{ Personas } & $\begin{array}{l}\text { Coeficiente de } \\
\text { correlación }\end{array}$ & $.263^{* *}$ & $.254^{* *}$ & 1.000 & -.068 & .184 & $.254^{* *}$ \\
\hline & & $\begin{array}{l}\text { Sig. (bilateral) } \\
\mathrm{N}\end{array}$ & $\begin{array}{l}.006 \\
106\end{array}$ & $\begin{array}{l}.009 \\
106\end{array}$ & 106 & $\begin{array}{l}489 \\
106\end{array}$ & $\begin{array}{l}.059 \\
106\end{array}$ & $\begin{array}{l}.009 \\
106\end{array}$ \\
\hline & \multirow{3}{*}{ Recursos } & $\begin{array}{l}\text { Coeficiente de } \\
\text { correlación }\end{array}$ & .153 & -.082 & -.068 & 1.000 & $.211^{*}$ & $301^{* *}$ \\
\hline & & Sig. (bilateral) & .117 & .405 & .489 & & .030 & .002 \\
\hline & & $\mathrm{N}$ & 106 & 106 & 106 & 106 & 106 & 106 \\
\hline & \multirow{2}{*}{ Procesos } & $\begin{array}{l}\text { Coeficiente de } \\
\text { correlación }\end{array}$ & .125 & $.194^{\circ}$ & .184 & $.211^{*}$ & 1.000 & $.533^{* *}$ \\
\hline & & $\begin{array}{l}\text { Sig. (bilateral) } \\
\mathrm{N}\end{array}$ & $\begin{array}{l}.201 \\
106\end{array}$ & $\begin{array}{l}.046 \\
106\end{array}$ & $\begin{array}{l}.059 \\
106\end{array}$ & $\begin{array}{l}.030 \\
106\end{array}$ & 106 & $\begin{array}{l}.000 \\
106\end{array}$ \\
\hline & \multirow{2}{*}{ Desemp.ExR } & $\begin{array}{l}\text { Coeficiente de } \\
\text { correlación }\end{array}$ & $.506^{* *}$ & $.354^{* *}$ & $.254^{* *}$ & $.301^{* *}$ & $.533^{* *}$ & 1.000 \\
\hline & & $\begin{array}{l}\text { Sig. (bilateral) } \\
\mathrm{N}\end{array}$ & $\begin{array}{l}.000 \\
106\end{array}$ & $\begin{array}{l}.000 \\
106\end{array}$ & $\begin{array}{l}.009 \\
106\end{array}$ & $\begin{array}{l}.002 \\
106\end{array}$ & $\begin{array}{l}.000 \\
106\end{array}$ & 106 \\
\hline
\end{tabular}

*: La correlación es significativa en el nivel 0.01 (bilateral); *. La correlación es significativa en el nivel 0,05 (bilateral).

Elaboración: Raymundo y Paúcar (2020) - Extraido de SPSS 22 


\subsubsection{Contrastación de las hipótesis}

Para la contrastación de hipótesis se utilizó el coeficiente de correlación Rho de Spearman, con lo cual se pudo ratificar los resultados que se han conseguido.

\subsubsection{Hipótesis general.}

La gestión de la calidad total se relaciona con el desempeño de las empresas MYPES exportadoras de quinua del Perú 2020.

i. Planteamiento de las hipótesis

$\mathrm{H}_{0}: \rho=0$, (La gestión de la calidad total NO se relaciona con el desempeño de las empresas MYPES exportadoras de quinua del Perú 2020)

$\mathrm{H}_{1}: \rho \neq 0$, (La gestión de la calidad total SI se relaciona con el desempeño de las empresas MYPES exportadoras de quinua del Perú 2020)

ii. Nivel de significancia $(\alpha)$

Nivel de significancia que se toma en cuenta: $\alpha=0.05$.

iii. Cálculo del estadístico de prueba:

Tabla 58:

Hipótesis general - Resultado de Rho de Spearman

\begin{tabular}{|c|c|c|c|}
\hline & & & Desemp Exp \\
\hline & & Coeficiente de correlación & $.747^{* *}$ \\
\hline \multirow[t]{2}{*}{ Spearman's tho } & Gest_Cal_Iotal & Sig. (bilateral) & .000 \\
\hline & & $\mathrm{N}$ & 106 \\
\hline
\end{tabular}

Elaboración: Raymundo y Paúcar (2020) - Extraido de SPSS 22

iv. Toma de decisiones

Existe evidencia estadística para Rho dado que el nivel de significancia es menor a 0.05 ( $\mathrm{r}=$ 0.747; p_valor $=0.000<0.05)$, afirmando que la gestión de la calidad total si se relaciona con el desempeño de las empresas MYPES exportadoras de quinua del Perú. 


\subsubsection{Primera hipótesis específica.}

El liderazgo se relaciona con el desempeño de las empresas MYPES exportadoras de quinua del Perú 2020.

i. Planteamiento de las hipótesis

$\mathrm{H}_{0}: \rho=0$, (El liderazgo NO se relaciona con el desempeño de las empresas MYPES exportadoras de quinua del Perú 2020)

$\mathrm{H}_{1}: \rho \neq 0$, (El liderazgo SI se relaciona con el desempeño de las empresas MYPES exportadoras de quinua del Perú 2020)

ii. $\quad$ Nivel de significancia $(\alpha)$

Nivel de significancia que se toma en cuenta: $\alpha=0.05$.

iii. Cálculo del estadístico de prueba:

Tabla 59:

Primera hipótesis específica - Resultado de Rho de Spearman

\begin{tabular}{|c|c|c|c|}
\hline & & & Desemp Exp \\
\hline & & Coeficiente de correlación & $.506^{*}$ \\
\hline \multirow[t]{2}{*}{ Spearman's rho } & Liderazgo & Sig. (bilateral) & .000 \\
\hline & & $\mathrm{N}$ & 106 \\
\hline
\end{tabular}

Elaboración: Raymundo y Paúcar (2020) - Extraido de SPSS 22

iv. Toma de decisiones

Existe evidencia estadística para Rho dado que el nivel de significancia es menor a $0.05(\mathrm{r}=$ 0.506; $p_{-}$valor $=0.000<0.05$ ), afirmando que el liderazgo si se relaciona con el desempeño de las empresas MYPES exportadoras de quinua del Perú. 


\subsubsection{Segunda hipótesis específica.}

La estrategia se relaciona con el desempeño de las empresas MYPES exportadoras de quinua del Perú 2020.

i. Planteamiento de las hipótesis

$\mathrm{H}_{0}: \rho=0$, (La estrategia NO se relaciona con el desempeño de las empresas MYPES exportadoras de quinua del Perú 2020)

$\mathrm{H}_{1}: \rho \neq 0$, (La estrategia SI se relaciona con el desempeño de las empresas MYPES exportadoras de quinua del Perú 2020)

ii. Nivel de significancia $(\alpha)$

Nivel de significancia que se toma en cuenta: $\alpha=0.05$.

iii. Cálculo del estadístico de prueba:

Tabla 60:

Segunda hipótesis específica - Resultado de Rho de Spearman

\begin{tabular}{lllc}
\hline & & Desemp. Exp \\
\hline \multirow{3}{*}{ Spearman's rho } & \multirow{3}{*}{ Estrategia } & Coeficiente de correlación & $.354^{* *}$ \\
& & Sig. (bilateral) & .000 \\
& $\mathrm{~N}$ & 106 \\
\hline
\end{tabular}

Elaboración: Raymundo y Paúcar (2020) - Extraído de SPSS 22

iv. Toma de decisiones

Existe evidencia estadística para Rho dado que el nivel de significancia es menor a 0.05 ( $\mathrm{r}=$ $0.354 ;$ p_valor $=0.000<0.05)$, afirmando que la estrategia si se relaciona con el desempeño de las empresas MYPES exportadoras de quinua del Perú. 


\subsubsection{Tercera hipótesis específica.}

Las personas se relacionan con el desempeño de las empresas MYPES exportadoras de quinua del Perú 2020.

i. Planteamiento de las hipótesis

$\mathrm{H}_{0}: \rho=0$, (Las personas NO se relaciona con el desempeño de las empresas MYPES exportadoras de quinua del Perú 2020)

$\mathrm{H}_{1}: \rho \neq 0$, (Las personas SI se relaciona con el desempeño de las empresas MYPES exportadoras de quinua del Perú 2020)

ii. Nivel de significancia $(\alpha)$

Nivel de significancia que se toma en cuenta: $\alpha=0.05$.

iii. Cálculo del estadístico de prueba:

Tabla 61:

Tercera hipótesis específica - Resultado de Rho de Spearman

\begin{tabular}{llcc}
\hline & & Desemp. Exp \\
\hline & & Coeficiente de correlación & $.254^{* *}$ \\
Spearman's rho & Personas & Sig. (bilateral) & .009 \\
& & $\mathrm{~N}$ & 106 \\
\hline
\end{tabular}

Elaboración: Raymundo y Paúcar (2020) - Extraido de SPSS 22

iv. Toma de decisiones

Existe evidencia estadística para Rho dado que el nivel de significancia es menor a 0.05 ( $\mathrm{r}=$ 0.254 ; p_valor $=0.009<0.05)$, afirmando que las personas si se relacionan con el desempeño de las empresas MYPES exportadoras de quinua del Perú. 


\subsubsection{Cuarta hipótesis específica.}

Los recursos se relacionan con el desempeño de las empresas MYPES exportadoras de quinua del Perú 2020.

i. Planteamiento de las hipótesis

$\mathrm{H}_{0}: \rho=0$, (Los recursos NO se relacionan con el desempeño de las empresas MYPES exportadoras de quinua del Perú 2020)

$\mathrm{H}_{1}: \rho \neq 0$, (Los recursos SI se relacionan con el desempeño de las empresas MYPES exportadoras de quinua del Perú 2020)

ii. Nivel de significancia $(\alpha)$

Nivel de significancia que se toma en cuenta: $\alpha=0.05$.

iii. Cálculo del estadístico de prueba:

Tabla 62:

Cuarta hipótesis específica - Resultado de Rho de Spearman

\begin{tabular}{llcc}
\hline & & Desemp.Exp \\
\hline \multirow{3}{*}{ Spearman's rho } & \multirow{2}{*}{ Recursos } & Coeficiente de correlación & $.301^{* *}$ \\
& & Sig. (bilateral) & .002 \\
& $\mathrm{~N}$ & 106 \\
\hline
\end{tabular}

Elaboración: Raymundo y Paúcar (2020) - Extraído de SPSS 22

iv. Toma de decisiones

Existe evidencia estadística para Rho dado que el nivel de significancia es menor a 0.05 ( $\mathrm{r}=$ 0.301 ; p_valor $=0.002<0.05)$, afirmando que los recursos si se relacionan con el desempeño de las empresas MYPES exportadoras de quinua del Perú. 


\subsubsection{Quinta hipótesis específica.}

Los procesos se relacionan con el desempeño de las empresas MYPES exportadoras de quinua del Perú 2020.

i. Planteamiento de las hipótesis

$\mathrm{H}_{0}: \rho=0$, (Los procesos NO se relaciona con el desempeño de las empresas MYPES exportadoras de quinua del Perú 2020)

$\mathrm{H}_{1}: \rho \neq 0$, (Los procesos SI se relaciona con el desempeño de las empresas MYPES exportadoras de quinua del Perú 2020)

ii. Nivel de significancia $(\alpha)$

Nivel de significancia que se toma en cuenta: $\alpha=0.05$.

iii. Cálculo del estadístico de prueba:

Tabla 63:

Quinta hipótesis específica - Resultado de Rho de Spearman

\begin{tabular}{lllc}
\hline & & Desemp Exp \\
\hline \multirow{3}{*}{ Spearman's rho } & \multirow{2}{*}{ Procesos } & Coeficiente de correlación & $.533^{* *}$ \\
& & Sig. (bilateral) & .000 \\
& & $\mathrm{~N}$ & 106 \\
\hline
\end{tabular}

Elaboración: Raymundo y Paúcar (2020) - Extraido de SPSS 22

iv. Toma de decisiones

Existe evidencia estadística para Rho dado que el nivel de significancia es menor a 0.05 ( $\mathrm{r}=$ 0.533 ; p_valor $=0.000<0.05)$, afirmando que los procesos si se relaciona con el desempeño de las empresas MYPES exportadoras de quinua del Perú. 


\subsection{Discusión}

En la presente investigación que lleva como título "Relación entre gestión de la calidad total y desempeño de las empresas MYPES exportadoras de quinua, Perú 2020” se logró desarrollar dos cuestionarios, los cuales se aplicaron a cada administrador y/o gerente de las empresas MYPES exportadoras de quinua del Perú, en cuanto a la relación entre las variables tomadas en cuenta: el cuestionario de gestión de la calidad total y el cuestionario de desempeño exportador en ambos casos los cuestionarios les pertenecen a los investigadores Imran, Hamid y Aziz (2018). Ambos cuestionarios se aplicaron con el fin de comprobar la relación entre la gestión de la calidad total y el desempeño exportador de las mismas empresas MYPES exportadoras. Los resultados conseguidos basados en los dos cuestionarios presentan semejanzas con otros resultados alcanzados por diferentes investigadores como se muestra a continuación.

\section{Hipótesis general}

Según los resultados alcanzados en la presente investigación, la hipótesis general "La gestión de la calidad total se relaciona con el desempeño de las empresas MYPES exportadoras de quinua del Perú 2020" es aprobada, en otras palabras, basados en que la gestión de la calidad total posee un coeficiente de correlación de Rho de Spearman de $r=0.747$; p_valor $=0.000<$ 0.05, por ende, la gestión de la calidad total si se relaciona con el desempeño empresas MYPES exportadoras de quinua del Perú, por tal la hipótesis general se aprueba. En seguida, se realiza la comparación con investigaciones de diferentes autores que obtuvieron el mismo resultado, como en la investigación de Jonah, Ornguga \& Torsen (2016) quienes lograron el mismo resultado, haciendo énfasis en que la gestión de la calidad total si se relaciona con el desempeño exportador.

\section{Primera hipótesis específica}


Según los resultados alcanzados en la presente investigación, la primera hipótesis específica "El liderazgo se relaciona con el desempeño de las empresas MYPES exportadoras de quinua del Perú 2020" es aprobada, en otras palabras, basados en que el liderazgo tiene un coeficiente de correlación de Rho de Spearman de r $=0.506 ; p_{-}$valor $=0.000<0.05$, por ende, el liderazgo si se relaciona con el desempeño empresas MYPES exportadoras de quinua del Perú, por tal la primera hipótesis específica se aprueba. En seguida, se realiza la comparación con investigaciones de diferentes autores que obtuvieron el mismo resultado, como en la investigación de Imran, Aziz, Hamid, Shabbir, Salman y Jian (2018) quienes obtuvieron el mismo resultado, haciendo énfasis en que el liderazgo si se relaciona con el desempeño exportador.

\section{Segunda hipótesis específica}

Según los resultados alcanzados en la presente investigación, la segunda hipótesis específica "La estrategia se relaciona con el desempeño de las empresas MYPES exportadoras de quinua del Perú 2020 " es aprobada, en otras palabras, basados en que la estrategia tiene un coeficiente de correlación de Rho de Spearman de $r=0.354 ;$ p_valor $=0.000<0.05$, por ende, la estrategia si se relaciona con el desempeño empresas MYPES exportadoras de quinua del Perú, por tal la segunda hipótesis específica se aprueba. En seguida, se realiza la comparación con investigaciones de diferentes autores que obtuvieron el mismo resultado, como en la investigación de Abeykoon y De Alwis (2015) quienes obtuvieron el mismo resultado, haciendo énfasis en que la estrategia si se relaciona con el desempeño exportador.

\section{Tercera hipótesis específica}

Según los resultados alcanzados en la presente investigación, la tercera hipótesis específica "Las personas se relacionan con el desempeño de las empresas MYPES exportadoras de quinua 
del Perú 2020" es aprobada, en otras palabras, basados en que las personas tiene un coeficiente de correlación de Rho de Spearman de $r=0.254$; $p_{-}$valor $=0.009<0.05$, por ende, las personas si se relacionan con el desempeño empresas MYPES exportadoras de quinua del Perú, por tal la tercera hipótesis específica se aprueba. En seguida, se realiza la comparación con investigaciones de diferentes autores que obtuvieron el mismo resultado, como en la investigación de Tahir, Batool y Takrim (2016) quienes obtuvieron el mismo resultado, haciendo énfasis en que las personas si se relacionan con el desempeño exportador.

\section{Cuarta hipótesis específica}

Según los resultados alcanzados en la presente investigación, la cuarta hipótesis específica "Los recursos se relacionan con el desempeño de las empresas MYPES exportadoras de quinua del Perú 2020" es aprobada, en otras palabras, basados en que los recursos tiene un coeficiente de correlación de Rho de Spearman de r $=0.301 ; p_{-}$valor $=0.002<0.05$, por ende, los recursos si se relacionan con el desempeño empresas MYPES exportadoras de quinua del Perú, por tal la cuarta hipótesis específica se aprueba. En seguida, se realiza la comparación con investigaciones de diferentes autores que obtuvieron el mismo resultado, como en la investigación de Imran, Hamid y Aziz (2018) quienes obtuvieron el mismo resultado, haciendo énfasis en que los recursos si se relacionan con el desempeño exportador.

\section{Quinta hipótesis específica}

Según los resultados alcanzados en la presente investigación, la quinta hipótesis específica "Los procesos se relacionan con el desempeño de las empresas MYPES exportadoras de quinua del Perú 2020" es aprobada, en otras palabras, basados en que los procesos tiene un coeficiente de correlación de Rho de Spearman de $r=0.533$; $p \_$valor $=0.000<0.05$, por ende, los procesos si se relacionan con el desempeño empresas MYPES exportadoras de quinua del Perú, por tal la 
quinta hipótesis específica se aprueba. En seguida, se realiza la comparación con investigaciones de diferentes autores que obtuvieron el mismo resultado, como en la investigación de Gharakhani, Rahmati, Farrokhi y Farahmandian (2013) quienes obtuvieron el mismo resultado, haciendo énfasis en que los procesos si se relacionan con el desempeño exportador.

\subsection{Conclusiones}

De acuerdo con los resultados alcanzados en la presente investigación, basados en los cuestionarios de gestión de la calidad total y el desempeño exportador, se llega a las siguientes conclusiones.

1) La gestión de la calidad total es un factor importante para que el desempeño de las empresas MYPES exportadoras de quinua del Perú crezca. Por tal motivo en la presente investigación se ratifica que la gestión de la calidad total si se relaciona con el desempeño exportador, con lo que se afirma que si las empresas MYPES exportadoras de quinua del Perú llegaran a mejorar sus productos, procesos y servicios para obtener la satisfacción de sus clientes a bajo costo, el desempeño exportador mejoraría igualmente. Basados en los datos recolectados de los cuestionarios, y después de obtener los resultados mediante el Rho de Spearman, se corrobora que, la gestión de la calidad total se relaciona con el desempeño de las empresas MYPES exportadoras de quinua del Perú por ende, se ratifica la hipótesis planteada.

2) El liderazgo es un elemento importante para que el desempeño de las empresas MYPES exportadoras de quinua del Perú crezca. Por tal motivo en la presente investigación se ratifica que el liderazgo si se relaciona con el desempeño exportador, con lo que se afirma que si las empresas MYPES exportadoras de quinua del Perú 
llegaran a tener líderes que desarrollen y faciliten la obtención de la misión y visión de la empresa, el desempeño exportador mejoraría igualmente. Basados en los datos recolectados de los cuestionarios, y después de obtener los resultados mediante el Rho de Spearman, se corrobora que, el liderazgo se relaciona con el desempeño de las empresas MYPES exportadoras de quinua del Perú por ende, se ratifica la hipótesis planteada.

3) La estrategia es importante para que el desempeño de las empresas MYPES exportadoras de quinua del Perú crezca. Por tal motivo en la presente investigación se ratifica que la estrategia si se relaciona con el desempeño exportador, con lo que se afirma que si las empresas MYPES exportadoras de quinua del Perú llegaran a implementar la misión y visión por medio del desarrollo de una estrategia centrada en las partes interesadas tomando en cuenta al mercado y sector donde operan, el desempeño exportador mejoraría igualmente. Basados en los datos recolectados de los cuestionarios, y después de obtener los resultados mediante el Rho de Spearman, se corrobora que, la estrategia se relaciona con el desempeño de las empresas MYPES exportadoras de quinua del Perú por ende, se ratifica la hipótesis planteada.

4) Las personas son importantes para que el desempeño de las empresas MYPES exportadoras de quinua del Perú crezca. Por tal motivo en la presente investigación se ratifica que las personas si se relacionan con el desempeño exportador, con lo que se afirma que si las empresas MYPES exportadoras de quinua del Perú llegaran a administrar, desarrollar y liberar el potencial de los empleados a nivel individual, de equipo y organizacional, el desempeño exportador mejoraría igualmente. Basados en los datos recolectados de los cuestionarios, y después de obtener los resultados 
mediante el Rho de Spearman, se corrobora que, las personas se relacionan con el desempeño de las empresas MYPES exportadoras de quinua del Perú por ende, se ratifica la hipótesis planteada.

5) Los recursos son importantes para que el desempeño de las empresas MYPES exportadoras de quinua del Perú crezca. Por tal motivo en la presente investigación se ratifica que los recursos si se relacionan con el desempeño exportador, con lo que se afirma que si las empresas MYPES exportadoras de quinua del Perú llegaran a tener líderes que desarrollen y faciliten la obtención de la misión y visión de la empresa, el desempeño exportador mejoraría igualmente. Basados en los datos recolectados de los cuestionarios, y después de obtener los resultados mediante el Rho de Spearman, se corrobora que, los recursos se relacionan con el desempeño de las empresas MYPES exportadoras de quinua del Perú por ende, se ratifica la hipótesis planteada.

6) Los procesos son un elemento importante para que el desempeño de las empresas MYPES exportadoras de quinua del Perú crezca. Por tal motivo en la presente investigación se ratifica que los procesos si se relacionan con el desempeño exportador, con lo que se afirma que si las empresas MYPES exportadoras de quinua del Perú llegaran a diseñar, gestionar y mejorar los procesos para satisfacer plenamente y generar un valor creciente para los clientes y otras partes interesadas, el desempeño exportador mejoraría igualmente. Basados en los datos recolectados de los cuestionarios, y después de obtener los resultados mediante el Rho de Spearman, se corrobora que, los procesos se relacionan con el desempeño de las empresas MYPES exportadoras de quinua del Perú por ende, se ratifica la hipótesis planteada. 


\subsection{Recomendaciones}

1) A las empresas MYPES exportadoras de quinua se les recomienda implementar sistemas de gestión de la calidad para poder desarrollar o fortalecer la capacidad exportadora, para esto deberán de capacitarse mediante programas de gestión de la calidad ofrecidos por ejemplo por PROMPERÚ, el cual abarca la capacitación y asistencia técnica y es financiado por el mismo PROMPERÚ.

2) A los líderes de las empresas MYPES exportadoras de quinua se les recomienda establecer valores comunes y modelos éticos en toda la empresa, para esto deberán de infundir un sentido de valores y ética (ya establecidos en la misión de la empresa) actuando como modelos para inspirar a los empleados a ser parte de las iniciativas de gestión de calidad basadas en estos valores comunes.

3) A las empresas MYPES exportadoras de quinua se les recomienda elaborar estrategias adecuadas para la empresa, para esto deberán de tomar en cuenta los aspectos externos que se consideren útiles para poder definir estas estrategias, logrando identificar y analizar las expectativas y necesidades de los grupos de interés que puedan afectar o verse afectados o puedan afectar a la empresa.

4) A las empresas MYPES exportadoras de quinua se les recomienda involucrar a los empleados en la gestión de la calidad, para esto deberán de explicar cuales son los beneficios de manera clara, dado que conociendo cuales son estos beneficios se podrá contar con una eficaz gestión de la calidad para que puedan participar de manera adecuada en todas las etapas de dicha gestión.

5) A las empresas MYPES exportadoras de quinua se les recomienda planificar y gestionar alianzas externas y sus recursos internos en apoyo de la política y estrategia 
y del eficaz funcionamiento de sus procesos, para esto deberán identificar las oportunidades para establecer alianzas importantes con proveedores de acuerdo con las políticas, estrategias y la misión de la empresa.

6) A las empresas MYPES exportadoras de quinua se les recomienda planificar, depurar y controlar los procesos en la empresa, para esto deberán de constituir una óptima estrategia para mejorar la gestión de la calidad, dado que sirve para aumentar el desempeño, así como el analizar de manera regular acerca de la calidad que percibe el cliente y las alternativas de mejorar los servicios que reciben 


\section{Referencias bibliográficas}

Abeykoon, M. W. B., \& De Alwis, C. (2015). The Impact of Total Quality Management Practices on Export Performance of Apparel Exporters in Sri Lanka.

Agrodata Perú (2019). "Exportación de quinua" Recuperado de: https://www.agrodataperu.com/category/exportaciones/quinua-exportacion

Agrodata Perú (2020). Recuperado de: https://www.agrodataperu.com/

Ambrosini, V., \& Bowman, C. (2009). What are dynamic capabilities and are they a useful construct in strategic management?. International journal of management reviews, 11(1), $29-49$.

Barney, J. (1991). Firm resources and sustained competitive advantage. Journal of management, 17(1), 99-120.

Barney, J. B. (2001). Resource-based theories of competitive advantage: A ten-year retrospective on the resource-based view. Journal of management, 27(6), 643-650.

Bon, A. T., \& Mustafa, E. M. (2013). Impact of total quality management on innovation in service organizations: Literature review and new conceptual framework. Procedia Engineering, 53(0), 516-529.

Cavusgil, S. T., \& Zou, S. (1994). Marketing strategy-performance relationship: an investigation of the empirical link in export market ventures. Journal of marketing, 58(1), 1-21.

Chang, S. J., \& Rosenzweig, P. M. (2001). The choice of entry mode in sequential foreign direct investment. Strategic management journal, 22(8), 747-776.

Collis, D. J. (1991). A resource-based analysis of global competition: the case of the bearings industry. Strategic management journal, 12(S1), 49-68. 
Dutta, S., Zbaracki, M. J., \& Bergen, M. (2003). Pricing process as a capability: A resourcebased perspective. Strategic management journal, 24(7), 615-630.

El Shenawy, E., Baker, T., \& Lemak, D. J. (2007). A meta-analysis of the effect of TQM on competitive advantage. International Journal of Quality \& Reliability Management.

Gharakhani, D., Rahmati, H., Farrokhi, M. R., \& Farahmandian, A. (2013). Total quality management and organizational performance. American Journal of Industrial Engineering, 1(3), 46-50.

Goh, P. L. \& Ridgway, K. (1994). The implementation of total quality management in small and medium-sized manufacturing companies. The TQM magazine.

Hernández, R., Fernández, C., \& Baptista, P. (2014). Metodología de la investigación. México: Editorial Mc Graw Hill.

Hofer, C. W., \& Schendel, D. E. (1978). Strategy formulation: Analysis and concepts. St. Paul, MN: West Publishing.

Imran, M., \& Khaliq, M. (2019). The Influence of Total Quality Management and Export Market Orientation on company export performance of Furniture Industry in Pakistan: A moderating role of Business Network. In Third Padang International Conference On Economics Education, Economics, Business and Management, Accounting and Entrepreneurship (PICEEBA 2019). Atlantis Press.

Imran, M., Aziz, A., \& Hamid, S. (2017). Total quality management, export market orientation and firm export performance: A conceptual framework. International Journal of Academic Research in Business and Social Sciences, 7(9), 591-601. 
Imran, M., Aziz, A., Hamid, S., Shabbir, M., Salman, R., \& Jian, Z. (2018). The mediating role of total quality management between entrepreneurial orientation and SMEs export performance. Management Science Letters, 8(6), 519-532.

Imran, M., binti Abdul Hamid, S. N., \& binti Aziz, A. (2017). Total quality management, export market orientation and firm export performance: A Conceptual Framework. International Journal of Academic Research in Business and Social Sciences, 7(9), 591601.

Imran, M., binti Aziz, A., \& binti Abdul Hamid, S. N. (2016). Moderating role of environmental turbulence on the relationship between enterpreneural orientation, business networks orientation, export market orientation and SMEs export performance: A research framework. Journal of Business Management, Commerce \& Research,6(15).

Imran, M., binti Aziz, A., \& binti Abdul Hamid, S. N. (2017). The relationship between entrepreneurial orientation, business networks orientation, export market orientation and SME export performance: A proposed research framework. International Journal of Academic Research in Business and Social Sciences, 7(10), 230-248.

Imran, M., Hamid, S., \& Aziz, A. (2018). The influence of TQM on export performance of SMEs: Empirical evidence from manufacturing sector in Pakistan using PLSSEM. Management Science Letters, 8(5), 483-496.

Iqbal, T., Huq, F., \& Bhutta, M. K. S. (2018). Agile manufacturing relationship building with TQM, JIT, and firm performance: An exploratory study in apparel export industry of Pakistan. International Journal of Production Economics, 203, 24-37. 
Jonah, N., Ornguga, I, G., Torsen, E. (2016). The Effect of Total 4 Quality Management (TQM) on the Organizational Growth of Adama Beverages: 5 A Marketing Mix Perspective. International Journal of Science and Research, 7, 7, 1096- 61102

Lages, L. F., Silva, G., \& Styles, C. (2009). Relationship capabilities, quality, and innovation as determinants of export performance. Journal of international Marketing, 17(4), 47-70.

Lizarzaburu, E. (2016). La gestión de la calidad en Perú: un estudio de la norma ISO 9001, sus beneficios y los principales cambios en la versión 2015. Revista Universidad y Empresa, 18(30), 33-54.

Mahmud, N., \& Hilmi, M. F. (2014). TQM and Malaysian SMEs performance: The mediating roles of organization learning. Procedia-Social and Behavioral Sciences, 130, 216-225.

MINAGRI (2019). "Perú se consolida como primer exportador de quinua". Recuperado de: https://www.gob.pe/institucion/minagri/noticias/29672-peru-se-consolida-comoprimer-exportador-de-quinua

MINAGRI (2020) Recuperado de: https://www.gob.pe/minagri

Morgan, N. A., Kaleka, A., \& Katsikeas, C. S. (2004). Antecedents of export venture performance: A theoretical model and empirical assessment. Journal of marketing, 68(1), 90-108.

Phatak, A. (1998). International management, concepts and cases. Cincinnati, OH: Southwestern Publishing.

Prange, C., \& Verdier, S. (2011). Dynamic capabilities, internationalization processes and performance. Journal of World Business, 46(1), 126-133.

Sadikoglu, E., \& Zehir, C. (2010). Investigating the effects of innovation and employee performance on the relationship between total quality management practices and firm 
performance: An empirical study of Turkish firms. International journal of production economics, 127(1), 13-26.

Scheaffer, R. L., Mendenhall, W., \& Ott, L. (2006). Elementos de muestreo. Editorial Paraninfo. Shafiq, M., Lasrado, F., \& Hafeez, K. (2019). The effect of TQM on organisational performance: empirical evidence from the textile sector of a developing country using SEM. Total Quality Management \& Business Excellence, 30(1-2), 31-52.

SIICEX (2020).

Recuperado

de: http://www.siicex.gob.pe/siicex/portal5ES.asp?_page_=172.17100\&_portletid_=sficha productoinit\&scriptdo=cc_fp_init\&pproducto=\%20179\%20\&pnomproducto=\%20Qui nua

Sorokina, V. (2012). Factors influencing export performance: A study of Swedish companies exporting to Russia.

Tahir, M., Batool, S., \& Takrim, K. (2016). The Effects of Total Quality Management on Exports in Manufacturing Based Small and Medium Enterprise's: A Case Study of Organizations from Selected Regions of Pakistan. NUML International Journal of Business \& Management, 11(1), 173-197.

Teece, D. J. (2007). Explicating dynamic capabilities: the nature and microfoundations of (sustainable) enterprise performance. Strategic management journal, 28(13), 1319-1350.

Teece, D. J. (2014). A dynamic capabilities-based entrepreneurial theory of the multinational enterprise. Journal of international business studies, 45(1), 8-37.

Trade

Map

(2020).

Recuperado

de:

https://www.trademap.org/Country_SelProductCountry_TS.aspx?nvpm=3\%7c604\%7c $\% 7 \mathrm{c} \% 7 \mathrm{c} \% 7 \mathrm{c} 100850 \% 7 \mathrm{c} \% 7 \mathrm{c} \% 7 \mathrm{c} 6 \% 7 \mathrm{c} 1 \% 7 \mathrm{c} 1 \% 7 \mathrm{c} 2 \% 7 \mathrm{c} 2 \% 7 \mathrm{c} 1 \% 7 \mathrm{c} 2 \% 7 \mathrm{c} 1 \% 7 \mathrm{c} 1$ 
Universidad San Ignacio de Loyola (2013). Guía para la presentación de proyectos e informes de tesis. Lima: Universidad San Ignacio de Loyola, Centro de Investigación.

Universidad San Ignacio de Loyola (2017). Guía de estilo editorial USIL. Lima: Universidad San Ignacio de Loyola, Centro de Investigación.

Valos, M., \& Baker, M. (1996). Developing an Australian model of export marketing performance determinants. Marketing Intelligence \& Planning.

Vasquez, E. (2020). "Perú es 'primer exportador mundial de arándanos, espárragos y quinua".

Recuperado

de: https://www.elmercurio.com/Inversiones/Noticias/Noticias/2020/02/21/Peru-es-primerexportador-mundial-de-arandanos-esparragos-y-quinua--Mincetur.aspx

Voerman, J. A. (2003). The export performance of European SMEs. The Netherlands: Labyrint Publication.

Wernerfelt, B. (1984). A resource-based view of the firm. Strategic management journal, 5(2), $171-180$.

Zou, S., \& Stan, S. (1998). The determinants of export performance: a review of the empirical literature between 1987 and 1997. International marketing review. 


\section{Anexos}

\section{Anexo 1. Matriz de consistencia}

Tabla 64:

Matriz de consistencia

\begin{tabular}{|c|c|c|c|c|}
\hline PROBLEMA & OBJETIVOS & HIPOTESIS & VARIABLES & METODOLOGIA \\
\hline $\begin{array}{l}\text { Problema general } \\
\text { ¿Cómo se relaciona la } \\
\text { gestión de la calidad total } \\
\text { con el desempeño de las } \\
\text { empresas MYPES } \\
\text { exportadoras de quinua del } \\
\text { Perú } 2020 \text { ? } \\
\text { Problemas especificos } \\
\text { ¿Cómo se relaciona el } \\
\text { liderazgo con el desempeño } \\
\text { de las empresas MYPES } \\
\text { exportadoras de quinua del } \\
\text { Perú } 2020 \text { ? } \\
\text { ¿Cómo se relaciona la } \\
\text { estrategia y el desempeño } \\
\text { de las empresas MYPES } \\
\text { exportadoras de quinua del } \\
\text { Perú } 2020 \text { ? } \\
\text { ¿Cómo se relacionan las } \\
\text { personas con el desempeño } \\
\text { de las empresas MYPES } \\
\text { exportadoras de quinua del } \\
\text { Perú } 2020 \text { ? } \\
\text { ¿Cómo se relacionan los } \\
\text { recursos con el desempeño } \\
\text { de las empresas MYPES } \\
\text { exportadoras de quinua del } \\
\text { Perú } 2020 \text { ? } \\
\text { ¿ómo se relacionan los } \\
\text { procesos con el desempeño } \\
\text { de las empresas MYPES } \\
\text { exportadoras de quinua del } \\
\text { Perú } 2020 \text { ? }\end{array}$ & 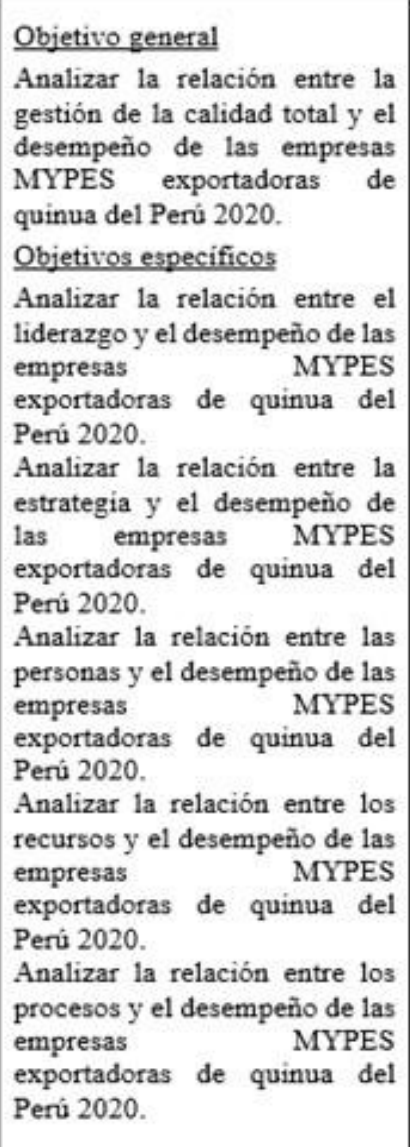 & $\begin{array}{l}\text { Hipótesis general } \\
\text { La gestión de la calidad total } \\
\text { se relaciona con el } \\
\text { desempeño de las empresas } \\
\text { MYPES exportadoras de } \\
\text { quinua del Perú } 2020 \text {. } \\
\text { Hipótesis especificas } \\
\text { E1 liderazgo se relaciona con } \\
\text { el desempeño de las empresas } \\
\text { MYPES exportadoras de } \\
\text { quinua del Perú } 2020 . \\
\text { La estrategia se relaciona con } \\
\text { el desempeño de las empresas } \\
\text { MYPES exportadoras de } \\
\text { quinua del Perú } 2020 \text {. } \\
\text { Las personas se relacionan } \\
\text { con el desempeño de las } \\
\text { empresas MYPES } \\
\text { exportadoras de quinua del } \\
\text { Perú } 2020 \text {. } \\
\text { Los recursos se relacionan } \\
\text { con el desempeño de las } \\
\text { empresas MYPES } \\
\text { exportadoras de quinua del } \\
\text { Perú } 2020 \text {. } \\
\text { Los procesos se relacionan } \\
\text { con el desempeño de las } \\
\text { empresas MYPES } \\
\text { exportadoras de quinua del } \\
\text { Perú } 2020 \text {. }\end{array}$ & $\begin{array}{l}\mathrm{X} 1 \text { : gestión de la calidad } \\
\text { total. } \\
\mathrm{X} 1 \mathrm{~A} \text { : liderazgo. } \\
\mathrm{X} 1 \mathrm{~B} \text { : estrategia. } \\
\mathrm{X} 1 \mathrm{C} \text { : personas. } \\
\mathrm{X} 1 \mathrm{D} \text { : recursos. } \\
\mathrm{X} 1 \mathrm{E} \text { : procesos. } \\
\mathrm{X} 2 \text { : desempeño exportador. } \\
\mathrm{X} 2 \mathrm{~A} \text { : financiero. } \\
\mathrm{X} 2 \mathrm{~B} \text { : estratégico. } \\
\mathrm{X} 2 \mathrm{C} \text { : satisfacción. }\end{array}$ & 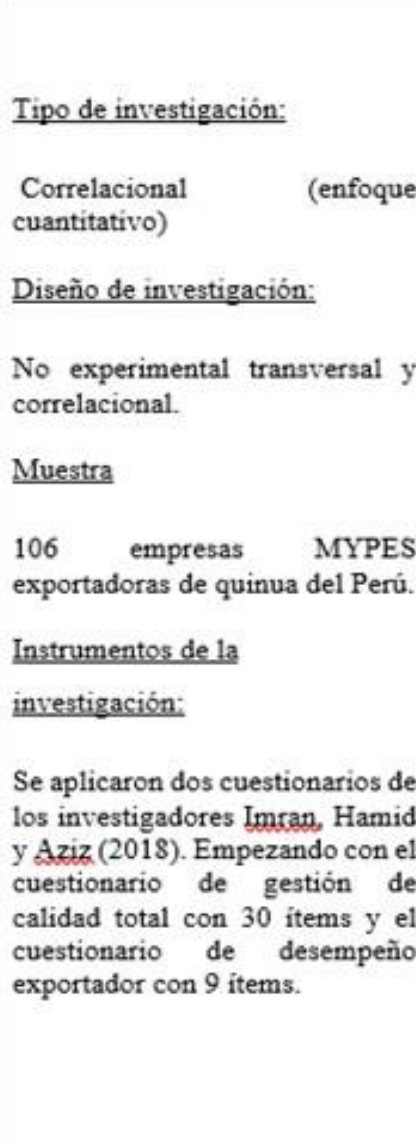 \\
\hline
\end{tabular}




\section{Anexo 2. Cuestionario}

Tabla 65:

Cuestionario de gestión de la calidad total

Tema: "RELACION ENTRE GESTION DE LA CALIDAD TOTAL Y DESEMPEÑO DE LAS EMPRESAS MYPES EXPORTADORAS DE QUINUA, PERÚ 2020”

VARIABLE: gestión de la calidad total

Instrucción:

En seguida, se muestra una serie de afirmaciones que se deben de responder por usted. Tiene que leer detalladamente cada afirmación, con el fin de marcar una sola opción con un X en la casilla que corresponde a la afirmación designada. Es esencial que sus respuestas sean con la total franqueza, dado que de esto dependerá el éxito de la presente investigación.

NOTA: Para cada pregunta se considera la escala de 1 a 5 donde:

\begin{tabular}{|c|c|c|c|c|}
\hline $\begin{array}{c}\text { Totalmente } \\
\text { en } \\
\text { desacuerdo }\end{array}$ & $\begin{array}{c}\text { En } \\
\text { desacuerdo }\end{array}$ & Neutral & De acuerdo & $\begin{array}{c}\text { Totalmente } \\
\text { de acuerdo }\end{array}$ \\
\hline
\end{tabular}

\begin{tabular}{|c|l|l|l|l|l|l|}
\hline Número & \multicolumn{1}{|c|}{ ITEM } & $\mathbf{1}$ & $\mathbf{2}$ & $\mathbf{3}$ & $\mathbf{4}$ & $\mathbf{5}$ \\
\hline $\mathbf{1}$ & $\begin{array}{l}\text { Los gerentes de nuestra empresa } \\
\text { consideran que el costo es más } \\
\text { importante en comparación con la } \\
\text { calidad de los productos. }\end{array}$ & & & & & \\
\hline $\mathbf{2}$ & $\begin{array}{l}\text { Los gerentes de nuestra empresa se } \\
\text { presentan como modelos a seguir para } \\
\text { los empleados. }\end{array}$ & & & & & \\
\hline $\mathbf{3}$ & $\begin{array}{l}\text { Los gerentes de nuestra empresa se } \\
\text { aseguran de que los empleados } \\
\text { conozcan los planes a largo plazo de la } \\
\text { empresa. }\end{array}$ & & & & & \\
\hline
\end{tabular}




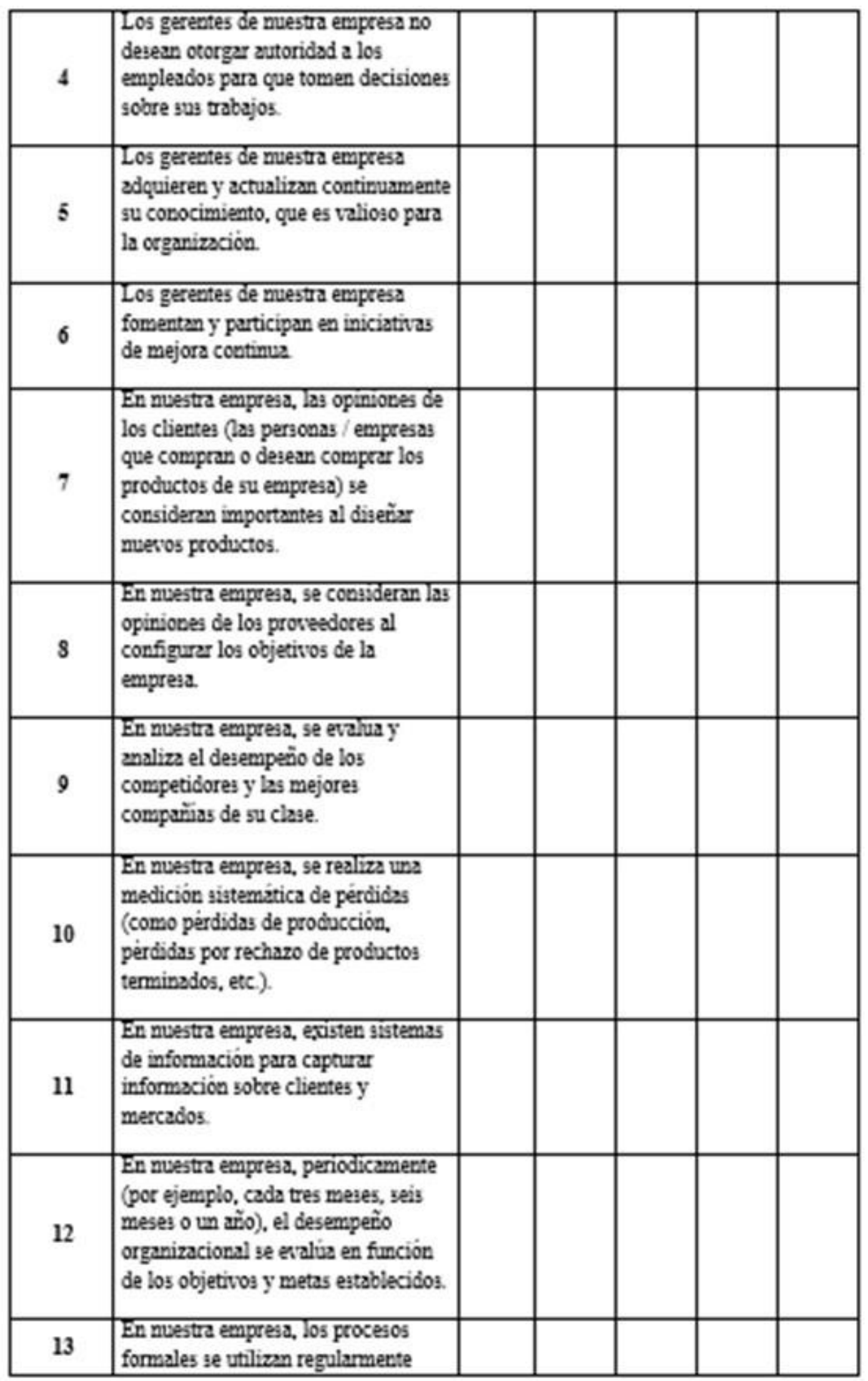




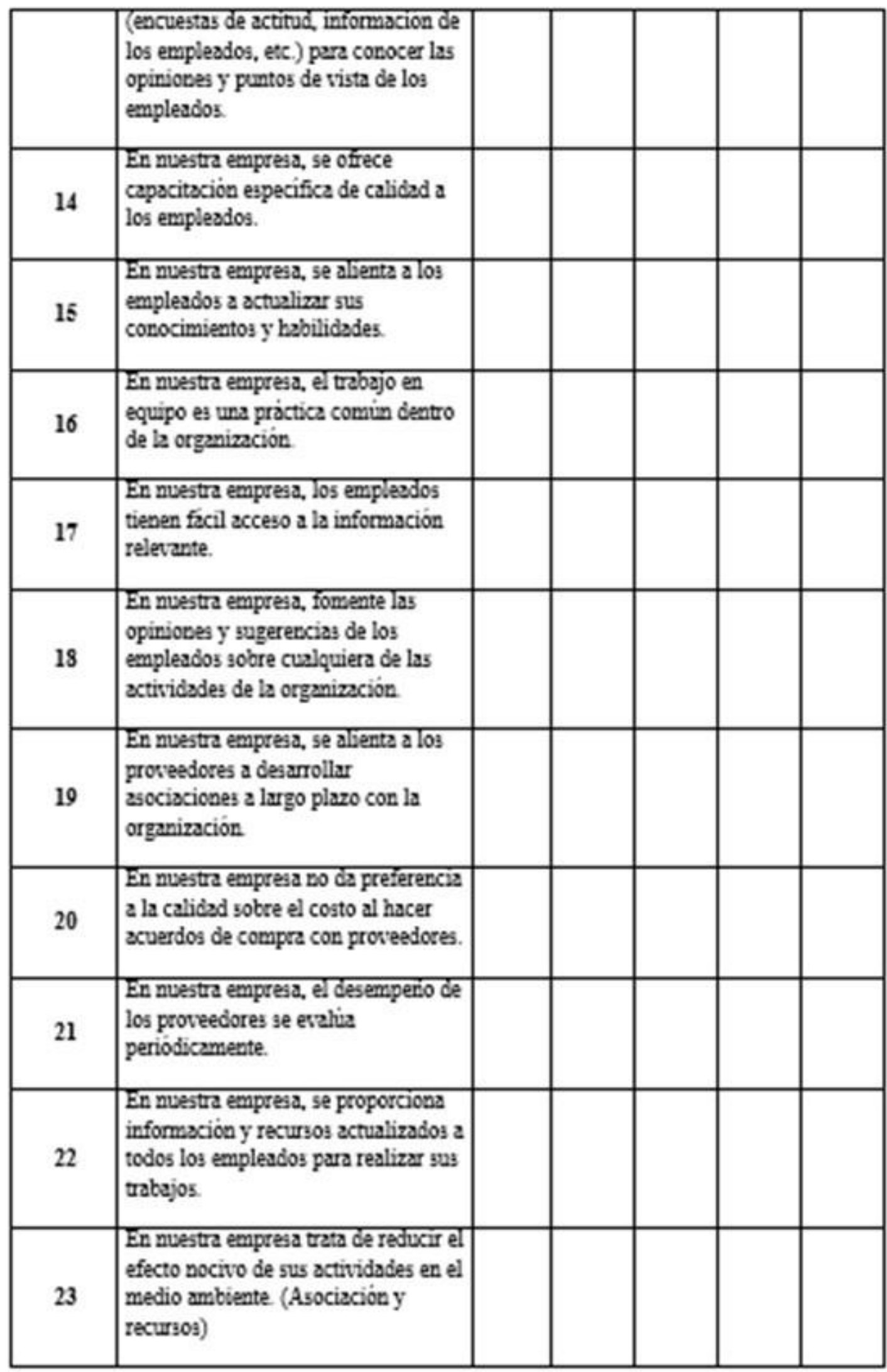




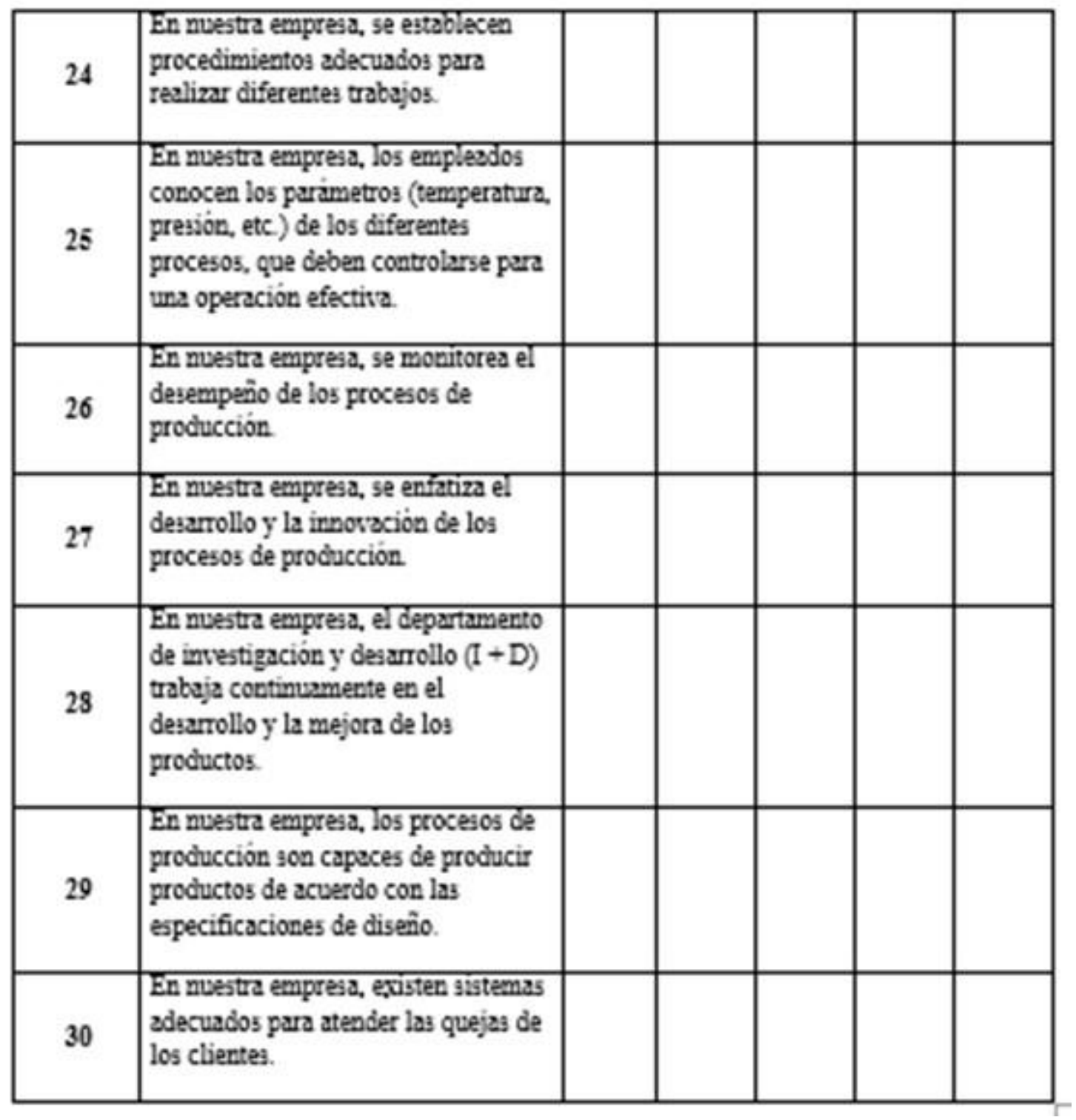


Tabla 66:

Cuestionario de desempeño exportador

\section{UNIVERSIDAD SAN IGNACIO DE LOYOLA}

\section{CARRERA: NEGOCIOS INTERNACIONALES}

\section{Tema: "RELACION ENTRE GESTION DE LA CALIDAD TOTAL Y DESEMPEÑO DE}

\section{LAS EMPRESAS MYPES EXPORTADORAS DE QUINUA, PERÚ 2020”}

VARIABLE: desempeño exportador

Instrucción:

A continuación, se presenta una serie de ítems para que sean respondidos por usted. Lea detenidamente cada enunciado, marque una sola alternativa con un $\mathrm{X}$ en la casilla correspondiente al enunciado elegido. Es fundamental su absoluta sinceridad dentro de las respuestas, pues de ellas depende el éxito de la presente investigación.

NOTA: Para cada pregunta se considera la escala de 1 a 5 donde:

\begin{tabular}{|c|c|c|c|c|}
\hline $\begin{array}{c}\text { Totalmente } \\
\text { en } \\
\text { desacuerdo }\end{array}$ & $\begin{array}{c}\text { En } \\
\text { desacuerdo }\end{array}$ & Neutral & De acuerdo & $\begin{array}{c}\text { Totalmente } \\
\text { de acuerdo }\end{array}$ \\
\hline
\end{tabular}

\begin{tabular}{|c|l|l|l|l|l|l|}
\hline Número & \multicolumn{1}{|c|}{ ITEM } & $\mathbf{1}$ & $\mathbf{2}$ & $\mathbf{3}$ & $\mathbf{4}$ & $\mathbf{5}$ \\
\hline $\mathbf{1}$ & $\begin{array}{l}\text { La exportación de la empresa ha sido } \\
\text { muy rentable. }\end{array}$ & & & & & \\
\hline $\mathbf{2}$ & $\begin{array}{l}\text { La exportación de la empresa ha } \\
\text { generado un alto volumen de ventas. }\end{array}$ & & & & & \\
\hline $\mathbf{3}$ & $\begin{array}{l}\text { La exportación de la empresa ha logrado } \\
\text { un rápido crecimiento. }\end{array}$ & & & & & \\
\hline $\mathbf{4}$ & $\begin{array}{l}\text { La exportación de la empresa ha } \\
\text { mejorado nuestra competitividad global. }\end{array}$ & & & & & \\
\hline
\end{tabular}




\begin{tabular}{|c|l|l|l|l|l|l|}
\hline $\mathbf{5}$ & $\begin{array}{l}\text { La exportación de la empresa ha } \\
\text { fortalecido nuestra posición estratégica. }\end{array}$ & & & & & \\
\hline $\mathbf{6}$ & $\begin{array}{l}\text { La exportación de la empresa ha } \\
\text { aumentado significativamente nuestra } \\
\text { participación en el mercado global. }\end{array}$ & & & & & \\
\hline 7 & $\begin{array}{l}\text { El desempeño de exportación de nuestra } \\
\text { firma ha sido satisfactorio. }\end{array}$ & & & & & \\
\hline 8 & $\begin{array}{l}\text { La exportación de la empresa ha sido } \\
\text { exitosa. }\end{array}$ & & & & & \\
\hline 9 & $\begin{array}{l}\text { La exportación de la empresa ha } \\
\text { cumplido plenamente nuestras } \\
\text { expectativas. }\end{array}$ & & & & & \\
\hline
\end{tabular}


Anexo 3. Coeficiente de Aiken

\begin{tabular}{|c|c|c|c|c|c|c|c|c|c|c|c|c|c|c|}
\hline \multirow{2}{*}{$\begin{array}{c}\text { JUECES } \\
\text { ITEM }\end{array}$} & \multicolumn{4}{|c|}{ JUEZ 1} & \multicolumn{4}{|c|}{ JUEZ 2} & \multicolumn{4}{|c|}{ JUEZ 3} & \multirow[b]{2}{*}{ SUMA } & \multirow[b]{2}{*}{ V AIKEN } \\
\hline & $\mathbf{C}$ & $\mathrm{CO}$ & $\mathrm{CON}$ & DC & $\mathbf{C}$ & $\mathrm{CO}$ & $\mathrm{CON}$ & DC & $\mathbf{C}$ & $\mathrm{CO}$ & $\mathrm{CON}$ & DC & & \\
\hline GCT1 & 3 & 3 & 4 & 4 & 4 & 4 & 4 & 4 & 4 & 4 & 4 & 4 & 46.00 & 0.77 \\
\hline GCT2 & 5 & 5 & 5 & 5 & 4 & 4 & 4 & 4 & 4 & 4 & 4 & 4 & 52.00 & 0.87 \\
\hline GCT3 & 5 & 5 & 5 & 5 & 5 & 5 & 5 & 5 & 4 & 4 & 4 & 4 & 56.00 & 0.93 \\
\hline GCT4 & 4 & 4 & 5 & 5 & 4 & 4 & 4 & 4 & 4 & 4 & 4 & 4 & 50.00 & 0.83 \\
\hline GCT5 & 5 & 5 & 5 & 4 & 4 & 4 & 4 & 4 & 4 & 4 & 4 & 4 & 51.00 & 0.85 \\
\hline GCT6 & 5 & 5 & 5 & 5 & 5 & 5 & 5 & 5 & 4 & 4 & 4 & 4 & 56.00 & 0.93 \\
\hline GCT7 & 3 & 3 & 3 & 3 & 5 & 5 & 5 & 5 & 4 & 4 & 4 & 4 & 48.00 & 0.80 \\
\hline GCT8 & 5 & 5 & 5 & 5 & 4 & 4 & 4 & 4 & 4 & 4 & 4 & 4 & 52.00 & 0.87 \\
\hline GCT9 & 5 & 5 & 5 & 5 & 4 & 4 & 4 & 4 & 4 & 4 & 4 & 4 & 52.00 & 0.87 \\
\hline GCT10 & 3 & 3 & 3 & 3 & 4 & 4 & 4 & 4 & 4 & 4 & 4 & 4 & 44.00 & 0.73 \\
\hline GCT11 & 5 & 5 & 5 & 5 & 5 & 5 & 5 & 5 & 4 & 4 & 4 & 4 & 56.00 & 0.93 \\
\hline GCT12 & 5 & 5 & 5 & 5 & 5 & 5 & 5 & 5 & 4 & 4 & 4 & 4 & 56.00 & 0.93 \\
\hline GCT13 & 5 & 5 & 5 & 5 & 4 & 4 & 4 & 4 & 4 & 4 & 4 & 4 & 52.00 & 0.87 \\
\hline GCT14 & 4 & 3 & 3 & 3 & 5 & 5 & 5 & 5 & 4 & 4 & 4 & 4 & 49.00 & 0.82 \\
\hline GCT15 & 5 & 5 & 5 & 5 & 4 & 4 & 4 & 4 & 4 & 4 & 4 & 4 & 52.00 & 0.87 \\
\hline GCT16 & 5 & 5 & 5 & 5 & 5 & 5 & 5 & 5 & 4 & 4 & 4 & 4 & 56.00 & 0.93 \\
\hline GCT17 & 3 & 3 & 3 & 3 & 5 & 5 & 5 & 5 & 4 & 4 & 4 & 4 & 48.00 & 0.80 \\
\hline GCT18 & 5 & 5 & 5 & 5 & 5 & 5 & 5 & 5 & 4 & 4 & 4 & 4 & 56.00 & 0.93 \\
\hline GCT19 & 3 & 3 & 3 & 3 & 5 & 5 & 5 & 5 & 4 & 4 & 4 & 4 & 48.00 & 0.80 \\
\hline GCT20 & 3 & 3 & 4 & 4 & 5 & 5 & 5 & 5 & 4 & 4 & 4 & 4 & 50.00 & 0.83 \\
\hline GCT21 & 5 & 5 & 5 & 5 & 4 & 4 & 4 & 4 & 4 & 4 & 4 & 4 & 52.00 & 0.87 \\
\hline GCT22 & 5 & 5 & 5 & 5 & 5 & 5 & 5 & 5 & 4 & 4 & 4 & 4 & 56.00 & 0.93 \\
\hline GCT23 & 4 & 4 & 4 & 5 & 4 & 4 & 4 & 4 & 4 & 4 & 4 & 4 & 49.00 & 0.82 \\
\hline GCT24 & 5 & 4 & 5 & 4 & 4 & 4 & 4 & 4 & 4 & 4 & 4 & 4 & 50.00 & 0.83 \\
\hline GCT25 & 3 & 3 & 3 & 3 & 4 & 4 & 4 & 4 & 4 & 4 & 4 & 4 & 44.00 & 0.73 \\
\hline
\end{tabular}




\begin{tabular}{lllllllllllllll} 
GCT26 & 5 & 5 & 5 & 5 & 5 & 5 & 5 & 5 & 4 & 4 & 4 & 4 & 56.00 & 0.93 \\
GCT27 & 5 & 5 & 5 & 5 & 4 & 4 & 4 & 4 & 4 & 4 & 4 & 4 & 52.00 & 0.87 \\
GCT28 & 4 & 4 & 3 & 4 & 4 & 4 & 4 & 4 & 4 & 4 & 4 & 4 & 47.00 & 0.78 \\
GCT29 & 3 & 4 & 3 & 4 & 4 & 4 & 4 & 4 & 4 & 4 & 4 & 4 & 46.00 & 0.77 \\
GCT30 & 4 & 4 & 4 & 4 & 5 & 5 & 5 & 5 & 4 & 4 & 4 & 4 & 52.00 & 0.87 \\
\hline
\end{tabular}

CLARIDAD: C; CONGRUENCIA: CO; CONTEXTO: CON; DOMINIO DE CONSTRUCTO: DC

\begin{tabular}{|c|c|c|c|c|c|c|c|c|c|c|c|c|c|c|}
\hline \multirow{2}{*}{$\begin{array}{c}\text { JUECES } \\
\text { ITEM }\end{array}$} & \multicolumn{4}{|c|}{ JUEZ 1} & \multicolumn{4}{|c|}{ JUEZ 2} & \multicolumn{4}{|c|}{ JUEZ 3} & \multirow[b]{2}{*}{ SUMA } & \multirow[b]{2}{*}{ V AIKEN } \\
\hline & C & $\mathrm{CO}$ & $\mathrm{CON}$ & DC & C & $\mathrm{CO}$ & $\mathrm{CON}$ & DC & $\mathbf{C}$ & $\mathrm{CO}$ & $\mathrm{CON}$ & DC & & \\
\hline DE1 & 5 & 5 & 5 & 5 & 4 & 4 & 4 & 4 & 4 & 4 & 4 & 4 & 52.00 & 0.87 \\
\hline DE2 & 5 & 5 & 5 & 5 & 4 & 4 & 4 & 4 & 4 & 4 & 4 & 4 & 52.00 & 0.87 \\
\hline DE3 & 5 & 5 & 5 & 5 & 5 & 5 & 5 & 5 & 4 & 4 & 4 & 4 & 56.00 & 0.93 \\
\hline DE4 & 5 & 5 & 5 & 5 & 4 & 4 & 4 & 4 & 4 & 4 & 4 & 4 & 52.00 & 0.87 \\
\hline DE5 & 4 & 4 & 4 & 4 & 4 & 4 & 4 & 4 & 4 & 4 & 4 & 4 & 48.00 & 0.80 \\
\hline DE6 & 4 & 4 & 4 & 4 & 5 & 5 & 5 & 5 & 4 & 4 & 4 & 4 & 52.00 & 0.87 \\
\hline DE7 & 4 & 4 & 4 & 4 & 5 & 5 & 5 & 5 & 4 & 4 & 4 & 4 & 52.00 & 0.87 \\
\hline DE8 & 4 & 4 & 4 & 4 & 5 & 5 & 5 & 5 & 4 & 4 & 4 & 4 & 52.00 & 0.87 \\
\hline DE9 & 5 & 5 & 5 & 5 & 5 & 5 & 5 & 5 & 4 & 4 & 4 & 4 & 56.00 & 0.93 \\
\hline \multicolumn{14}{|c|}{ V AIKEN } & 0.87 \\
\hline
\end{tabular}

CLARIDAD: C; CONGRUENCIA: CO; CONTEXTO: CON; DOMINIO DE CONSTRUCTO: DC 


\title{
Anexo 4. Validación de jueces
}

\section{Juez $\mathrm{N}^{\circ} 1$}

\section{INSTRUMENTO PARA LA VALIDEZ DE CONTENIDO}

(JUICIO DE EXPERTOS)

\begin{abstract}
El presente documento tiene como finalidad validar los cuestionarios de gestión de la calidad total y desempeño exportador, el mismo que será aplicado a los gerentes y/o administradores de las empresas MYPES exportadoras de quinua del Perú que forman parte del estudio "RELACION ENTRE GESTION DE LA CALIDAD TOTAL Y DESEMPEÑO DE LAS EMPRESAS MYPES EXPORTADORAS DE QUINUA, PERÚ 2020" que corresponde a un diseño de investigación cuantitativo correlacional no experimental transversal
\end{abstract}

\section{Instrucciones}

La evaluación requiere de la lectura detallada y completa de cada uno de los items propuestos a fin de cotejarlos de manera cualitativa con los criterios propuestos relativos a: Claridad de la redacción, Congruencia con el contenido, Contexto correcto del ítem y Dominio del Constructo. Para ello deberá asignar una valoración si el item presenta o no los criterios propuestos, y en caso necesario se ofrece un espacio para las observaciones si hubiera.

Juez $\mathrm{N}^{0}$ :

Fecha actual:

10 de septiembre de 2020

Nombres y Apellidos de Juez: Zarif Yunis Martinez

Institución donde labora: Inversiones Vieri.

Años de experiencia profesional o cientifica: __ 8 años

Grado de Instrucción: Maestría en Agronegocios.

Puesto que desempeña: Jefe de Producción

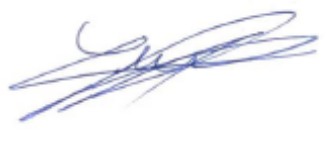

Firma y/o Sello 


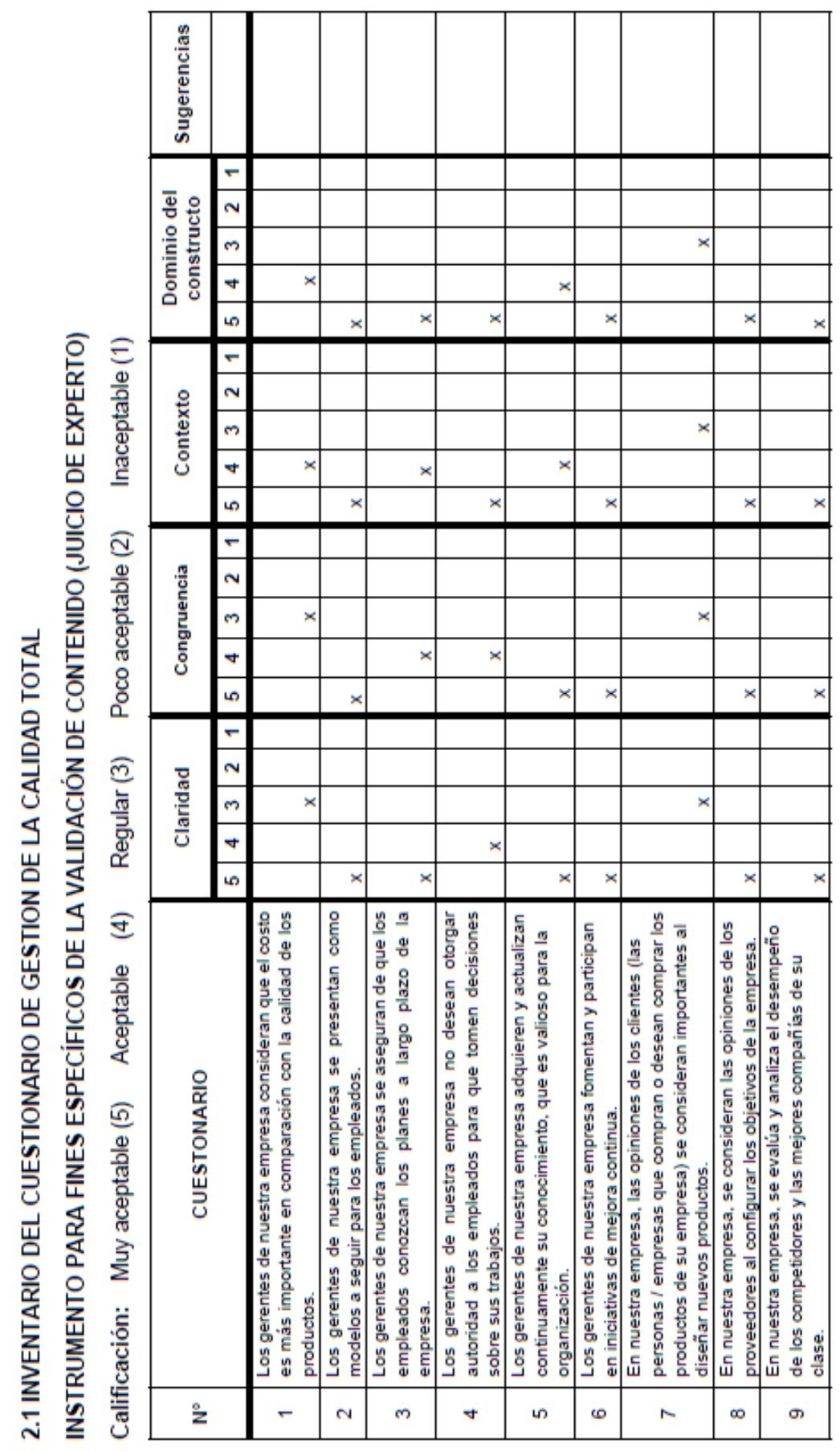




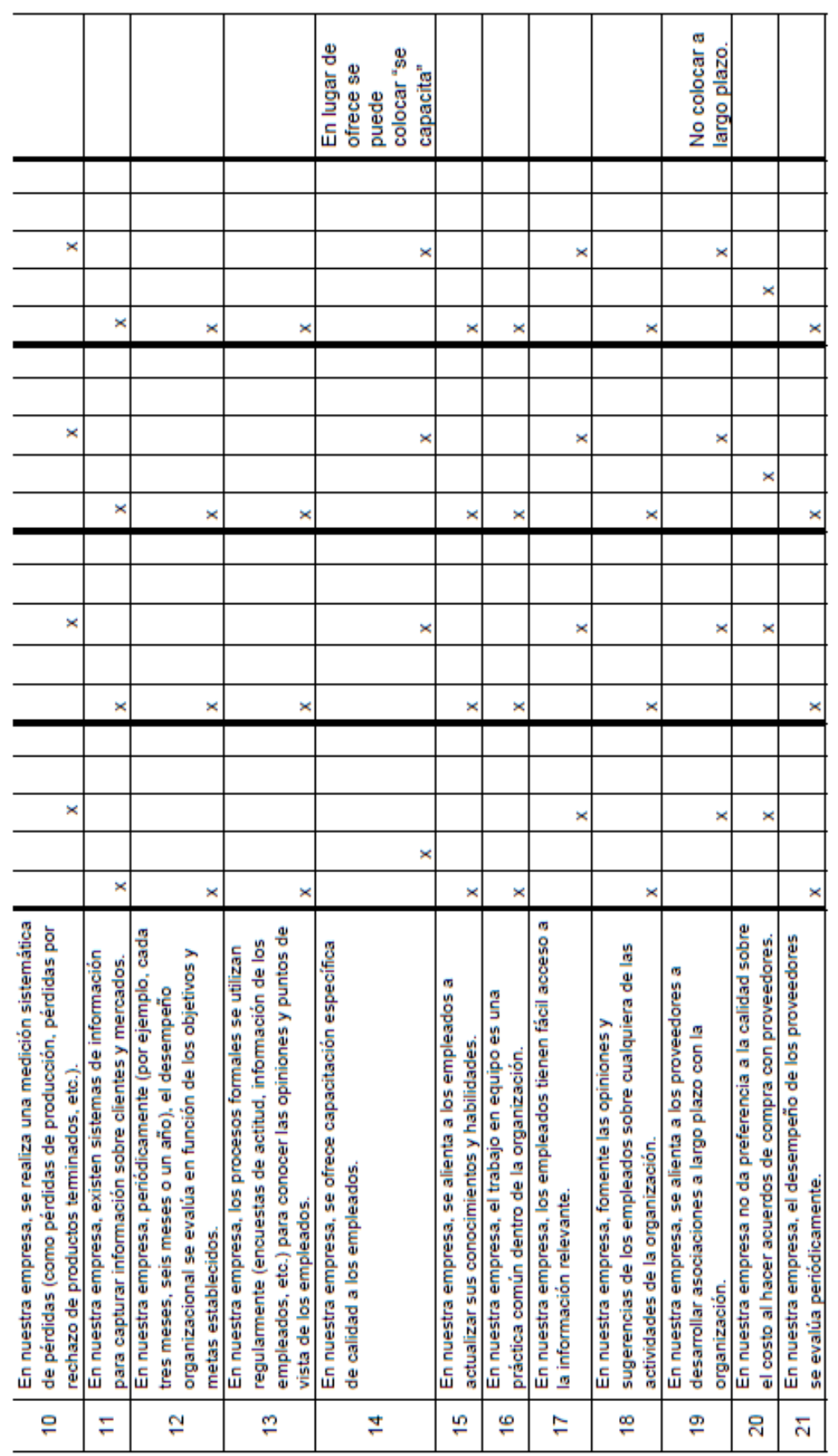




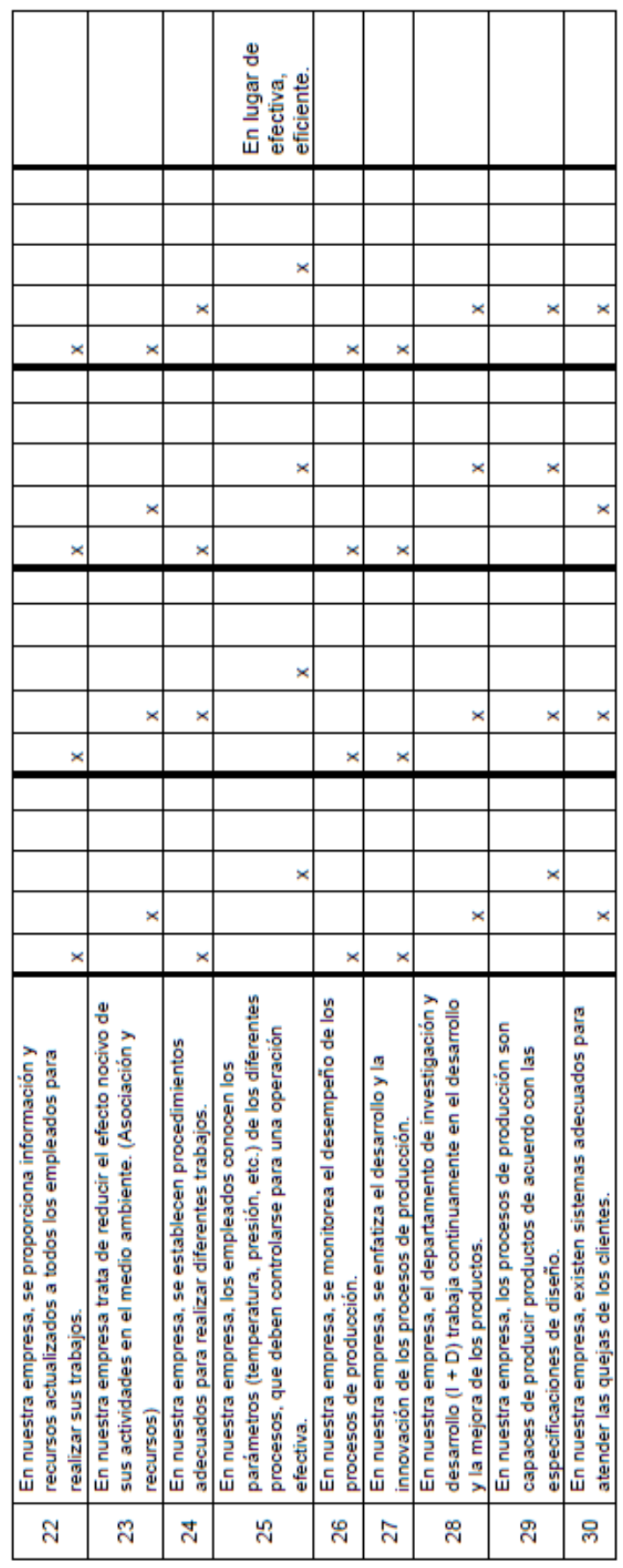




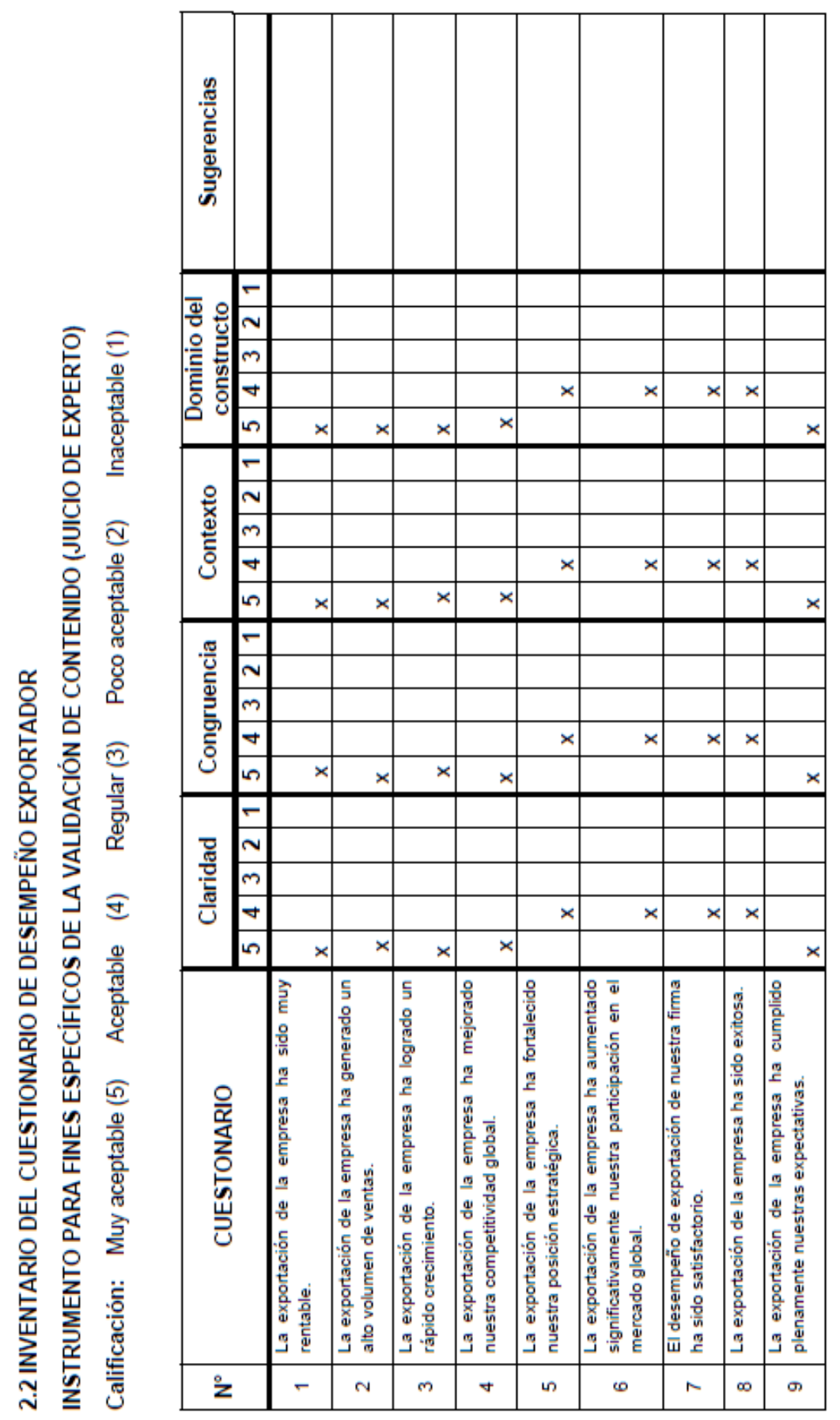




\section{Juez $\mathrm{N}^{\circ} 2$}

\section{INSTRUMENTO PARA LA VALIDEZ DE CONTENIDO}

\section{(JUICIO DE EXPERTOS)}

El presente documento tiene como finalidad validar los cuestionarios de gestión de la calidad total y desempeño exportador, el mismo que será aplicado a los gerentes y/o administradores de las empresas MYPES exportadoras de quinua del Perú que forman parte del estudio "RELACION ENTRE GESTION DE LA CALIDAD TOTAL Y DESEMPEÑO DE LAS EMPRESAS MYPES EXPORTADORAS DE QUINUA, PERÚ 2020 " que corresponde a un diseño de investigación cuantitativo correlacional no experimental transversal.

\section{Instrucciones}

La evaluación requiere de la lectura detallada y completa de cada uno de los ítems propuestos a fin de cotejarlos de manera cualitativa con los criterios propuestos relativos a: Claridad de la redacción, Congruencia con el contenido, Contexto correcto del item y Dominio del Constructo. Para ello deberá asignar una valoración si el ítem presenta o no los criterios propuestos, y en caso necesario se ofrece un espacio para las observaciones si hubiera.

Juez $\mathrm{N}^{0}$ : 2

Fecha actual: _09-09-2020

Nombres y Apellidos de Juez: NATALI ARANDA VILLALOBOS

Institución donde labora:_IMPORT \& EXPORT IZAM S.A.C

Años de experiencia profesional o cientifica: 15 AÑOS

Grado de Instrucción: MAESTRIA

Puesto que desempeña: PRODUCT \& QUALITY MANAGER

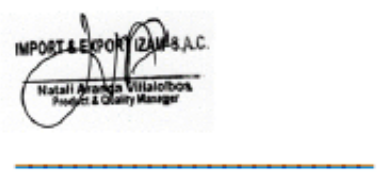

Firma y/o Sello 


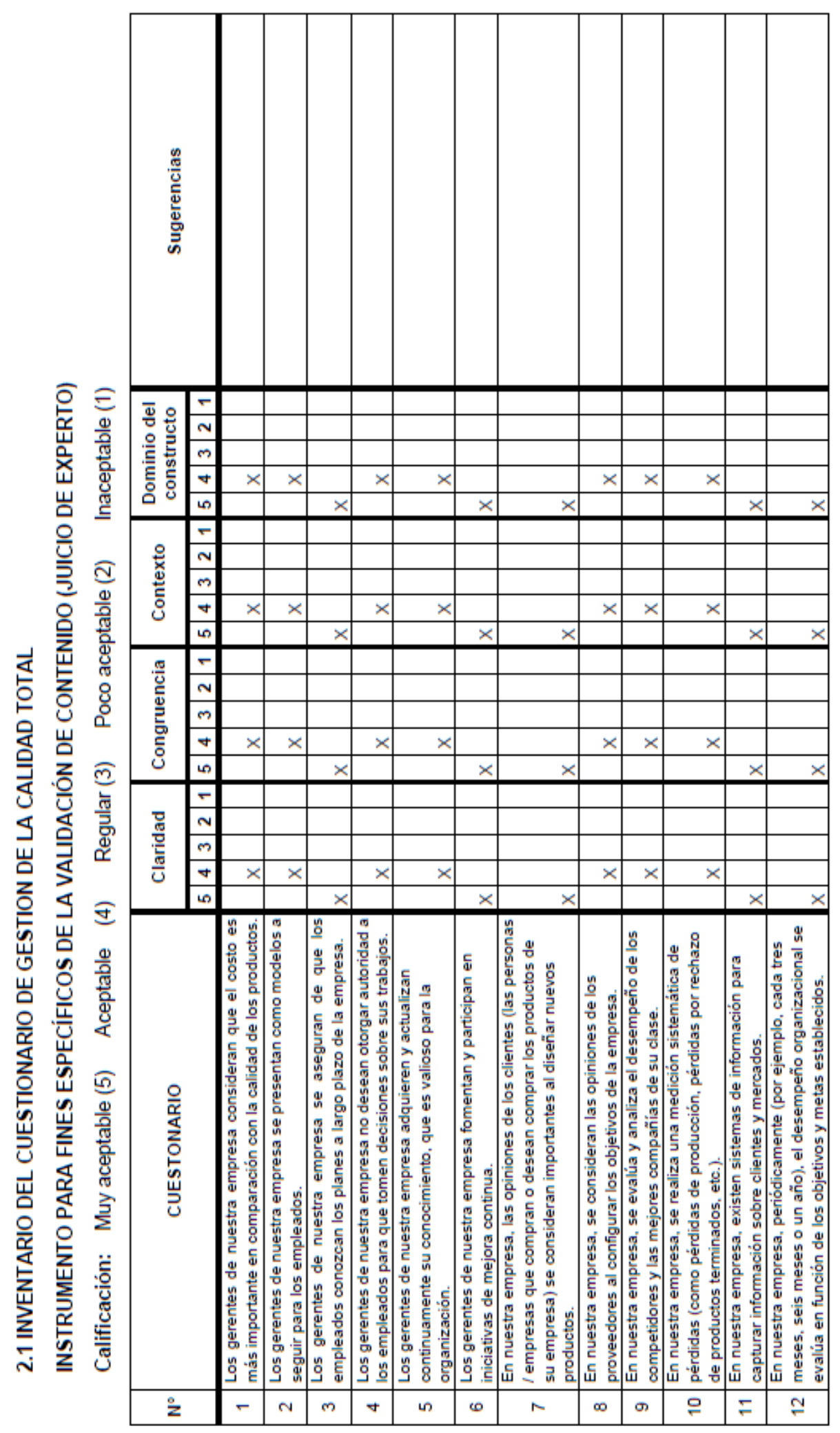




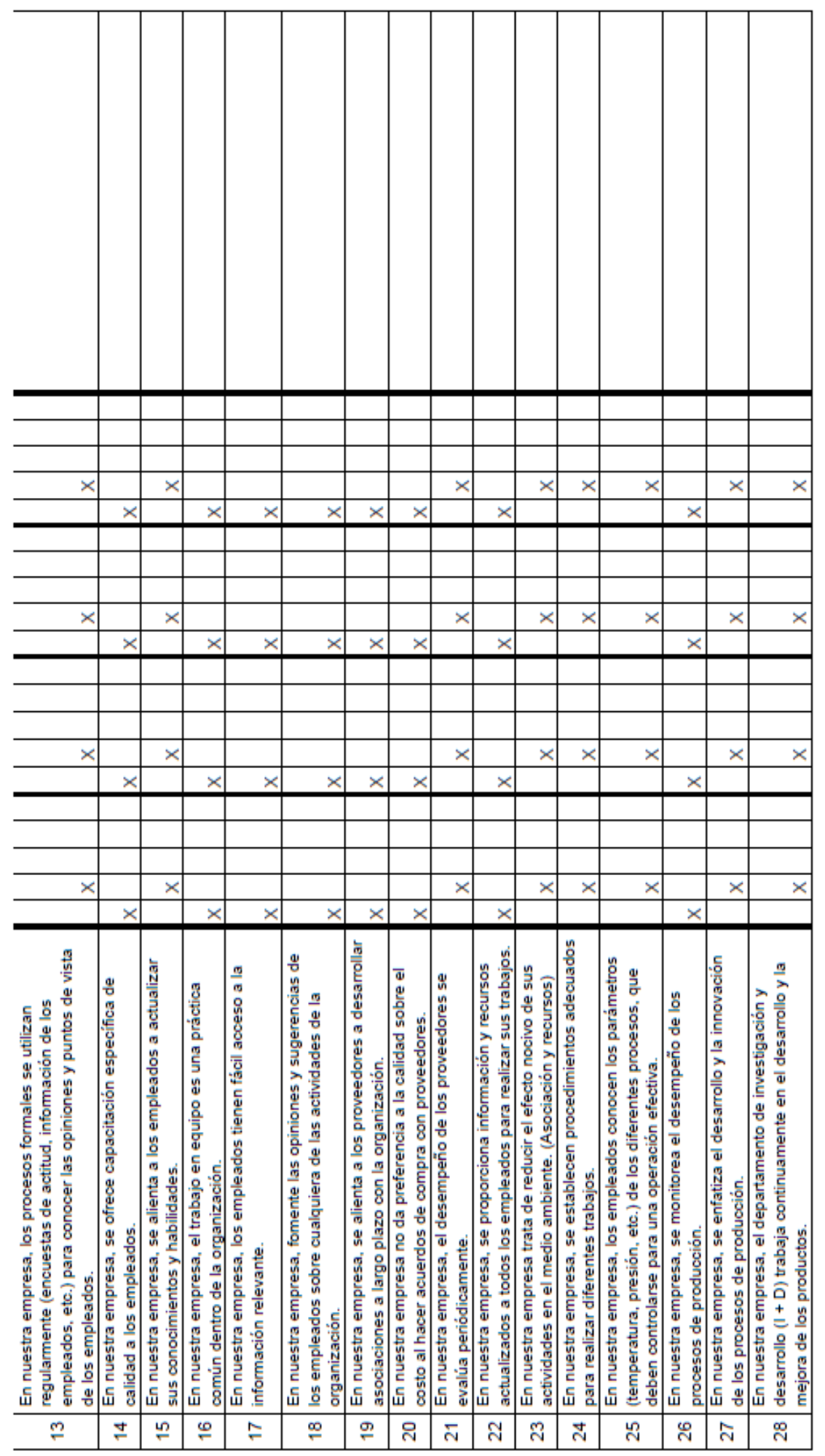




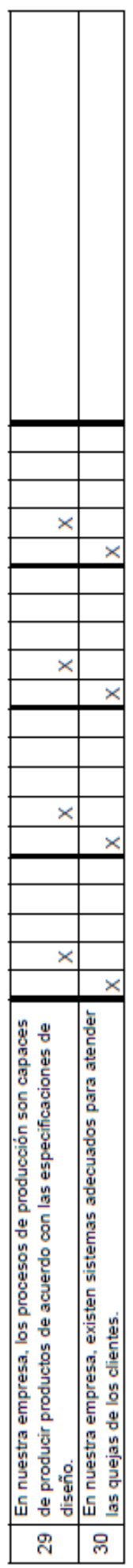




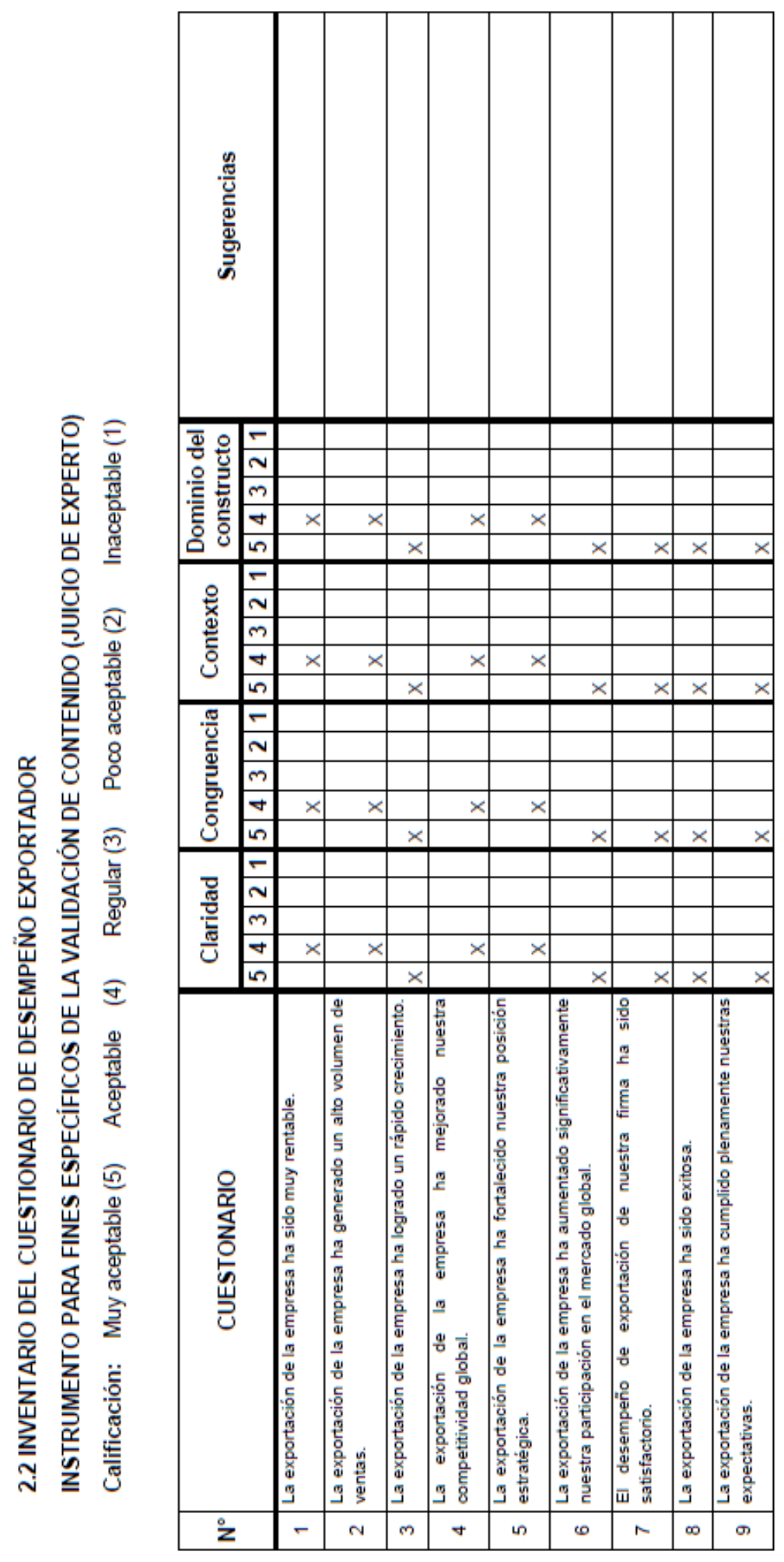




\section{Juez $N^{\circ} 3$}

\section{INSTRUMENTO PARA LA VALIDEZ DE CONTENIDO}

\section{(JUICIO DE EXPERTOS)}

El presente documento tiene como finalidad validar los cuestionarios de gestión de la calidad total y desempeño exportador, el mismo que será aplicado a los gerentes y/o administradores de las empresas MYPES exportadoras de quinua del Perú que forman parte del estudio "RELACION ENTRE GESTION DE LA CALIDAD TOTAL Y DESEMPEÑO DE LAS EMPRESAS MYPES EXPORTADORAS DE QUINUA, PERÚ 2020 " que corresponde a un diseño de investigación cuantitativo correlacional no experimental transversal.

\section{Instrucciones}

La evaluación requiere de la lectura detallada y completa de cada uno de los ítems propuestos a fin de cotejarlos de manera cualitativa con los criterios propuestos relativos a: Claridad de la redacción, Congruencia con el contenido, Contexto correcto del ítem y Dominio del Constructo. Para ello deberá asignar una valoración si el ítem presenta o no los criterios propuestos, y en caso necesario se ofrece un espacio para las observaciones si hubiera.

Juez $\mathrm{N}^{\circ}$. 3

Fecha actual: 11-09-2020

Nombres y Apellidos de Juez: BRAGGI A. BAMBERGER VARGAS

Institución donde labora: FINANCE CONSULT EIRL

Años de experiencia profesional o cientifica: 22 AÑOS

Grado de Instrucción: DOCTOR EN CONTABILIDAD Y FINANZAS

Puesto que desempeña: CONSULTOR FINANCIERO

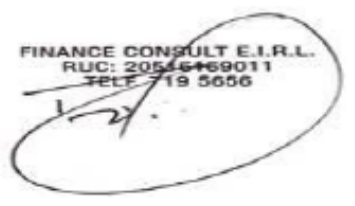

Firma y/o Sello 


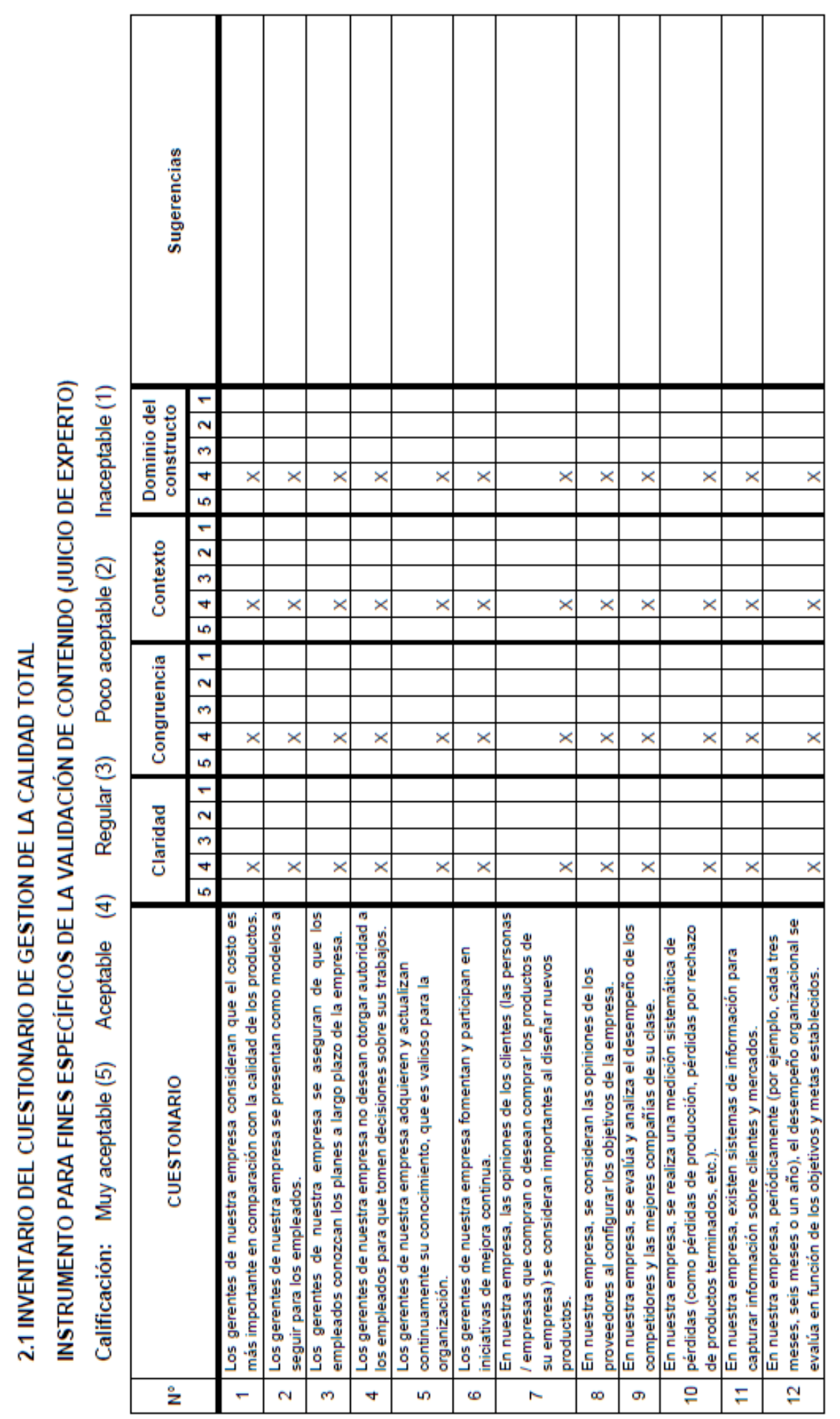




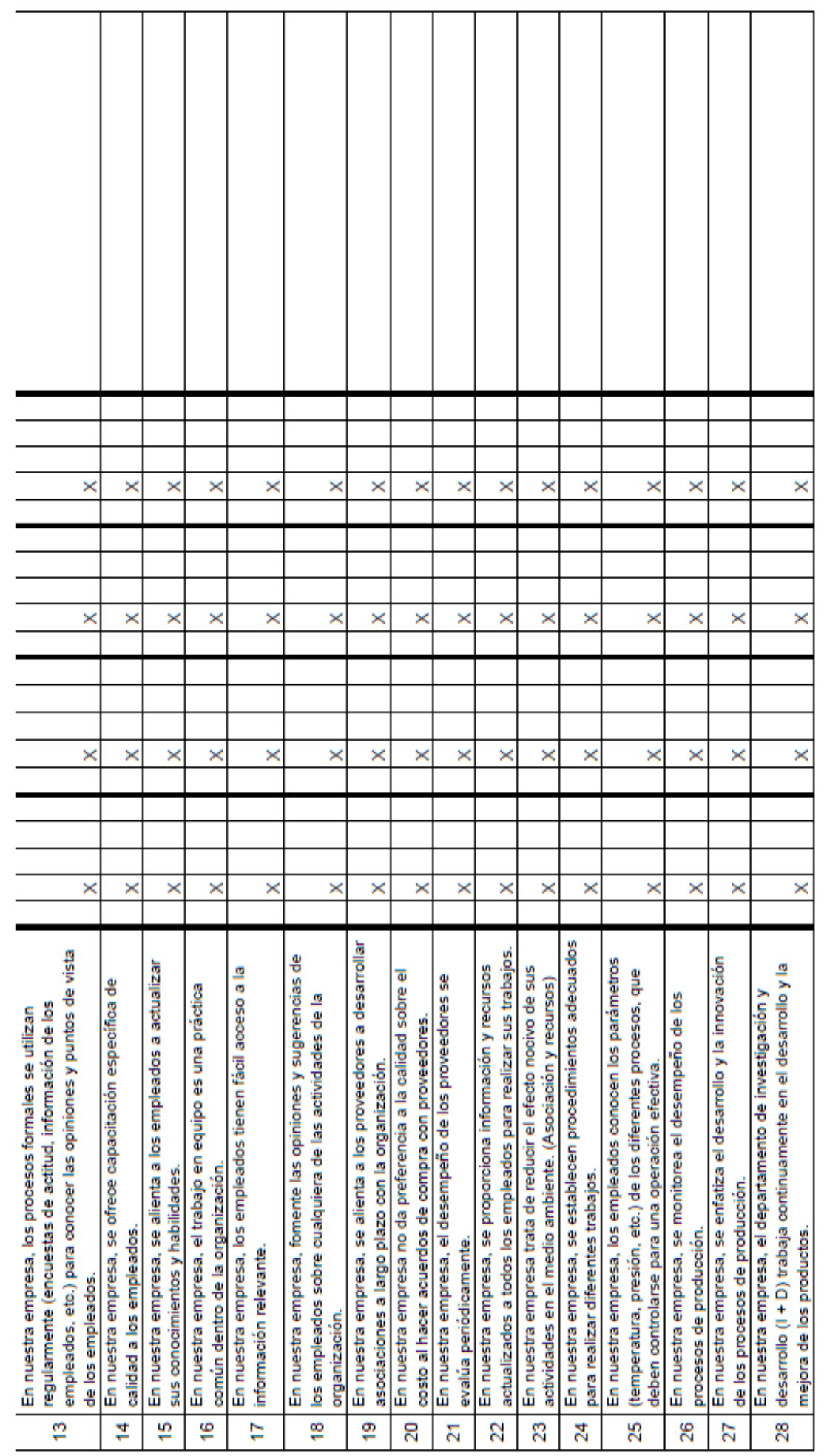




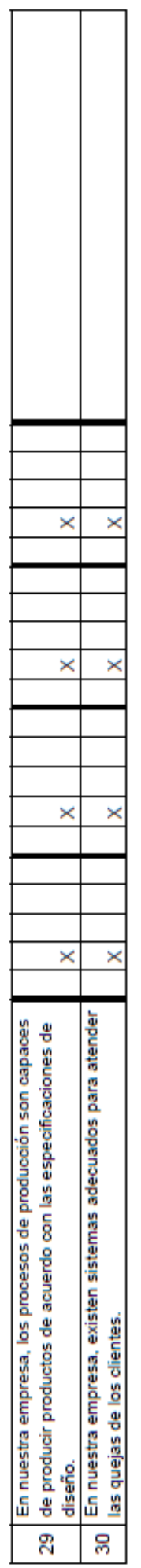




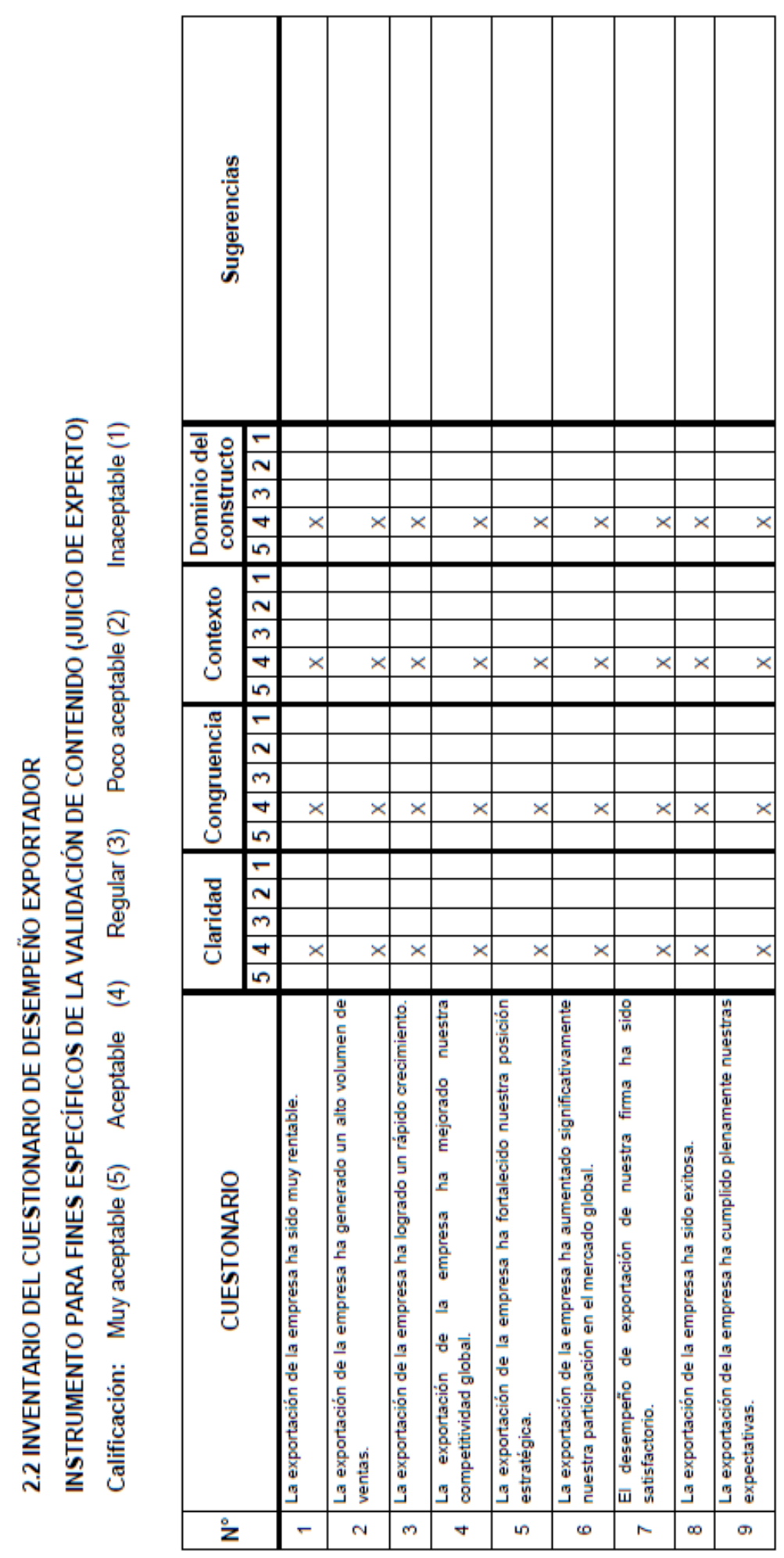




\section{Anexo 5. Alfa de Cronbach \\ Gestión de calidad total}

\section{Liderazgo}

\begin{tabular}{llrr}
\multicolumn{3}{c}{ Case Processing Summary } \\
& \multicolumn{1}{c}{$\mathrm{N}$} & \multicolumn{1}{c}{$\%$} \\
\hline \multirow{3}{*}{ Cases } & Valid & 106 & 100.0 \\
\cline { 2 - 4 } & Excluded $^{\mathrm{a}}$ & 0 & .0 \\
\cline { 2 - 4 } & Total & 106 & 100.0 \\
\hline
\end{tabular}

a. Listwise deletion based on all variables in the procedure.

\section{Reliability Statistics}

\begin{tabular}{r|r} 
Cronbach's Alpha & N of Items \\
\hline .908 & 6 \\
\hline
\end{tabular}

\begin{tabular}{|c|c|c|c|c|}
\hline & \multicolumn{4}{|c|}{ Item-Total Statistics } \\
\hline & $\begin{array}{l}\text { Scale Mean } \\
\text { if Item } \\
\text { Deleted }\end{array}$ & $\begin{array}{c}\text { Scale } \\
\text { Variance if } \\
\text { Item Deleted }\end{array}$ & $\begin{array}{l}\text { Corrected Item- } \\
\text { Total } \\
\text { Correlation }\end{array}$ & $\begin{array}{l}\text { Cronbach's } \\
\text { Alpha if Item } \\
\text { Deleted }\end{array}$ \\
\hline $\begin{array}{l}\text { GCT1. Los gerentes de nuestra } \\
\text { empresa consideran que el costo es } \\
\text { más importante en comparación con la } \\
\text { calidad de los productos. }\end{array}$ & 20.83 & 10.828 & .928 & .861 \\
\hline $\begin{array}{l}\text { GCT2. Los gerentes de nuestra } \\
\text { empresa se presentan como modelos a } \\
\text { seguir para los empleados. }\end{array}$ & 19.99 & 13.343 & .816 & .889 \\
\hline $\begin{array}{l}\text { GCT3. Los gerentes de nuestra } \\
\text { empresa se aseguran de que los } \\
\text { empleados conozcan los planes a largo } \\
\text { plazo de la empresa. }\end{array}$ & 20.71 & 11.028 & .728 & .900 \\
\hline $\begin{array}{l}\text { GCT4. Los gerentes de nuestra } \\
\text { empresa no desean otorgar autoridad a } \\
\text { los empleados para que tomen } \\
\text { decisiones sobre sus trabajos. }\end{array}$ & 20.48 & 12.252 & .650 & .907 \\
\hline
\end{tabular}




\begin{tabular}{|c|c|c|c|c|}
\hline $\begin{array}{l}\text { GCT5, Los gerentes de nuestra } \\
\text { empresa adquieren y actualizan } \\
\text { continuamente su conocimiento, que } \\
\text { es valioso para la organización. }\end{array}$ & 20.05 & 12.560 & .873 & .878 \\
\hline $\begin{array}{l}\text { GCT6. Los gerentes de nuestra } \\
\text { empresa fomentan y participan en } \\
\text { iniciativas de mejora continua. }\end{array}$ & 20.44 & 13.487 & .617 & .908 \\
\hline
\end{tabular}

\section{Estrategia}

\begin{tabular}{llrr}
\multicolumn{3}{c}{ Case Processing Summary } \\
& \multicolumn{1}{c}{$\mathrm{N}$} & \multicolumn{1}{c}{$\%$} \\
\hline \multirow{3}{*}{ Cases } & Valid & 106 & 100.0 \\
\cline { 2 - 4 } & Excluded $^{\mathrm{a}}$ & 0 & .0 \\
\cline { 2 - 4 } & Total & 106 & 100.0 \\
\hline
\end{tabular}

a. Listwise deletion based on all variables in the procedure.

Reliability Statistics

\begin{tabular}{r|r} 
Cronbach's Alpha & N of Items \\
\hline .883 & 6 \\
\hline
\end{tabular}

Item-Total Statistics

\begin{tabular}{|c|c|c|c|c|}
\hline & $\begin{array}{l}\text { Scale } \\
\text { Mean if } \\
\text { Item } \\
\text { Deleted }\end{array}$ & $\begin{array}{l}\text { Scale } \\
\text { Variance if } \\
\text { Item } \\
\text { Deleted }\end{array}$ & $\begin{array}{l}\text { Corrected } \\
\text { Item-Total } \\
\text { Correlation }\end{array}$ & $\begin{array}{l}\text { Cronbach's } \\
\text { Alpha if Item } \\
\text { Deleted }\end{array}$ \\
\hline $\begin{array}{l}\text { GCT7. En nuestra empresa, las opiniones } \\
\text { de los clientes (las personas / empresas que } \\
\text { compran o desean comprar los productos } \\
\text { de su empresa) se consideran importantes } \\
\text { al diseñar nuevos productos. }\end{array}$ & 23.04 & 5.199 & .802 & .844 \\
\hline $\begin{array}{l}\text { GCT8. En nuestra empresa, se consideran } \\
\text { las opiniones de los proveedores al } \\
\text { configurar los objetivos de la empresa. }\end{array}$ & 22.57 & 6.172 & .643 & .871 \\
\hline $\begin{array}{l}\text { GCT9. En nuestra empresa, se evalúa y } \\
\text { analiza el desempeño de los competidores } \\
\text { y las mejores compañias de su clase. }\end{array}$ & 22.58 & 6.132 & .629 & .873 \\
\hline
\end{tabular}




$\begin{aligned} & \text { GCT10. En nuestra empresa, se realiza una } \\ & \text { medición sistemática de pérdidas (como } \\ & \text { pérdidas de producción, pérdidas por }\end{aligned}$
$\begin{aligned} & \text { rechazo de productos terminados, etc.). } \\ & \text { GCT11. En nuestra empresa, existen }\end{aligned}$
$\begin{aligned} & \text { sistemas de información para capturar } \\ & \text { información sobre clientes y mercados. }\end{aligned}$

\section{Personas}

Case Processing Summary

\begin{tabular}{|c|c|c|c|}
\hline & & & $\%$ \\
\hline & Valid & 106 & 100.0 \\
\hline Cases & Excluded $^{\mathrm{a}}$ & 0 & .0 \\
\hline & Total & 106 & 100.0 \\
\hline
\end{tabular}

a. Listwise deletion based on all variables in the procedure.

Reliability Statistics

\begin{tabular}{r|r} 
Cronbach's Alpha & N of Items \\
\hline .885 & 6 \\
\hline
\end{tabular}

Item-Total Statistics

\begin{tabular}{l|r|r|r|r} 
& $\begin{array}{c}\text { Scale } \\
\text { Mean if } \\
\text { Item } \\
\text { Deleted }\end{array}$ & $\begin{array}{c}\text { Scale } \\
\text { Variance if } \\
\text { Item } \\
\text { Deleted }\end{array}$ & $\begin{array}{c}\text { Corrected } \\
\text { Item-Total } \\
\text { Correlation }\end{array}$ & $\begin{array}{c}\text { Cronbach's } \\
\text { Alpha if Item } \\
\text { Deleted }\end{array}$ \\
\hline $\begin{array}{l}\text { GCT13. En nuestra empresa, los procesos } \\
\text { formales se utilizan regularmente } \\
\text { (encuestas de actitud, información de los }\end{array}$ & 20.03 & 7.742 & & \\
\hline $\begin{array}{l}\text { empleados, etc.) para conocer las } \\
\text { opiniones y puntos de vista de los }\end{array}$ & & & & \\
\hline \begin{tabular}{l} 
empleados. \\
\hline
\end{tabular} & & & & \\
\hline
\end{tabular}




\begin{tabular}{|c|c|c|c|c|}
\hline $\begin{array}{l}\text { GCT14. En nuestra empresa, se da } \\
\text { capacitación especifica de calidad a los } \\
\text { empleados. }\end{array}$ & 20.09 & 7.096 & .901 & .830 \\
\hline $\begin{array}{l}\text { GCT15. En nuestra empresa, se alienta a } \\
\text { los empleados a actualizar sus } \\
\text { conocimientos y habilidades. }\end{array}$ & 20.00 & 7.905 & .755 & .857 \\
\hline $\begin{array}{l}\text { GCT16. En nuestra empresa, el trabajo en } \\
\text { equipo es una práctica común dentro de la } \\
\text { organización. }\end{array}$ & 20.12 & 7.899 & .665 & .870 \\
\hline $\begin{array}{l}\text { GCT17. En nuestra empresa, los } \\
\text { empleados tienen fäcil acceso a la } \\
\text { información relevante. }\end{array}$ & 20.77 & 7.224 & .661 & .876 \\
\hline $\begin{array}{l}\text { GCT18. En nuestra empresa, fomente las } \\
\text { opiniones y sugerencias de los empleados } \\
\text { sobre cualquiera de las actividades de la } \\
\text { organización. }\end{array}$ & 20.35 & 8.458 & .472 & .900 \\
\hline
\end{tabular}

\section{Recursos}

\section{Case Processing Summary}

\begin{tabular}{|c|c|c|c|}
\hline & & & $\%$ \\
\hline \multirow{3}{*}{ Cases } & Valid & 106 & 100.0 \\
\hline & Excluded $^{\text {a }}$ & 0 & .0 \\
\hline & Total & 106 & 100.0 \\
\hline
\end{tabular}

a. Listwise deletion based on all variables in the procedure.

\section{Reliability Statistics}

\begin{tabular}{r|r} 
Cronbach's Alpha & N of Items \\
\hline .899 & 5 \\
\hline
\end{tabular}

\begin{tabular}{|c|c|c|c|c|}
\hline \multicolumn{5}{|c|}{ Item-Total Statistics } \\
\hline & $\begin{array}{l}\text { Scale Mean } \\
\text { if Item } \\
\text { Deleted }\end{array}$ & $\begin{array}{c}\text { Scale } \\
\text { Variance if } \\
\text { Item Deleted }\end{array}$ & $\begin{array}{l}\text { Corrected } \\
\text { Item-Total } \\
\text { Correlation }\end{array}$ & $\begin{array}{l}\text { Cronbach's } \\
\text { Alpha if Item } \\
\text { Deleted }\end{array}$ \\
\hline $\begin{array}{l}\text { GCT19. En nuestra empresa, se alienta } \\
\text { a los proveedores a desarrollar } \\
\text { asociaciones con la organización. }\end{array}$ & 17.34 & 4.988 & .841 & .857 \\
\hline
\end{tabular}




\begin{tabular}{|c|c|c|c|c|}
\hline $\begin{array}{l}\text { GCT20. En nuestra empresa no da } \\
\text { preferencia a la calidad sobre el costo } \\
\text { al hacer acuerdos de compra con } \\
\text { proveedores. }\end{array}$ & 17.68 & 5.039 & .644 & .909 \\
\hline $\begin{array}{l}\text { GCT21. En nuestra empresa, el } \\
\text { desempeño de los proveedores se } \\
\text { evalúa periódicamente. }\end{array}$ & 17.22 & 5.200 & .849 & .857 \\
\hline $\begin{array}{l}\text { GCT22. En nuestra empresa, se } \\
\text { proporciona información y recursos } \\
\text { actualizados a todos los empleados } \\
\text { para realizar sus trabajos. }\end{array}$ & 17.27 & 5.591 & .694 & .889 \\
\hline $\begin{array}{l}\text { GCT23. En nuestra empresa trata de } \\
\text { reducir el efecto nocivo de sus } \\
\text { actividades en el medio ambiente. } \\
\text { (Asociación y recursos) }\end{array}$ & 17.25 & 5.387 & .773 & .873 \\
\hline
\end{tabular}

\section{Procesos}

\begin{tabular}{llrr}
\multicolumn{4}{c}{ Case Processing Summary } \\
& \multicolumn{1}{l}{ N } & \multicolumn{1}{c}{$\%$} \\
\hline \multirow{3}{*}{ Cases } & Valid & 106 & 100.0 \\
\cline { 2 - 4 } & Excluded $^{\mathrm{a}}$ & 0 & .0 \\
\cline { 2 - 4 } & Total & 106 & 100.0 \\
\hline
\end{tabular}

a. Listwise deletion based on all variables in the procedure.

Reliability Statistics

\begin{tabular}{r|r} 
Cronbach's Alpha & N of Items \\
\hline .938 & 7 \\
\hline
\end{tabular}

\begin{tabular}{l|l|l|r|r}
\multicolumn{2}{c}{$\begin{array}{r}\text { Item-Total Statistics } \\
\text { Scale } \\
\text { Mean if } \\
\text { Item } \\
\text { Deleted }\end{array}$} & $\begin{array}{c}\text { Scale } \\
\text { Variance if } \\
\text { Item } \\
\text { Deleted }\end{array}$ & $\begin{array}{c}\text { Corrected } \\
\text { Item-Total } \\
\text { Correlation }\end{array}$ & $\begin{array}{c}\text { Cronbach's } \\
\text { Alpha if Item } \\
\text { Deleted }\end{array}$ \\
\hline $\begin{array}{l}\text { GCT24. En nuestra empresa, se } \\
\text { establecen procedimientos adecuados para } \\
\text { realizar diferentes trabajos. }\end{array}$ & 25.56 & 20.116 & .843 & \\
\hline
\end{tabular}




\begin{tabular}{|c|c|c|c|c|}
\hline $\begin{array}{l}\text { GCT25. En nuestra empresa, los } \\
\text { empleados conocen los parámetros } \\
\text { (temperatura, presión, etc.) de los } \\
\text { diferentes procesos, que deben controlarse } \\
\text { para una operación eficiente. }\end{array}$ & 25.62 & 19.723 & .705 & .937 \\
\hline $\begin{array}{l}\text { GCT26. En nuestra empresa, se monitore: } \\
\text { el desempeño de los procesos de } \\
\text { producción. }\end{array}$ & 25.59 & 19.443 & .829 & .925 \\
\hline $\begin{array}{l}\text { GCT27. En nuestra empresa, se enfatiza } \\
\text { el desarrollo y la innovación de los } \\
\text { procesos de producción. }\end{array}$ & 25.64 & 19.185 & .808 & .927 \\
\hline $\begin{array}{l}\text { GCT28. En nuestra empresa, el } \\
\text { departamento de investigación y } \\
\text { desarrollo }(I+D) \text { trabaja continuamente } \\
\text { en el desarrollo y la mejora de los } \\
\text { productos. }\end{array}$ & 25.73 & 19.305 & .822 & .925 \\
\hline $\begin{array}{l}\text { GCT29. En nuestra empresa, los procesos } \\
\text { de producción son capaces de producir } \\
\text { productos de acuerdo con las } \\
\text { especificaciones de diseño. }\end{array}$ & 25.58 & 19.426 & .901 & .919 \\
\hline $\begin{array}{l}\text { GCT30. En nuestra empresa, existen } \\
\text { sistemas adecuados para atender las } \\
\text { quejas de los clientes. }\end{array}$ & 25.59 & 20.415 & .695 & .937 \\
\hline
\end{tabular}

\section{Anexo 6. Alfa de Cronbach}

Desempeño exportador

\section{Financiero}

Case Processing Summary

\begin{tabular}{|c|c|c|c|}
\hline & & & $\%$ \\
\hline \multirow{3}{*}{ Cases } & Valid & 106 & 100.0 \\
\hline & Excluded $^{\mathrm{a}}$ & 0 & .0 \\
\hline & Total & 106 & 100.0 \\
\hline
\end{tabular}

a. Listwise deletion based on all variables in the procedure.

\section{Reliability Statistics}

Cronbach's Alpha N of Items 


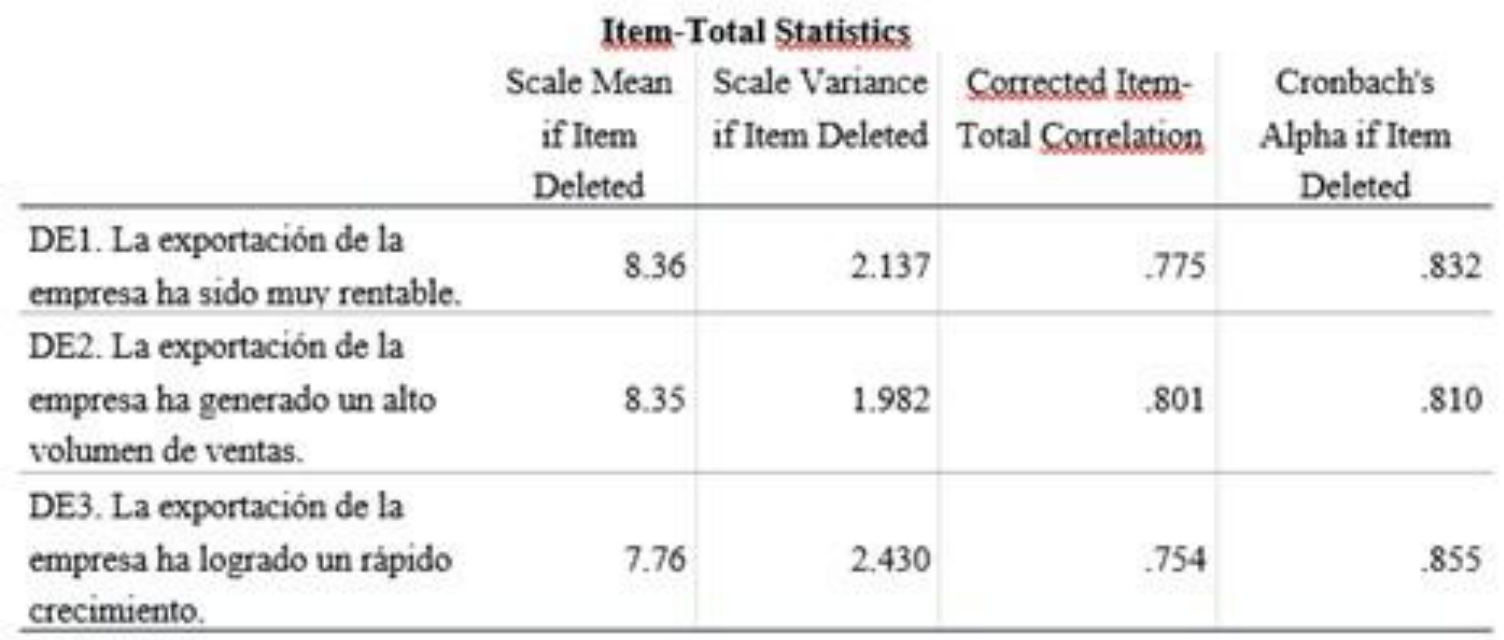

\section{Estratégico}

\begin{tabular}{llrr}
\multicolumn{4}{c}{ Case Processing Summary } \\
& \multicolumn{1}{l}{ N } & \multicolumn{1}{c}{$\%$} \\
\hline \multirow{3}{*}{ Cases } & Valid & 106 & 100.0 \\
\cline { 2 - 4 } & Excluded $^{\mathrm{a}}$ & 0 & .0 \\
\cline { 2 - 4 } & Total & 106 & 100.0 \\
\hline
\end{tabular}

a. Listwise deletion based on all variables in the procedure.

\section{Reliability Statistics}

\begin{tabular}{r|r} 
Cronbach's Alpha & N of Items \\
\hline .764 & 3 \\
\hline
\end{tabular}

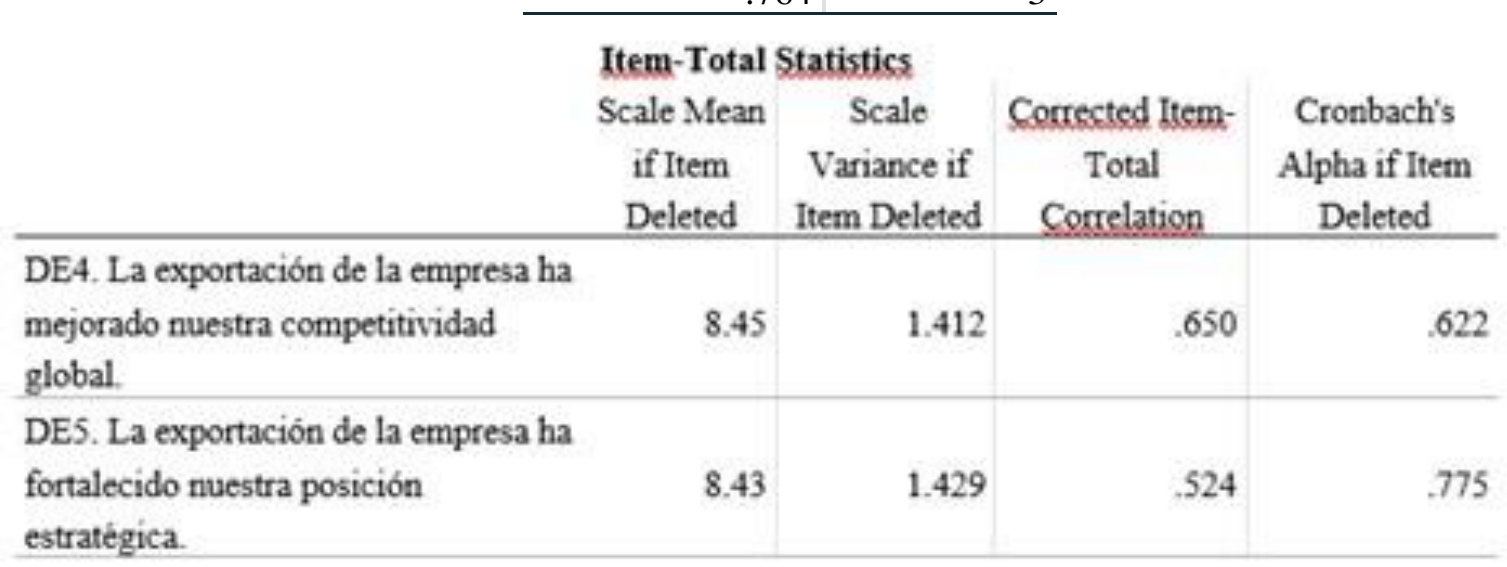


DE6. La exportación de la empresa ha aumentado significativamente nuestra

\section{Satisfacción}

\begin{tabular}{llrr}
\multicolumn{3}{c}{ Case Processing Summary } \\
& \multicolumn{1}{c}{$\mathrm{N}$} & \multicolumn{1}{c}{$\%$} \\
\hline \multirow{3}{*}{ Cases } & Valid & 106 & 100.0 \\
\cline { 2 - 4 } & Excluded $^{\mathrm{a}}$ & 0 & .0 \\
\cline { 2 - 4 } & Total & 106 & 100.0 \\
\hline
\end{tabular}

a. Listwise deletion based on all variables in the procedure.

\section{Reliability Statistics}

Cronbach's Alpha N of Items

\begin{tabular}{|c|c|c|c|c|}
\hline \multicolumn{5}{|c|}{ Item-Total Statistics } \\
\hline & $\begin{array}{l}\text { Scale Mean } \\
\text { if Item } \\
\text { Deleted }\end{array}$ & $\begin{array}{l}\text { Scale Variance } \\
\text { if Item Deleted }\end{array}$ & $\begin{array}{l}\text { Corrected Item- } \\
\text { Total Correlation }\end{array}$ & $\begin{array}{l}\text { Cronbach's } \\
\text { Alpha if Item } \\
\text { Deleted }\end{array}$ \\
\hline $\begin{array}{l}\text { DE7. El desempeño de } \\
\text { exportación de nuestra firma ha } \\
\text { sido satisfactorio. }\end{array}$ & 8.11 & 2.444 & .874 & .808 \\
\hline $\begin{array}{l}\text { DES. La exportación de la } \\
\text { empresa ha sido exitosa. }\end{array}$ & 8.38 & 2.009 & .831 & .857 \\
\hline $\begin{array}{l}\text { DE9. La exportación de la } \\
\text { empresa ha cumplido } \\
\text { plenamente nuestras } \\
\text { expectativas. }\end{array}$ & 8.30 & 2.784 & .751 & .909 \\
\hline
\end{tabular}




\section{Anexo 7. Análisis factorial \\ Gestión de la calidad total}

\begin{tabular}{llr}
\multicolumn{2}{c}{ KMO and Bartlett's Test } \\
Kaiser-Meyer-Olkin Measure of Sampling Adequacy. & .757 \\
\hline & Approx Chi-Square & 2962.828 \\
Bartlett's Test of Sphericity & df & 435 \\
\hline & Sig. & .000 \\
\hline
\end{tabular}

\section{Communalities}

\begin{tabular}{|c|c|c|}
\hline $\begin{array}{l}\text { GCT1. Los gerentes de nuestra empresa consideran que el costo es más importante } \\
\text { en comparación con la calidad de los productos. }\end{array}$ & 1.000 & .922 \\
\hline $\begin{array}{l}\text { GCT2. Los gerentes de nuestra empresa se presentan como modelos a seguir para } \\
\text { los empleados. }\end{array}$ & 1.000 & .796 \\
\hline $\begin{array}{l}\text { GCT3. Los gerentes de nuestra empresa se aseguran de que los empleados } \\
\text { conozcan los planes a largo plazo de la empresa. }\end{array}$ & 1.000 & .686 \\
\hline $\begin{array}{l}\text { GCT4. Los gerentes de nuestra empresa no desean otorgar autoridad a los } \\
\text { empleados para que tomen decisiones sobre sus trabajos. }\end{array}$ & 1.000 & .592 \\
\hline $\begin{array}{l}\text { GCT5. Los gerentes de nuestra empresa adquieren y actualizan continuamente su } \\
\text { conocimiento, que es valioso para la organización. }\end{array}$ & 1.000 & .872 \\
\hline $\begin{array}{l}\text { GCT6. Los gerentes de nuestra empresa fomentan y participan en iniciativas de } \\
\text { mejora continua. }\end{array}$ & 1.000 & .570 \\
\hline $\begin{array}{l}\text { GCT7. En nuestra empresa, las opiniones de los clientes (las personas / empresas } \\
\text { que compran o desean comprar los productos de su empresa) se consideran } \\
\text { importantes al diseñar nuevos productos. }\end{array}$ & 1.000 & .723 \\
\hline $\begin{array}{l}\text { GCT8. En nuestra empresa, se consideran las opiniones de los proveedores al } \\
\text { configurar los objetivos de la empresa. }\end{array}$ & 1.000 & .645 \\
\hline $\begin{array}{l}\text { GCT9. En nuestra empresa, se evalúa y analiza el desempeño de los competidores } \\
\text { y las mejores compañias de su clase. }\end{array}$ & 1.000 & .556 \\
\hline $\begin{array}{l}\text { GCT10. En nuestra empresa, se realiza una medición sistemática de pérdidas } \\
\text { (como pérdidas de producción, pérdidas por rechazo de productos terminados, } \\
\text { etc.). }\end{array}$ & 1.000 & .661 \\
\hline $\begin{array}{l}\text { GCT11. En nuestra empresa, existen sistemas de información para capturar } \\
\text { información sobre clientes y mercados. }\end{array}$ & 1.000 & .626 \\
\hline
\end{tabular}


GCT12. En nuestra empresa, periódicamente (por ejemplo, cada tres meses, seis meses o un año), el desempeño organizacional se evalua en función de los objetivos y metas establecidos.

GCT13. En nuestra empresa, los procesos formales se utilizan regularmente (encuestas de actitud, información de los empleados, etc.) para conocer las opiniones $\mathrm{y}$ puntos de vista de los empleados.

GCT14. En nuestra empresa, se da capacitación específica de calidad a los empleados.

GCT15. En nuestra empresa, se alienta a los empleados a actualizar sus conocimientos $\mathrm{y}$ habilidades.

GCT16. En nuestra empresa, el trabajo en equipo es una práctica comun dentro de la organización.

GCT17. En nuestra empresa, los empleados tienen fácil acceso a la información relevante.

\begin{tabular}{|c|c|c|}
\hline $\begin{array}{l}\text { GCT18. En nuestra empresa, fomente las opiniones y sugerencias de los } \\
\text { empleados sobre cualquiera de las actividades de la organización. }\end{array}$ & 1.000 & .421 \\
\hline $\begin{array}{l}\text { GCT19. En nuestra empresa, se alienta a los proveedores a desarrollar } \\
\text { asociaciones con la orzanización. }\end{array}$ & 1.000 & .848 \\
\hline $\begin{array}{l}\text { GCT20. En nuestra empresa no da preferencia a la calidad sobre el costo al hacer } \\
\text { acuerdos de compra con proveedores. }\end{array}$ & 1.000 & .644 \\
\hline $\begin{array}{l}\text { GCT21. En nuestra empresa, el desempeño de los proveedores se evalúa } \\
\text { periódicamente. }\end{array}$ & 1.000 & .857 \\
\hline $\begin{array}{l}\text { GCT22. En nuestra empresa, se proporciona información y recursos actualizados a } \\
\text { todos los empleados para realizar sus trabajos. }\end{array}$ & 1.000 & .751 \\
\hline $\begin{array}{l}\text { GCT23. En nuestra empresa trata de reducir el efecto nocivo de sus actividades en } \\
\text { el medio ambiente. (Asociación y recursos) }\end{array}$ & 1.000 & .787 \\
\hline $\begin{array}{l}\text { GCT24. En nuestra empresa, se establecen procedimientos adecuadios para realizar } \\
\text { diferentes trabajos. }\end{array}$ & 1.000 & .824 \\
\hline $\begin{array}{l}\text { GCT25. En nuestra empresa, los empleados conocen los parámetros (temperatura, } \\
\text { presión, etc.) de los diferentes procesos, que deben controlarse para una operación } \\
\text { eficiente. }\end{array}$ & 1.000 & .665 \\
\hline $\begin{array}{l}\text { GCT26. En nuestra empresa, se monitorea el desempeño de los procesos de } \\
\text { producción. }\end{array}$ & 1.000 & .772 \\
\hline $\begin{array}{l}\text { GCT27. En nuestra empresa, se enfatiza el desarrollo y la innovación de los } \\
\text { procesos de producción. }\end{array}$ & 1.000 & .785 \\
\hline $\begin{array}{l}\text { GCT28. En nuestra empresa, el departamento de investigación y desarrollo }(I+D) \\
\text { trabaja continuamente en el desarrollo y la mejora de los productos. }\end{array}$ & 1.000 & .779 \\
\hline
\end{tabular}




\begin{tabular}{|c|c|c|}
\hline $\begin{array}{l}\text { GCT29. En nuestra empresa, los procesos de producción son capaces de producir } \\
\text { productos de acuerdo con las especificaciones de diseño. }\end{array}$ & 1.000 & .878 \\
\hline $\begin{array}{l}\text { GCT30. En nuestra empresa, existen sistemas adecuados para atender las quejas } \\
\text { de los clientes. }\end{array}$ & 1.000 & .642 \\
\hline
\end{tabular}

Extraction Method: Pribcipal Component Analysis.

\section{Anexo 8. Análisis factorial}

Desempeño exportador

\section{KMO and Bartlett's Test}

Kaiser-Meyer-Olkin Measure of Sampling Adequacy.

Approx Chi-Square $\quad 539.666$

Bartlett's Test of Sphericity

df $\quad 36$

Sig.

.000

\section{Communalities}

DE1. La exportación de la empresa ha sido muy rentable.

Initial Extraction

DE2. La exportación de la empresa ha generado un alto volumen de ventas. $\quad 1.000 \quad 846$

\begin{tabular}{lll} 
DE3. La exportación de la empresa ha logrado un rápido crecimiento. & 1.000 & .773 \\
\hline
\end{tabular}

DE4. La exportación de la empresa ha mejorado nuestra competitividad global. $\quad 1.000 \quad 765$

DE5. La exportación de la empresa ha fortalecido nuestra posición estratégica. $\quad 1.000 \quad .691$

DE6. La exportación de la empresa ha aumentado significativamente nuestra

participación en el mercado global.

$1.000 \quad .719$

DE7. El desempeño de exportación de nuestra firma ha sido satisfactorio.

$1.000 \quad .891$

DE8. La exportación de la empresa ha sido exitosa.

$1.000 \quad .857$

DE9. La exportación de la empresa ha cumplido plenamente nuestras expectativas. $1.000 \quad .822$

Extraction Method: Principal Component Analysis. 